TRABAJO FIN DE MÁSTER

MÁSTER AVANCES EN CALIDAD Y TECNOLOGÍA ALIMENTARIA

UNIVERSIDAD DE GRANADA

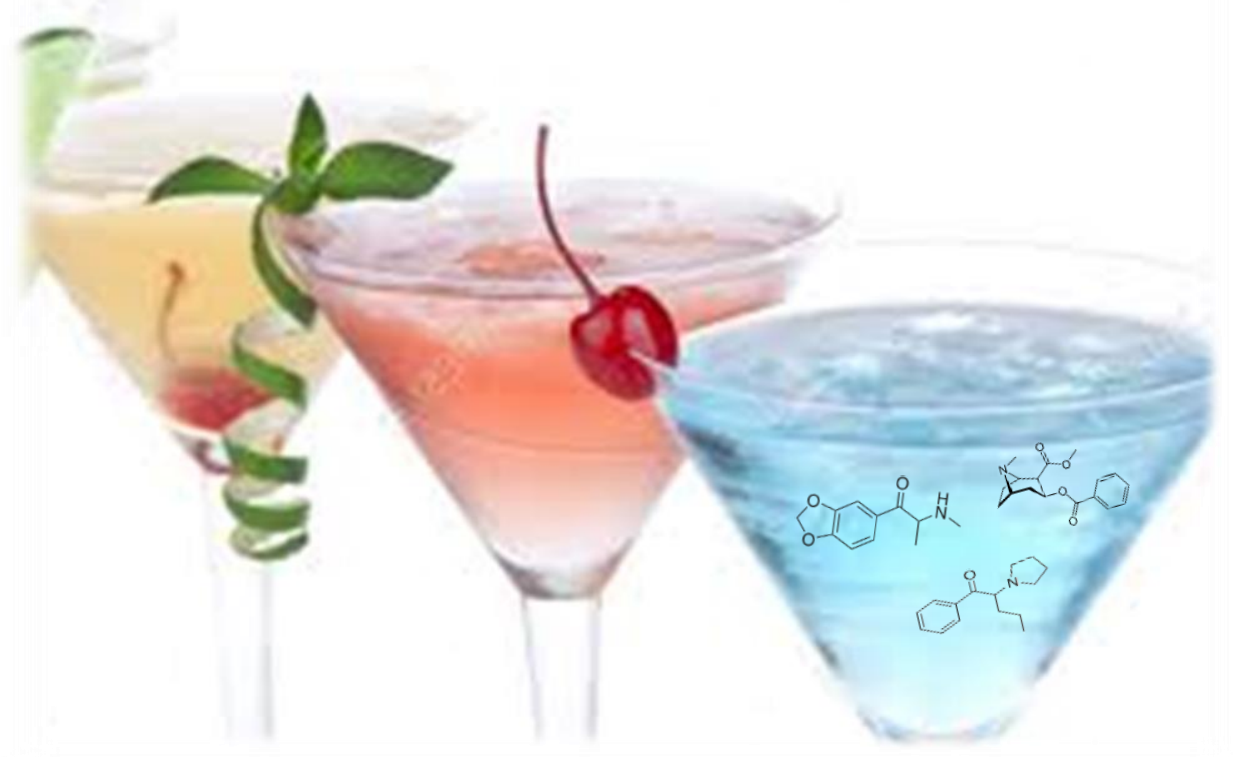

DETERMINACIÓN DE DROGAS DE ABUSO EMPLEADAS EN SUMISIÓN QUÍMICA MEDIANTE CROMATOGRAFÍA LÍQUIDA CAPILAR

Departamento de Química Analítica

ELENA ÁLVAREZ GONZÁLEZ 


\author{
TRABAJO FIN DE MÁSTER
}

MÁSTER AVANCES EN CALIDAD Y TECNOLOGÍA ALIMENTARIA

UNIVERSIDAD DE GRANADA

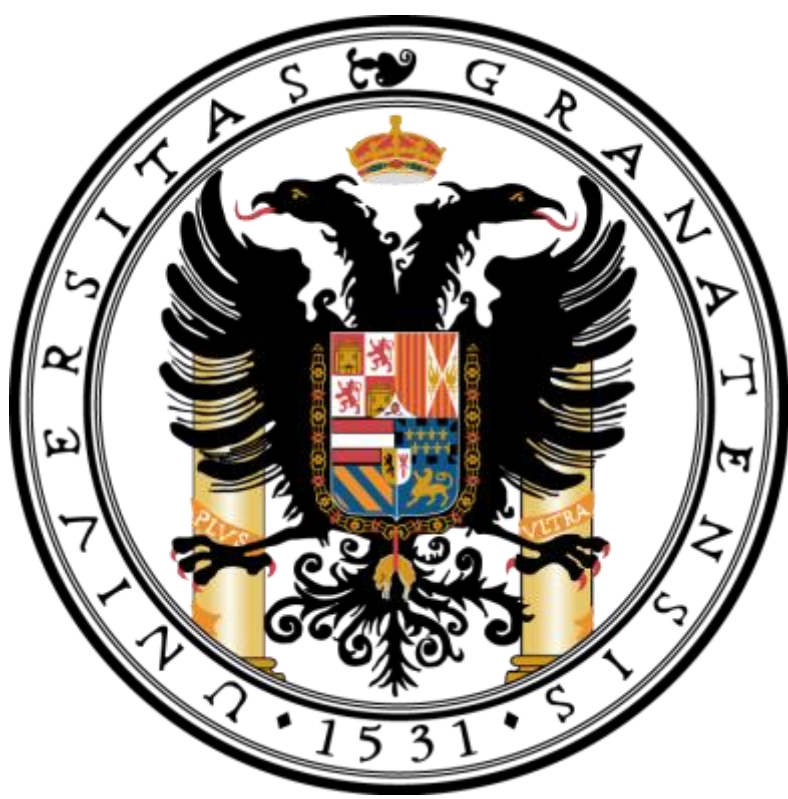

Departamento de Química Analítica

DETERMINACIÓN DE DROGAS DE ABUSO EMPLEADAS EN SUMISIÓN QUÍMICA MEDIANTE CROMATOGRAFÍA LÍQUIDA CAPILAR

ELENA ÁLVAREZ GONZÁLEZ

GRANADA, 2016 



\title{
DETERMINACIÓN DE DROGAS DE ABUSO EMPLEADAS EN SUMISIÓN QUÍMICA MEDIANTE CROMATOGRAFÍA LÍQUIDA CAPILAR
}

\author{
Memoria del Trabajo Fin de Máster por Elena Álvarez González
}

Los Directores de la Memoria

Fdo. Dra. Carmen Cruces Blanco

Catedrática del Departamento de Química

Analítica de la Universidad de Granada
Fdo. Dr. Maykel Hernández Mesa Doctor contratado del Departamento de Química Analítica de la Universidad de Granada 


\section{AGRADECIMIENTOS}

Llegados a este punto, en el que este trabajo está a punto de ver la luz, no quisiera dejar pasar la oportunidad de expresar mis más sinceros agradecimientos a todas las personas que lo han hecho posible.

En primer lugar, quisiera agradecerles a mis tutores Carmen Cruces Blanco y Maykel Hernández Mesa todo el tiempo y la dedicación que me han dedicado durante estos meses. Vosotros confiasteis en mí en mi último curso de Grado y me disteis la oportunidad de trabajar en la Química Analítica. Carmen, de ti he aprendido que en la Ciencia, como en la vida, nada se consigue con suerte, sino con trabajo y esfuerzo. Tú me has transmitido tu pasión por la Toxicología Forense, lo cual, de una forma u otra, ha marcado mi futuro. Maykel, gracias por tu paciencia y tu esfuerzo y por enseñarme no sólo conocimientos, sino cosas esenciales en la vida. De ti me llevo la ilusión y fuerza para luchar por mis sueños.

No quisiera dejar de agradecer a los compañeros del laboratorio Carmen, Ahmed y Francisco por el buen ambiente de trabajo y ayudarme siempre que he tenido algún problema. Y como no, agradecerle a Ana $M^{a}$ García Campaña haberme dado la oportunidad de formar parte de este equipo.

No podría terminar sin darle las gracias a mi madre que siempre me ha dado todo lo que tiene y que si hoy estoy escribiendo esto es gracias a su esfuerzo y amor. A mis hermanos, que siempre me apoyan y hacen mi vida especial. Y como no, a Abel, que en este año me ha enseñado a confiar y a disfrutar de cada momento, que me ha aguantado incluso cuando yo no me aguanto y nunca se rinde cuando quiere sacarme una sonrisa.

Finalmente, decir que para mí, el máster en el que he desarrollado este trabajo ha supuesto un cambio académico dada mi formación previa, Grado en Química. Este máster me ha proporcionado conocimientos sobre Calidad Alimentaria, lo cual me ha permitido complementar mi formación en Química Analítica. También me ha proporcionado conocimientos de Tecnología Alimentaria que para mí ha sido un campo nuevo y muy interesante. Gracias a todos los que han hecho posible que este cambio se lleve a cabo de manera satisfactoria.

Por todo ello, GRACIAS. 
"Considero a la Naturaleza como un amplio laboratorio químico en el que tienen lugar toda clase de sintesis y descomposiciones"

Antoine-Laurent de Lavoisier 



\section{ÍNDICE}

1 LINEA DE INVESTIGACIÓN Y OBJETIVO DE LA MEMORIA 1

1.1 LÍNEA DE INVESTIGACIÓN …............................................................ 1

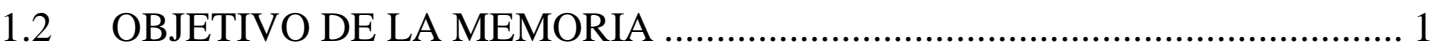

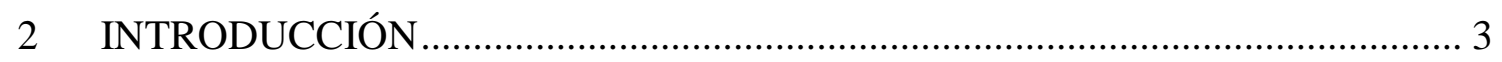

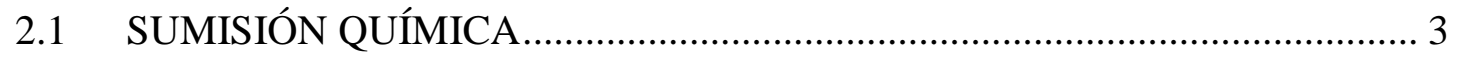

2.2 TOXICOLOGÍA FORENSE: ASPECTOS GENERALES .............................. 7

2.3 DROGAS DE ABUSO: GENERALIDADES Y CLASIFICACIÓN ............... 9

2.3.1 CLASIFICACIÓN DE LAS DROGAS DE ABUSO ILÍCITAS .............. 12

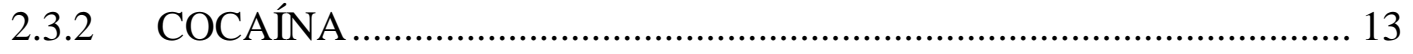

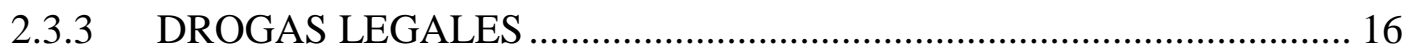

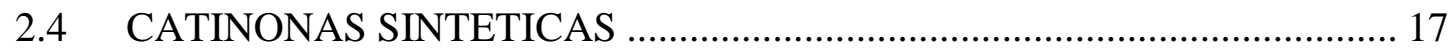

2.4.1 ESTRUCTURA QUÍMICA DE LAS CATINONAS SINTÉTICAS ...... 21

2.4.2 ACTIVIDAD DE LAS CATINONAS SINTÉTICAS ........................... 23

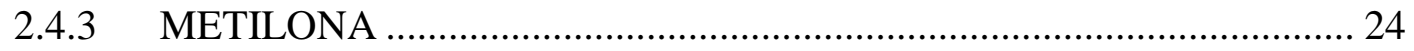

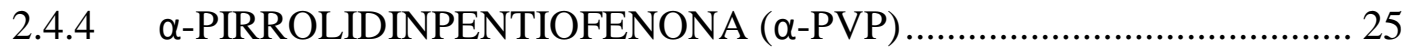

2.5 MÉTODOS PARA LA DETERMINACIÓN DE CATINONAS SINTÉTICAS

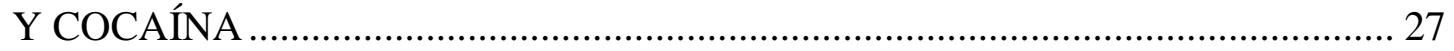

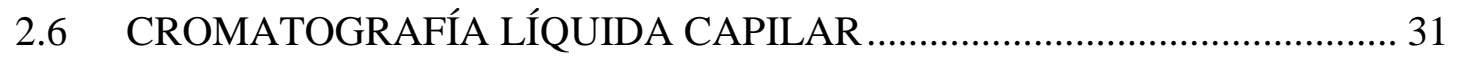

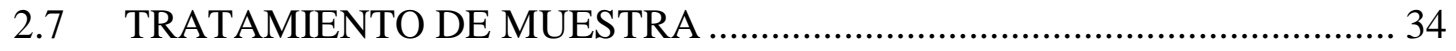

2.7.1 EXTRACCIÓN EN FASE SÓLIDA................................................... 34

2.7.2 EXTRACCIÓN LÍQUIDO-LÍQUIDO DISPERSIVA........................... 36

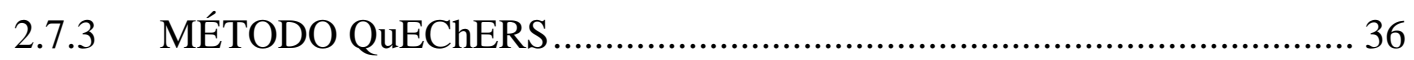

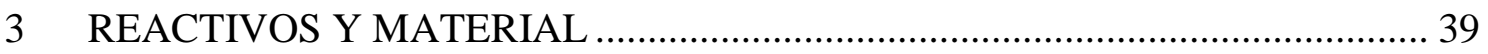

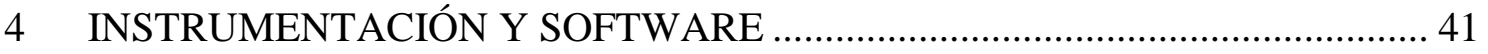


5 RESULTADOS Y DISCUSIÓN 42

5.1 IDENTIFICACIÓN DE LOS PICOS CROMATOGRÁFICOS ..................... 42

5.2 OPTIMIZACIÓN DE LA SEPARACIÓN CROMATOGRÁFICA ................ 44

5.2.1 ESTUDIO DE LA COMPOSICIÓN DE LA FASE MÓVIL ................... 44

5.2.2 ESTUDIO DEL GRADIENTE DE ELUCIÓN ….................................. 48

5.2.3 OPTIMIZACIÓN DEL CAUDAL DE FASE MÓVIL............................. 50

5.2.4 OPTIMIZACIÓN DE LA TEMPERATURA ........................................ 52

5.2.5 REOPTIMIZACIÓN DEL GRADIENTE DE ELUCIÓN....................... 54

5.2.6 EVALUACIÓN DEL MEDIO DE INYECCIÓN ................................... 54

5.2.7 OPTIMIZACIÓN DEL VOLUMEN DE INYECCIÓN .......................... 55

5.2.8 RESUMEN DE LA OPTIMIZACIÓN DE VARIABLES DEL MÉTODO

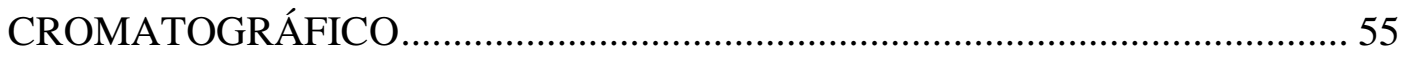

5.3 CARACTERIZACIÓN DEL MÉTODO CROMATOGRÁFICO EN

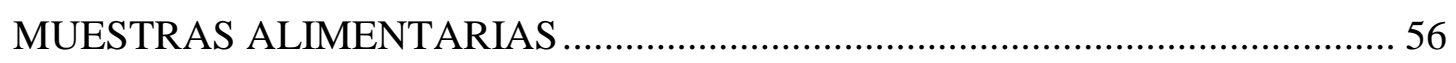

5.3.1 ESTABLECIMIENTO DE LA CURVA DE CALIBRADO Y PARÁMETROS DE CALIDAD ...................................................................... 57

5.3.2 ESTUDIO DE LA PRECISIÓN DEL MÉTODO ................................... 60

5.4 ESTUDIO DE LA VERACIDAD DEL MÉTODO .................................... 61

5.5 ENSAYOS PRELIMINARES PARA LA APLICACIÓN DEL MÉTODO PROPUESTO A LA DETERMINACIÓN DE LAS DROGAS DE ABUSO EN

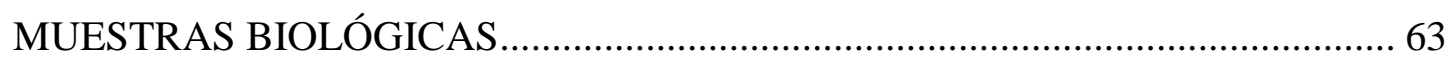

5.5.1 EVALUACIÓN DEL TRATAMIENTO DE MUESTRA....................... 64

5.5.2 ESTUDIOS REALIZADOS DE DLLME............................................ 72

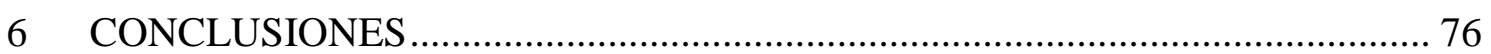

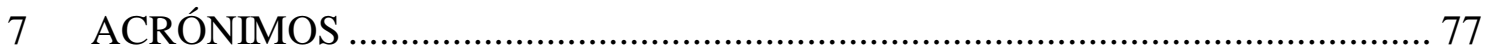

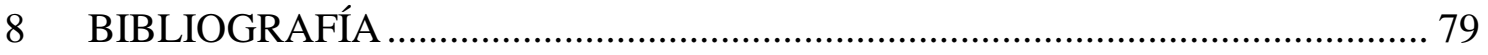




\section{LINEA DE INVESTIGACIÓN Y OBJETIVO DE LA MEMORIA}

\subsection{LÍNEA DE INVESTIGACIÓN}

El trabajo ha sido desarrollado en la línea de investigación "análisis de drogas de abuso en muestras de interés en los laboratorios forenses” dentro del Grupo de Investigación “Química Analítica Alimentaria, Ambiental y Clínica (FQM-302)”, cuya responsable es la Dra. Ana $\mathrm{M}^{\mathrm{a}}$ García Campaña y ha sido realizado bajo la dirección de la Dra. Carmen Cruces Blanco y del Dr. Maykel Hernández Mesa.

\subsection{OBJETIVO DE LA MEMORIA}

En los últimos años, el fenómeno de Sumisión Química (SQ) ha cobrado gran interés, siendo las drogas de abuso las más empleadas como arma, sobre todo en fenómenos de asalto sexual. Las catinonas sintéticas pertenecen a una familia de drogas ampliamente usadas con estos fines, debido a sus propiedades y al vacío legal que existe para algunos compuestos de esta familia, empleándose habitualmente en presencia de otras drogas, sobre todo en presencia de cocaína.

La orina, la sangre y la saliva son las muestras biológicas más analizadas en el campo de la SQ debido a la facilidad de recogida de muestra y conservación de las mismas. Sin embargo, debido a la dificultad de las víctimas para recordar lo ocurrido, a la baja permanencia de muchas drogas en el organismo y a la gran variedad de sustancias que se emplean, está cobrando gran interés el análisis de este tipo de drogas en restos de bebidas encontradas en la escena del delito, pues el análisis de estas muestras puede ser clave para la resolución de un caso.

En los laboratorios forenses se necesitan técnicas de rutina económicas para la determinación de este tipo de sustancias en una amplia variedad de muestras. La tendencia actual es recurrir a desarrollar métodos alternativos empleando técnicas miniaturizadas que van a consumir menos muestras y reactivos, por lo que, presentando las mismas prestaciones, serán más compatibles con la Química Verde. 
Teniendo en cuenta estas necesidades y el interés que los laboratorios forenses están mostrando en su aplicabilidad a muestras alimentarias, el objetivo de esta memoria es poner a punto un método de detección y cuantificación de dos catinonas sintéticas en presencia de una de las drogas de consumo más frecuentes, como es la cocaína, mediante una técnica miniaturizada de cromatografía líquida capilar (HPLC-capilar) y como sistema de detección la detección UV-Vis, muy poco estudiada en el campo de la Toxicología Forense y asequible para cualquier los laboratorio de rutina, para la determinación de catinonas sintéticas y cocaína en diferentes bebidas alcohólicas, que es la forma más común de ingesta de estas drogas para delitos de SQ.

Por otro lado, debido a la complejidad de las muestras biológicas, para llevar a cabo el análisis de estas drogas en muestras de orina es necesario emplear tratamientos de muestra muy eficaces, ya que hay que alcanzar límites de detección muy bajos (del orden de los $\mu \mathrm{g} / \mathrm{L})$. Por ello, se ha decidido llevar a cabo unos estudios de tratamiento de muestra preliminares para extrapolar el método desarrollado al análisis de los mismos compuestos en muestras de orina, ya que estos tratamientos no son necesarios emplearlos en las bebidas estudiadas y su conocimiento es de vital importancia en el campo de la Toxicología Alimentaria y Forense.

Estos objetivos se han llevado a cabo con la siguiente metodología:

$>\quad$ Selección de drogas de abuso objeto de estudio: contactando con los laboratorios forenses para realizar la selección de las drogas en base a la mayor demanda actual.

$>$ Desarrollo de un método empleando la cromatografía líquida capilar con detección UV-Vis.

$>\quad$ Evaluación del tratamiento de muestra más adecuado para el análisis de las catinonas sintéticas y cocaína en bebidas alcohólicas.

Caracterización de la metodología de análisis propuesta para el análisis de drogas de abuso en diferentes bebidas alcohólicas.

$>\quad$ Ensayos preliminares para la aplicación de la metodología desarrollada a muestras de orina. 


\section{INTRODUCCIÓN}

\subsection{SUMISIÓN QUÍMICA}

Uno de los campos en los que se centra la Toxicología Forense es la Sumisión Química (SQ), término empleado por primera vez en 1982 por Poyenm Rodor, Jouve, Galland, Lots y Jounglard para referirse a la administración de sustancias a una persona sin su conocimiento y teniendo como finalidad la de provocar una alteración en su grado de conciencia, vigilancia y capacidad de juicio. Actualmente, este término se ha ampliado a los casos en los que se aprovecha dicha situación para poder llevar a cabo un acto delictivo como el robo, firma de documentos, comunicación del número confidencial de tarjeta bancaria y sobre todo la agresión sexual de tal forma que, la víctima puede estar dormida o despierta bajo el control del agresor, pareciendo complacientes a los ojos de testigos y sin conservar ningún recuerdo [1].

A pesar de que la SQ no es un fenómeno nuevo, desde finales de la década de los noventa del siglo pasado está cobrando mayor interés debido al aumento de denuncias y casos publicados relacionados con delitos de agresión sexual. Además, también se han registrado casos de SQ relacionados con la sedación de niños, personas mayores o enfermos que requieren una atención constante por parte de sus familiares o cuidadores [2-4].

La Agencia Francesa de Seguridad Sanitaria y Productos Sanitarios (AFSSAPS) ha propuesto la siguiente clasificación para los casos de SQ [5]:

$>\quad$ Sumisión química probada: La presencia de sustancias psicoactivas se detecta mediante técnicas cromatográficas y la sintomatología coincide con la cronología de los hechos producidos por dicha sustancias.

$>\quad$ Sumisión química probable: Cuando se sospecha que ha habido una agresión pero no se dispone de suficiente información clínica o los resultados analíticos no son determinantes. 
$>\quad$ Vulnerabilidad química: Cuando la víctima reconoce haber consumido sustancias psicoactivas de forma voluntaria.

El fenómeno de SQ, cada vez acapara más la atención de los medios de comunicación social. Sin embargo, en el ámbito profesional (personal sanitario, toxicólogos, forenses, servicios sociales, servicio judicial, etc), su estudio sigue siendo bastante superficial, por lo que en la actualidad es necesario llevar a cabo estudios para conocer, identificar, prevenir y aconsejar a las posibles víctimas [6].

La modalidad de SQ más habitual es el uso de drogas como Facilitadores del Asalto Sexual (DFSA), siendo este fenómeno el más estudiado desde el punto de vista toxicológico. La droga más empleada para este fenómeno es el alcohol, pero cada vez se emplean más otras como la cocaína, cannabis, ketamina, anfetamina, metanfetaminas, GHB (ácido oxíbico), MDMA (éxtasis), burundanga, benzodiacepinas y otras drogas que van saliendo al mercado con el objetivo de no ser detectadas. De tal forma que estas sustancias se incorporan en bebidas como el café, refrescos, bebidas alcohólicas y zumos de frutas, e incluso en alimentos y productos de pastelería. La víctima consume estos nutrientes de forma voluntaria pero la ingesta de los productos psicoactivos se lleva a cabo en contra de su voluntad constituyendo un delito. Por tanto es de gran interés analizar distintos tipos de muestra para determinar la causa de la intoxicación, pues no siempre está muy claro el momento de la ingesta.

Debido a la dificultad para recordar lo ocurrido y detectar estas sustancias psicoactivas, es muy difícil conocer el número real de casos de delitos producido por este fenómeno y las propiedades de estas sustancias hacen difícil su prevención. Sin embargo, ya hay métodos desarrollados para la detección de algunas drogas basándose en la reacción de las mismas, como es el método del pintauñas que cambia de color en contacto con el GHT [7].

Por todo esto, las sustancias empleadas para llevar a cabo delitos de SQ tienen las siguientes características [8]:

$>\quad$ Son sustancias fáciles de obtener. Normalmente se obtienen en internet y tiendas "Smart \& Grow". Las sustancias más fáciles de obtener son el etanol, algunos psicofármacos y sustancias ilegales de uso frecuente. 
Son sustancias insípidas, inodoras, incoloras y muy solubles en medio acuoso.

Pasan inadvertidas pues poseen una alta actividad cuando se suministran dosis bajas. Además son sustancias que producen síntomas confusos y su diagnóstico puede ser confundido con una intoxicación etílica u otro trastorno.

$>\quad$ Son sustancias de actuación rápida y poca duración para cumplir el objetivo en el momento y sin levantar sospechas. La rápida absorción de estas sustancias provoca que la víctima pierda el conocimiento o anule su voluntad sin darse cuenta de la intención del agresor y éste no tenga que esperar demasiado tiempo para cometer el acto delictivo. Por otro lado, la rápida eliminación del organismo dificulta mucho la investigación del caso.

Son sustancias que se administran de forma discreta a la víctima, por ejemplo en bebidas alcohólicas, permitiendo enmascarar el sabor y color a la misma vez que potencian los efectos.

Producen los efectos buscados por el agresor, que suelen ser: amnesia, sedación (para perturbar la capacidad de atención) y desorientación temporal y espacial de la víctima.

Se han identificado más de 50 sustancias empleadas en fenómenos de SQ. En la Tabla 1 se muestran algunas de estas sustancias, entre las cuales se encuentran las catinonas sintéticas, sustancias objeto de este trabajo.

\begin{tabular}{ccc}
\hline Cocaína y cocaína “crack” & Heroína & Ketamina \\
\hline MDMA & Morfina & $\begin{array}{c}\text { Escopolamina } \\
\text { (burundanga) }\end{array}$ \\
\hline Metanfetamina & $\begin{array}{c}\text { Cannabinoides y cannabinoides } \\
\text { sintéticos }\end{array}$ & LSD \\
\hline Catinona y catinonas sintéticas & Alcohol (EtOH) & MDA \\
\hline \multicolumn{2}{c}{ Tabla 1. Algunas drogas empleadas en fenómenos de $S Q}$. \\
\hline
\end{tabular}

Debido a las bajas dosis que se suelen administrar, así como las distintas propiedades físicoquímicas y la gran variedad de drogas que se pueden emplear, es normal que a los laboratorios les pueda resultar difícil detectar su presencia mediante métodos analíticos corrientes, siendo necesario emplear metodologías más sensibles, empleándose siempre 
que se disponga de ellos, procedimientos validados. Entre las técnicas analíticas recomendadas se encuentran las técnicas cromatográficas y espectroscópicas [9].

La Toxicología Analítica tiene como objetivo, en estos casos, la detección y cuantificación de las posibles sustancias que puedan estar implicadas en los casos de SQ y la estrategia analítica a seguir dependerá del momento de la toma de muestra y del incidente ocurrido, siendo la etapa de toma de muestra la responsable de gran parte del éxito de la detección de estos casos [6].

Las muestras más empleadas son la sangre y la orina debido a la simplicidad del análisis y fácil disponibilidad de las mismas, siendo la orina la muestra preferida en comparación con la sangre debido a que permite un plazo de detección de aproximadamente 5 días (dependiendo del periodo de semidesintegración de la sustancia ingerida y sus metabolitos) [5]. Aun así, muchas víctimas no denuncian hasta pasados 20 días de la agresión, por lo que cada vez se tiende más a analizar muestras de pelo ya que permite la determinación de sustancias psicoactivas una vez pasadas semanas o incluso meses del delito, permitiendo incluso la diferenciación entre consumo ocasional y crónico analizando el pelo por mechones. El inconveniente del pelo es que requiere de técnicas analíticas costosas y no todos los laboratorios cuentan con los equipos necesarios.

Por ello, distintas asociaciones de Toxicología Analítica están haciendo hincapié en recoger además de las muestras biológicas, muestras de la bebida o alimento sospechoso de ser contaminado, si la victima puede aportarlos, pues facilitaría mucho la investigación $[5]$.

En la Tabla 2 se muestran algunas sustancias de abuso que deben buscarse en la orina en casos de sospechar que se ha producido un fenómeno de asalto sexual mediante DFSA con el límite mínimo de funcionamiento exigido (MRPL, del inglés: minimum required performance limit) en cada caso, que se corresponde con el límite de detección mínimo que debe cumplir un laboratorio que se ocupe de casos de SQ. 


\begin{tabular}{cc|}
\hline Sustancia psicotrópica & MRPL $(\boldsymbol{\mu g} / \mathbf{L})$ \\
\hline Cocaína & 50 \\
\hline Benzoilecgonina & 50 \\
\hline Metilecgonina & 50 \\
\hline MDMA & 10 \\
\hline Anfetamina & 10 \\
\hline
\end{tabular}

Tabla 2. Algunas sustancias identificadas en la orina después de un delito de SQ y su MRPL [9].

Debido a que las catinonas sintéticas son un grupo de drogas emergentes y aún hay un vacío legal sobre algunas de ellas, no se dispone de muchos métodos desarrollados para la determinación de estas sustancias psicoactivas en delitos de SQ. Sin embargo, se están publicando casos en los que se emplean catinonas sintéticas como DFSA [10].

\subsection{TOXICOLOGÍA FORENSE: ASPECTOS GENERALES}

La Química Forense es una rama de las Ciencias Forenses que se encarga del "análisis, clasificación y determinación de aquellos elementos o sustancias que se encontraron en el lugar de los hechos o que pudieran relacionarse con la comisión de un delito" [11].

La Toxicología Forense es una rama de la Química Forense y es la encargada de aplicar la ciencia para la resolución de preguntas que se plantean en los procesos judiciales, asociándose normalmente a estudios relacionados con los tribunales de justicia criminal. Pero también se encarga del análisis y la identificación de medicamentos para el mantenimiento de la legislación de salud agrícola, industrial y pública convirtiéndose esta ciencia en una herramienta multidisciplinaria en la investigación de una amplia gama de escenarios que implican los efectos potenciales de las drogas y sustancias químicas en los seres humanos y animales.

Uno de los grandes científicos del Renacimiento Europeo, Paracelso (1493-1541) fue el primero en definir el veneno postulando que "todas las sustancias son venenos: no hay ninguno que no es un veneno. La dosis correcta diferencia un veneno y un remedio". Hoy en día la definición de veneno es mucho más compleja, pero se ha demostrado que el enfoque de Paracelso es correcto. Además, este enfoque dio lugar a un interés en estudiar las propiedades de los venenos desarrollándose así la primera prueba de análisis forense espejo de arsénico en 1836 por el químico inglés Jame Marsh [12], cuyo objetivo 
era detectar el arsénico en muestras biológicas, ya que en esta época el arsénico era el veneno favorito para cometer crímenes debido a que los síntomas de envenenamiento por arsénico se parecen a los producidos por la bacteria del cólera [13].

Actualmente la Toxicologia Forense abarca la determinación de una enorme cantidad de sustancias potencialmente tóxicas. La toxicidad de estas sustancias se mide a través de la dosis letal media (DL50) que es la estimación estadística de la cantidad de una sustancia tóxica $(\mathrm{mg} / \mathrm{kg})$ por peso corporal, necesaria para matar al 50\% de la población, durante un período de tiempo determinado y seguimiento en un período post-exposición. En la Tabla 3 se muestra la clasificación de los tóxicos atendiendo al tiempo de exposición, comportamiento analítico y según los clasifica la Medicina Legal.

\section{Clasificación atendiendo a:}

Tiempo de exposición

Comportamiento analítico

Medicina Legal
Toxicidad aguda Toxicidad subaguda

Toxicidad crónica

- $\quad$ Compuestos gaseosos

- $\quad$ Compuestos volátiles

- Compuestos inorgánicos

- $\quad$ Compuestos orgánicos fijos (TOFs)

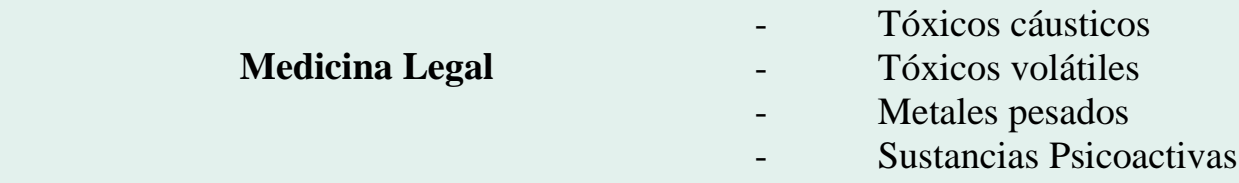

Tabla 3. Clasificación de los tóxicos.

Dentro de los tóxicos objeto de estudio de la Toxicologia Forense, se encuentran los tóxicos orgánicos fijos (TOFs), dentro de los cuales se engloban tóxicos como los plaguicidas, los medicamentos y las drogas de abuso.

Debido a que las drogas de abuso aparecen en todos los campos de trabajo de la Toxicología Forense, la sociedad demanda continuamente el establecimiento de nuevos métodos de identificación y cuantificación en numerosas muestras tanto biológicas (sangre, orina, pelo, saliva) como no biológicas (alimentos, medio ambiente, etc.). Es por ello, que la Química Analítica se ha hecho imprescindible para el trabajo del toxicólogo forense, ya que gracias a sus avances se consiguen identificar y cuantificar sustancias 
xenobióticas, así como sus metabolitos, a bajas concentraciones y en cantidades mínimas de muestra, mediante el empleo de técnicas analíticas adecuadas, jugando un papel fundamental en el diagnóstico y a veces en la prevención de delitos [14].

\subsection{DROGAS DE ABUSO: GENERALIDADES Y CLASIFICACIÓN}

El hombre ha consumido desde tiempos inmemorables sustancias de plantas o productos químicos para huir de la realidad, hacer frente a los problemas o por la incapacidad de hacer frente a dichos problemas, por placer o con fines médicos.

Alrededor del año 5000 a.C., el alcohol fue empleado para dichos fines y en Egipto, en la pirámide de Sakkara, se hallan pinturas y figuras relacionadas con la elaboración de cerveza y datadas entre los años 2000 y 4000 a.C. [15].

En 1920, en Estados Unidos, con la llegada de la Ley Seca, se prohibió la venta, exportación, importación y fabricación de bebidas alcohólicas promoviéndose la aparición de un mercado clandestino dirigido por organizaciones mafiosas e incrementándose las actividades criminales, por lo que en 1933 se derogó dicha ley y fue después de la Segunda Guerra Mundial cuando los patrones de consumo cambiaron incrementándose el consumo de alcohol por ocio.

Actualmente, la Organización Mundial de la Salud (OMS) define el término droga como "toda sustancia que, introducida en un organismo vivo pueda modificar una o varias de sus funciones" y se emplea para describir fármacos con preinscripción y como sustancias de abuso, siendo las drogas de abuso aquellas sustancias psicoactivas que no se emplean con fines médicos y producen una alteración en la percepción, en el estado de ánimo, en la consciencia y en el comportamiento. Así, la diferencia entre lo que hoy conocemos como droga y fármaco viene determinada por el fin con el que se emplee. Además la posesión de estas sustancias está restringida por la ley debido a sus efectos perjudiciales ya que, por ejemplo, los opiáceos como la morfina tienen uso terapéutico para aliviar el dolor pero algunas personas lo usan de forma abusiva con fines no terapéuticos.

Como consecuencia del mal uso inicial de los productos farmacéuticos, como la diamorfina, cocaína y anfetamina, las restricciones legales incrementaron y por 
consecuente la industria de las drogas ilícitas también, dando lugar a la aparición de mercados clandestinos y a la síntesis de una infinidad de sustancias psicoactivas con el objetivo de evitar el peso de la ley. Muchas de las drogas de abuso son estimulantes del sistema nervioso central (SNC), analgésicos, alucinógenos e hipnóticos [13].

Hoy en día muchas sustancias psicoactivas están prohibidas y sometidas a control ya que se consideran sustancias de abuso tanto para fines recreativos como para fines delictivos y otras como el alcohol, la cafeína y el tabaco se siguen comercializando legalmente.

En 1961 se llevó a cabo la primera Convención Internacional de Sustancias Psicotrópicas y tanto en la Convención de 1961 como en la de 1971 se clasificaron las sustancias controladas en cuatro listas (Listas I, II, III y IV) de acuerdo a su valor terapéutico y riesgo potencial de abuso. Posteriormente, la convención de 1988 añadió dos tablas en las que se listan los precursores, reactivos y disolventes utilizados frecuentemente en la fabricación ilegal de sustancias psicotrópicas. En Estados Unidos (EE.UU), la Ley de Sustancias Controladas (con siglas en inglés CSA, Controlled Substances Act) de 1970 es la que clasifica las sustancias psicoactivas [16-19].

En la Tabla 4 se muestran algunas de las drogas de abuso más comunes controladas en la Convención de 1961 y 1971 en las Naciones Unidas, así como las reguladas en EE.UU por la ley de 1970.

\begin{tabular}{|cccc|}
\hline Sustancia Psicoactiva & Naciones Unidas & Naciones Unidas & EE.UU \\
\hline Anfetamina & $\mathbf{1 9 6 1}$ & $\mathbf{1 9 7 1}$ & Lista II \\
\hline Metanfetamina & - & Lista II & Lista II \\
\hline MDMA & - & Lista II & Lista I \\
\hline Cocaína & - & Lista I & Lista II \\
\hline Benzodiacepinas & Lista I & - & Lista IV \\
\hline Heroína & - & Lista IV & Lista I \\
\hline Cannabis & Lista I & - & Lista I \\
\hline
\end{tabular}

Tabla 4. Algunas sustancias psicotrópicas controladas por las Naciones Unidas (NU) y en EE.UU.

Actualmente, hay ediciones más recientes que recogen las listas actualizadas de sustancias sometidas a fiscalización internacional comprendiendo estupefacientes, sustancias psicotrópicas y sustancias frecuentemente utilizadas para la fabricación ilícita 
de los mismos. Estas ediciones incluyen las Listas Amarilla, Verde y Roja elaboradas por la Junta Internacional de Estupefacientes con el fin de ayudar a los Gobiernos en completar las estadísticas anuales sobre estupefacientes, las estadísticas trimestrales de importaciones y exportaciones de estupefacientes y las previsiones de necesidades anuales de estupefacientes.

Por lo tanto, dentro del término droga se engloban dos clases, las drogas lícitas cuyo manejo está permitido bajo licencia, como es la morfina y benzodiacepinas y las drogas ilícitas procedentes de laboratorios clandestinos, entre las cuales las más comunes son la anfetamina, metanfetamina, metilendioximetanfetamina (MDMA), dietilamida del ácido lisérgico (LSD), heroína, cocaína, cannabis y cannabinoides (Imagen 1). Por ello, su análisis es muy importante en diferentes ramas de la Ciencia como la Medicina, Toxicología y también en control de dopaje, asuntos legales, pruebas para empleo o supervisión laboral y programas de rehabilitación.

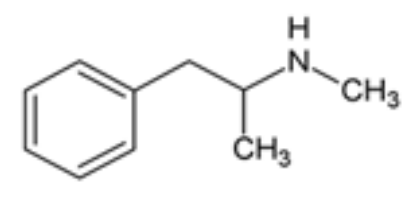

Metanfetamina<smiles>CC(Cc1ccc2c(c1)OCO2)NO</smiles>

MDMA

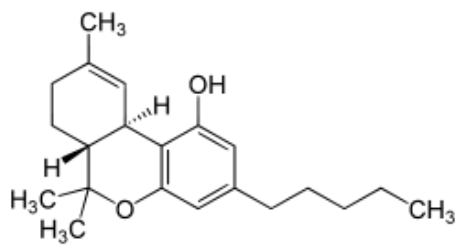

Tetrahidrocannabinol (THC)

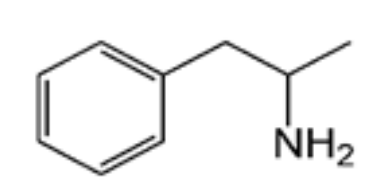

Anfetamina

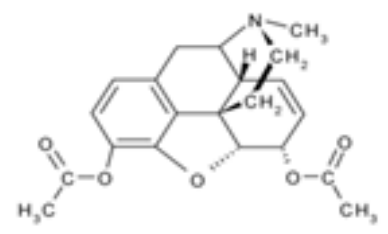

Heroina

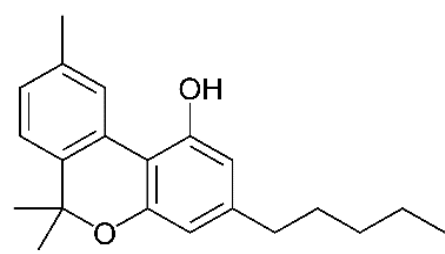

Cannabinol (CBN)

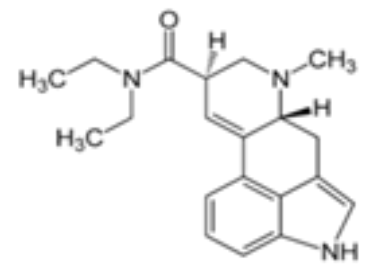

LSD

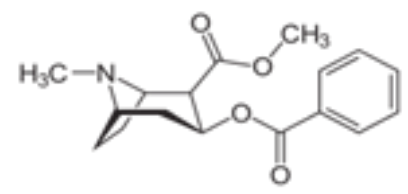

Cocaina

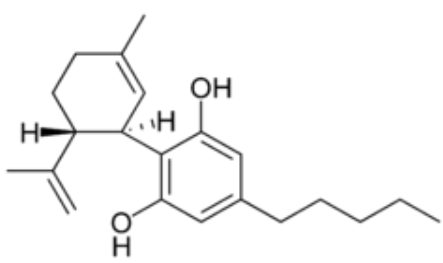

Cannabidiol (CBD)

Imagen 1. Estructura química de algunas drogas de abuso comunes. 
Debido a esta restricción legal, en los últimos años aparece el concepto droga de diseño o droga sintética, el cual hace referencia al conjunto de drogas sintetizadas en laboratorios de forma clandestina con el propósito de producir sustancias nuevas, mediante variaciones en la estructura química de otras sustancias, generalmente a partir de una anfetamina mediante adición, modificación o sustitución de grupos metilos consiguiendo una nueva droga con efectos similares a los de las drogas clásicas, o incluso más potentes, además de intentar evadir el peso de la ley [20].

En la Tabla 5 se muestra una clasificación de las drogas de abuso atendiendo a su naturaleza y a su legislación, así como algunos ejemplos de drogas que se engloban dentro de esos grupos.

\begin{tabular}{cccc}
\hline \multicolumn{2}{c}{ LEGISLACIÓN } & \multicolumn{2}{c}{ NATURALEZA } \\
\hline \multicolumn{1}{c}{ Lícitas } & Ilícitas & Naturales & Sintéticas (o de diseño) \\
\hline Café & Cocaína & & Catinonas sintéticas \\
Alcohol & Anfetamina & Cocaína & (metilona, $\alpha$-PVP, \\
Morfina & Metanfetaminas & Morfina & mefedrona, etc) \\
Benzodiacepinas & Cannabis & Catinona & MDMA (Éxtasis) \\
Catinonas sintéticas & Cannabinoides & Cannabis & Cannabinoides sintéticos \\
& Opio y opioides & & Metanfetamina \\
\end{tabular}

Tabla 5. Clasificación de las drogas de abuso.

\subsubsection{CLASIFICACIÓN DE LAS DROGAS DE ABUSO ILÍCITAS}

La clasificación de las drogas de abuso ilícitas no se basa en su estructura química sino en los efectos fisiológicos que éstas producen en el organismo, de tal forma que los principales grupos de drogas de abuso ilícitas son los que se muestran en la Tabla 6 [21]. 
Clasificación

\section{Estimulantes del SNC*}

Depresores del SNC

Alucinógenos

Cannabinoides

$1^{\circ}$ Generación:

antidepresivos tricíclicos.

Antidepresivos

$$
2^{\circ} \text { Generación: }
$$

$3^{\circ}$ Generación: Inhibidores

selectivos de la recaptación

de serotonina (ISRS)

\section{Ejemplos}

\section{Cocaína, anfetaminas}

Alcohol, opio, opioides, benzodiacepinas

LSD, mescalina, psilocibina, algunos alcaloides topánicos, triptaminas.

Marihuana y derivados, hachís y derivados.

Inhalantes

Imipramina, desipramina, ciomiprmina, amitriptilina, nortiptilina.

Maprotilina, mianserina, viloxacina

Trazodona, nefezodona, fluoxetina,

fluvoxamina, sertralina, paroxetina, citaloprán

Hidrocarburos (aromáticos y halogenados)

fluorocabonos, óxido nitroso y otros anestésicos gaseosos.

Tabla 6. Clasificación de las diferentes drogas de abuso ilícitas. * SNC (Sistema Nervioso Central).

\subsubsection{COCAÍNA}

La cocaína es un alcaloide encontrado en ciertas variedades de plantas del género Erythroxilum (Imagen 2) y se distribuye prácticamente por todo el mundo. Esta droga, en su forma básica se conoce como "crack" y fue extraída por primera vez en la segunda mitad del siglo XIX por Albert Niemann (Imagen 3) aunque el consumo de la hoja de coca se remonta al año 2000 a.C. en Chile y Perú con fines religiosos y sociales.

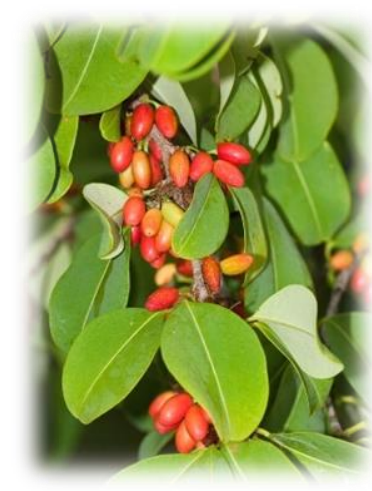

Imagen 2. Hojas de la planta Erythroxilum coca.

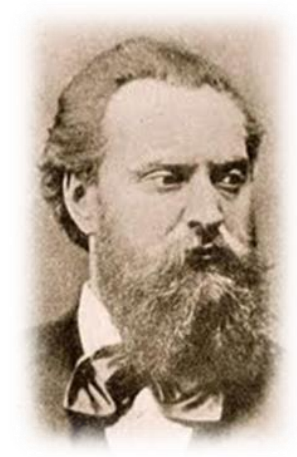

Imagen 3. Albert Niemann

Fue a partir de su aislamiento cuando se expandió por Europa aumentando el interés clínico por sus efectos estimulantes. Sigmund Freud, el padre del psicoanálisis, además de consumir cocaína incidió en sus efectos terapéuticos como analgésico, trastornos 
digestivos, tratamiento de hipocondría y como tratamiento contra adicciones al alcohol y la morfina. Incluso se llegaron a elaborar bebidas, preparados farmacéuticos y otras fórmulas galénicas con cocaína. Un caso llamativo es el de la Coca-Cola® que se comercializaba como bebida medicinal conteniendo cocaína o extractos de hoja de coca, aunque actualmente este compuesto se ha sustituido por cafeína [22].

La cocaína a veces se encuentra con alta pureza pero es muy común encontrarla combinada con otras sustancias. Estas sustancias, que hacen impura la cocaína, pueden ser azúcares como la glucosa, el manitol, la lactosa y cafeína para incrementar las propiedades estimulantes reduciendo el contenido en cocaína, y analgésicos como la lidocaína o benzocaína para reducir las propiedades analgésicas de la cocaína ya que ésta tiene propiedades como anestésico y es un vasoconstrictor.

La cocaína enlaza la recaptación de la dopamina transportadora en el SNC incrementando la concentración de dopamina y norefedrina. Como consecuencia se obtienen efectos como la euforia, charlatanería, sentido de conciencia y placer, alcanzando estos efectos de forma rápida tras su consumo. Sin embargo, la sensación de bienestar inicial suele ir seguida por una depresión intensa [13]. Además, la cocaína se metaboliza muy rápido, siendo su principal metabolito la benzoilecgonina, que se forma por la enzima carboxilestirasa hepática o simplemente por una hidrólisis, siendo un grupo metilo su única diferencia con la estructura de la cocaína. En la Tabla 7 se muestran algunos productos de degradación de la cocaína [23].

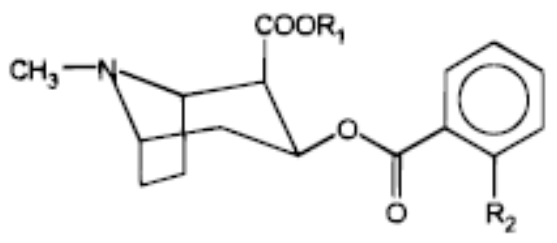

\begin{tabular}{cc}
$\mathbf{R} 1=\mathbf{C H}_{\mathbf{3}}$ & Cocaína \\
$\mathbf{R} 2=\mathbf{H}$ & Benzoilecgonina \\
$\mathbf{R} 1=\mathbf{H}$ & \\
$\mathbf{R} 2=\mathbf{H}$ & $2^{\prime}-$ Metilbenzoilecgonina \\
$\mathbf{R} 1=\mathbf{H}$ & \\
$\mathbf{R} 2=\mathbf{C H}_{\mathbf{3}}$ & Cocaetileno \\
$\mathbf{R} \mathbf{1}=\mathbf{C H}_{\mathbf{2}} \mathbf{C H}_{\mathbf{3}}$ & \\
$\mathbf{R} 2=\mathbf{H}$ & $2^{\prime}-$ Metilcocaína \\
$\mathbf{R} 1=\mathbf{C H}_{\mathbf{3}}$ & \\
$\mathbf{R} 2=\mathbf{C H}_{\mathbf{3}}$ & \\
\hline
\end{tabular}

Tabla 7. Estructura química de la cocaína y algunos de sus metabolitos. 
Debido a su alto potencial de abuso y dependencia, tanto la hoja de coca como la cocaína se sometieron a fiscalización internacional mediante su introducción en la Lista I de la Convención Única de 1961 sobre estupefacientes. Sin embargo, en algunos países se sigue empleando con fines medicinales como anestésico.

En cuanto a las propiedades químicas de la cocaína, así como su estructura química, se muestran en la Tabla 8. La cocaína es un éster metílico de benzoilecgonina que tiene dos formas diferentes de presentación: como una sal o como base libre.

Cuando la cocaína se presenta en forma de sal, normalmente como clorohidrato de cocaína, es soluble en agua, y es en el agua donde se disuelve previamente a su consumo por vía intravenosa, aunque también se puede aspirar. Mientras que la forma de base libre “crack" no es soluble en agua y se volatiliza cuando se calienta, por lo que normalmente se fuma [24].

Debido a su polaridad ( $\log$ P), la cocaína como base es hidrofóbica siendo factible su determinación y cuantificación por cromatografía en fase inversa.

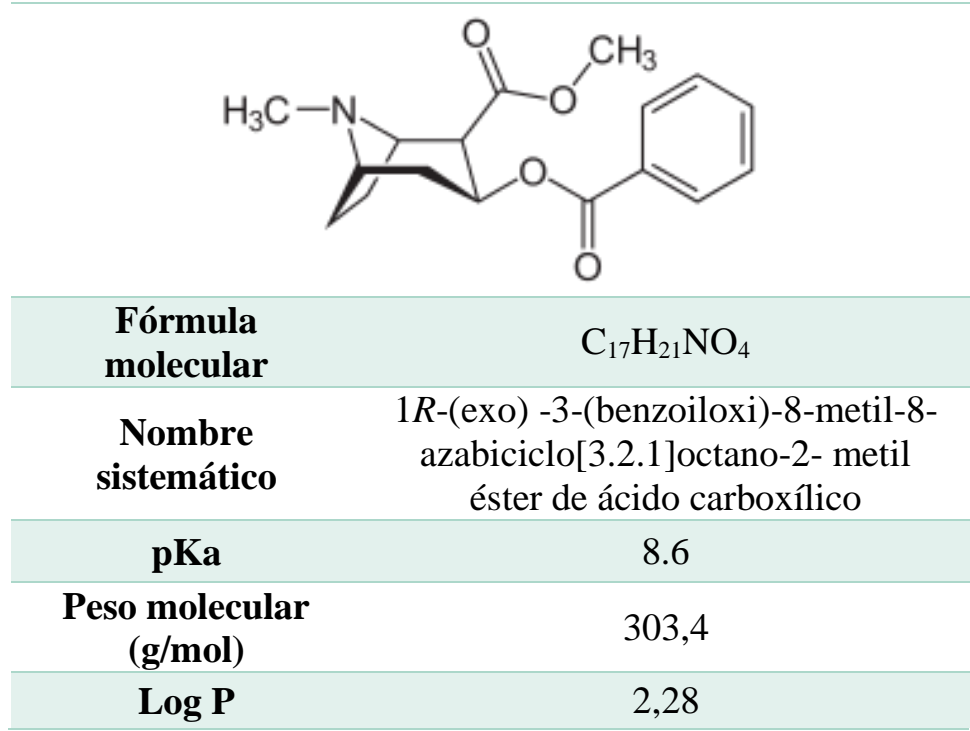

Tabla 8. Propiedades físicoquímicas de la cocaína. Datos obtenidos de la plataforma Chemicalize.org. 


\subsubsection{DROGAS LEGALES}

El término droga legal se emplea actualmente para referirse a las drogas de diseño obtenidas mediante la modificación de estructuras moleculares de drogas ya existentes, con el objetivo de evitar la ley ya que éstas aún no han sido controladas.

Aunque las drogas de diseño se conocen desde hace más de 20 años, el fenómeno de drogas derivatizadas está incrementado a gran velocidad debido al desarrollo de la tecnología, al bajo precio de la síntesis orgánica, disponibilidad de obtención de productos para la síntesis y la facilidad de venta a través de internet. Este tipo de sustancias inicialmente se consumen de forma involuntaria, ya que su consumo deriva de drogas adulteradas. Sin embargo, el consumo voluntario de las mismas está incrementando en los últimos años.

En los últimos años el incremento de casos publicados relacionados con este tipo de sustancias psicoactivas ha llamado la atención de las comunidades farmacéuticas, químicas, forenses, toxicológicas y analíticas [25].

Las drogas legales más comunes se pueden clasificar en cuatro grupos atendiendo a cual sea su componente activo (Imagen 4):

Feniletilaminas: Son una clase de sustancias que llevan en el mercado de las drogas desde hace más de veinte años, siendo las más comunes en Europa la anfetamina, metanferamina y MDMA (3,4-dimetoximetanfetamina).

$>$ Triptaminas: Muchas de ellas se encuentran en la naturaleza pero también se pueden producir de forma sintética. Las más conocidas son la psilocibina y psilocina que se obtienen de ciertos hongos indígenas en zonas tropicales del sur de América, México y USA.

Piperazinas: Muchos derivados de piperazinas son drogas muy populares entre las que se incluyen antidepresivos, antihistamínicos y antipsicóticos como la cozapina y olanzapina.

Catinonas: La catinona (-)- $\alpha$ - aminopropriofenona, es el principio activo del khat (Cathaedulis) y se aisló por primera vez en 1975 de las hojas del khat, un arbusto de hoja 
perenne y que ha sido usada tradicionalmente con fines medicinales por gente indígena del este de África. La estructura de la catinona está estrictamente relacionada con la estructura de la anfetamina. La única diferencia es la presencia del grupo carbonilo en posición beta. Actualmente, las catinonas sintéticas son el componente más común en las denominadas drogas legales.<smiles>[R]c1ccc(CC([R])N([R])[R])cc1</smiles>

Feniletilaminas<smiles>[R]c1cccc2c(CC([R])N([R6])C)c[nH]c12</smiles>

Triptaminas<smiles>[R]c1ccc(C(=O)C([R])N([R])[2H])cc1</smiles>

Catinonas

Imagen 4. Estructuras de diferentes drogas legales.

El Centro Europeo de Control de Drogas y Adicción (EMCDDA, del inglés European Monitoring Centre for Drugs and Drug Adiction) vigila una amplia gama de nuevas sustancias psicotrópicas, como los cannabinoides sintéticos, las catinonas sintéticas, las fenetilaminas, los opioides, las triptaminas, las benzodiazepinas y otra serie de sustancias. Entre 1997 y 2009, el número de sustancias notificadas oficialmente por el Sistema de Alerta Temprana (EWS, del inglés Early Warning Sistem) del EMCDDA fueron 32 fenetilaminas, 22 triptaminas, 15 catinonas y 12 piperazinas. Mientras que en el 2014, la lista de sustancias emitidas por la EMCDDA indicaba la presencia de 31 catinonas sintéticas y 30 cannabinoides sintéticos [26]. En 2015 se detectaron 98 sustancias nuevas, lo que eleva el número de sustancias nuevas vigiladas a más de 560 [27].

Al contrario que ha pasado con las catinonas sintéticas, la síntesis de derivados de las fenetilaminas y piperazinas ha ido decreciendo en los últimos años y se notifican menos casos de estas drogas en Europa.

\subsection{CATINONAS SINTETICAS}

Cathaedulis es un arbusto de hojas perennes cultivado en el este de África y en la Península Arábiga cuyas hojas y raíces se conocen como khat. La catinona (S-(-)-2amino-1-fenilpropan-1-ona) y la catina $((+)$ - norpseudofedrina) son dos alcaloides 
naturales presentes en la hoja del khat, normalmente en cantidades del $0,3 \%$ y $2,0 \%$ respectivamente, siendo estos compuestos los principios activos de esta planta. Ambas sustancias tienen una estructura química estrechamente relacionada a la estructura de la anfetamina y la metcatinona, produciendo efectos similares pero con un potencial mayor [28].

Las catinonas sintéticas son $\beta$-análogos de la catinona natural, estando todas compuestas por una $\beta$-cetofeniletilamina como estructura base. En la Imagen 5 se muestra la estructura de la catina y la catinona.
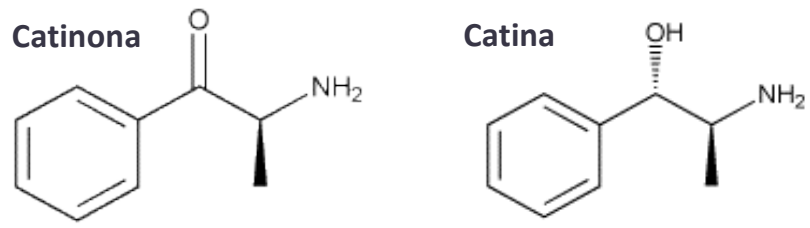

Imagen 5. Estructuras de Catinona y Catina, respectivamente.

Las catinonas sintéticas son un grupo muy reciente de drogas con carácter recreativo conocido popularmente como sales de baño principalmente en Estados Unidos, mientras que en Europa se conoce como alimento para plantas o alimento vegetal. Estas drogas forman parte de un amplio grupo conocido como drogas legales o nuevas drogas psicoactivas (NPDs). Este tipo de drogas se venden principalmente en tiendas en forma de polvos inodoros, blancos, amarillentos, marrones o cristales finos, aunque también se venden con menos frecuencia en forma de pastillas o cápsulas [29].

Aunque muchos productos adviertan en la etiqueta que nos son aptos para el consumo humano, el objetivo es producir los mismos síntomas que los obtenidos con las drogas ilegales como son la metanfetamina, la cocaína, la penciclina (PCP) o el ácido lisérgico de dietilamida (LSD). El componente activo en las sales de baño son las catinonas sintéticas, es decir, derivados sintéticos de la catinona para evitar su detección y el peso de la ley, empleándose cada vez más en delitos de SQ y por ello su determinación es un reto para la Toxicología Forense.

La mayoría de las catinonas sintéticas se originan en China y en la India, aunque se venden de forma legal en internet o en tiendas de tabaco y estaciones de servicio debido a que estas sustancias no están controladas [29]. En Europa el precio medio ronda entre 
18-25 €/g, siendo más baratas que otras drogas que no son de diseño. En la Tabla 5 se muestra la variación del precio de algunas drogas de abuso comunes en función de su pureza [30].

\begin{tabular}{|c|c|c|}
\hline Droga & $\begin{array}{c}\text { Pureza } \\
(\%)\end{array}$ & $\operatorname{Precio}(€ /$ g.) \\
\hline \multirow{4}{*}{ Cocaína } & $>64$ & 91 \\
\hline & $50-64$ & 72 \\
\hline & $36-50$ & 52 \\
\hline & $26-36$ & 46 \\
\hline \multirow{4}{*}{ Metanfetamina } & $>73$ & 116 \\
\hline & $67-73$ & 66 \\
\hline & $28-67$ & 15 \\
\hline & $9-28$ & 7 \\
\hline \multirow{4}{*}{ Anfetamina } & $>49$ & 37 \\
\hline & $27-49$ & 25 \\
\hline & $12-27$ & 10 \\
\hline & $1-12$ & 7 \\
\hline \multirow{4}{*}{ MDMA } & $>95$ & $16 € /$ pastilla \\
\hline & $68-95$ & $9 € /$ pastilla \\
\hline & $18-68$ & $5 € /$ pastilla \\
\hline & $<18$ & $3 € /$ pastilla \\
\hline
\end{tabular}

Tabla 9. Variación del precio de algunas drogas de abuso en función de su pureza.

Dentro de este tipo de drogas, las catinonas sintéticas son el segundo grupo de sustancias vigiladas por el EMCDDA, siendo detectadas por primera vez en Europa en 2004. Desde entonces se han identificado 103 catinonas nuevas, 26 de ellas en 2015, vendiéndose normalmente como sustitutos legales de estimulantes como la anfetamina, la MDMA y la cocaína.

Los datos notificados al Sistema de Alerta Rápida de la UE apuntan a un crecimiento continuado del mercado de drogas nuevas. En 2014, se incautaron más de 8000 catinonas sintéticas en Europa, siendo éstas el segundo grupo de sustancias incautadas, precedido de los cannabinoides sintéticos, representando entre ambas más del $80 \%$ de incautaciones en esta fecha [27].

Por otro lado, la lista de ingredientes no indica la presencia de sustancias psicoactivas y da poca información de seguridad. En conjunto, estos factores proporcionan una amenaza para los consumidores e incrementa el riesgo y toxicidad asociada con el uso de productos que contienen esta clase de sustancias. 
Desde 2007, que se obtuvo la primera evidencia de la mefedrona (4-metilmecatinona, 4MMC) y hasta finales de esa década, ésta fue la droga más popular en EE.UU bajo distintos nombres como Diablo XXX, MMCat, Meph o Burbujas. Esta droga es controlada en Estados Unidos y en la Unión Europea desde 2010, y como alternativa a la misma apareció en el mercado de forma legal la nafirona (naftilpirovalerona). Otro tipo de catinona, MDPV (3,4-metilendioxiprovalerona) se detectó por primera vez en 2006 en Japón seguido de Alemania en 2007 y Finlandia en 2008, mientras que en Estados Unidos y Polonia se detectó tras la prohibición de la mefedrona en 2010.

En 2012, algunos derivados ya estaban prohibidos en distintos Estados de la Unión Europea, como la mefedrona en Bélgica, Dinamarca, Alemania, Estonia, Irlanda, Francia, Italia, Lituania, Rumania, Suecia, Croacia y Noruega. La metilona estaba prohibida en Dinamarca, Irlanda, Rumania y Suecia, la butilona en Dinamarca, Irlanda, Rumania, Suecia y Noruega y el MDPV estaba prohibido en Dinamarca, Irlanda, Finlandia y Suecia [29].

En la lista I de la Convención de las Naciones Unidas de sustancias psicotrópicas en 1971 se enumeran la catinona y metcatinona, mientras que la pirovalerona y anfepramona están en la lista IV [17]. Sin embargo, hay muchos derivados que aún no están bajo control internacional como es el caso de la pentilona y el $\alpha$-PVP [31].

A pesar del incremento del consumo de las catinonas sintéticas se conoce muy poco acerca de su química y su actividad biológica, presentando estos compuestos estructuras similares a las de los derivados de la anfetamina. Además, análisis moleculares indican que las catinonas sintéticas son considerablemente menos lipofílicas y ejercen menos penetración hematoencefálica cuando se compara con su análogo derivado de la anfetamina.

Por otro lado, debido a sus propiedades y a los efectos que produce, se suele emplear con otras drogas ilícitas como son el éxtasis, el alcohol, la cocaína o el MDMA para la comisión de delitos mediante SQ, sobre todo en delitos de asalto sexual, provocando en algunos casos la muerte. El motivo de emplear sustancias mixtas dificulta la determinación de las mismas mediante técnicas analíticas al mismo tiempo que las van introduciendo en el mercado [32]. 


\subsubsection{ESTRUCTURA QUÍMICA DE LAS CATINONAS SINTÉTICAS}

Las catinonas sintéticas son $\beta$-cetoanfetaminas, siendo la estructura común de las mismas la mostrada en la Imagen 6.<smiles>[R]c1ccc(C(=O)C([R3])N([R])C)cc1[R]</smiles>

Imagen 6. Estructura de una catinona sintética. $(R 1, R 2, R 3$ y $R 4$ corresponden a los radicales que dan lugar a las distintas catinonas sintéticas).

Por lo general, las catinonas se caracterizan por la presencia de un grupo carbonilo en la posición del átomo de $\mathrm{C} \alpha$, es decir, el segundo carbono adyacente al átomo de nitrógeno. La presencia de este átomo de oxígeno con dos pares de electrones libres es el que proporciona sus propiedades espectrométricas. Además, tienen otras propiedades dadas por los sustituyentes en el anillo aromático y/o en el $\mathrm{C} \alpha$, así como también puede tener lugar una $\mathrm{N}$-alquilación o la incorporación de un anillo con un nitrógeno, dando lugar a una amplia variedad de catinonas sintéticas. En la Imagen 7 se muestran algunas de las muchas catinonas sintéticas existentes [33].<smiles>CNC(C)C(=O)c1ccc2c(c1)OCO2</smiles>

METILONA<smiles>CNC(C)C(=O)c1ccc(C)cc1</smiles>

MEFEDRONA<smiles>CC(NC(C)(C)C)C(=O)c1cccc(Cl)c1</smiles>

BUPROPION<smiles>CCC(NC)C(=O)c1ccc2c(c1)OCO2</smiles>

BUTILONA<smiles></smiles><smiles>CCCC(C(=O)c1ccc(C)cc1)N1CCCC1</smiles>

PIROVALERONA<smiles>CCNC(C)C(=O)c1ccc2c(c1)OCO2</smiles>

ETILONA<smiles>CNC(C)C(=O)c1ccc(F)cc1</smiles>

FLEFEDRONA<smiles>CCCC(C(=O)c1ccc2c(c1)OCO2)N1CCCC1</smiles>

MDPV

Imagen 7. Estructura de algunas catinonas sintéticas. 
Debido a su estructura, las catinonas sintéticas cristalizadas son solubles en agua, siendo consumidas, muchas veces, disueltas en bebidas, otro motivo por el cual se suele emplear en SQ.

En las Tablas 10 y 11 se muestran las propiedades fisicoquímicas de las catinonas sintéticas estudiadas en este trabajo.

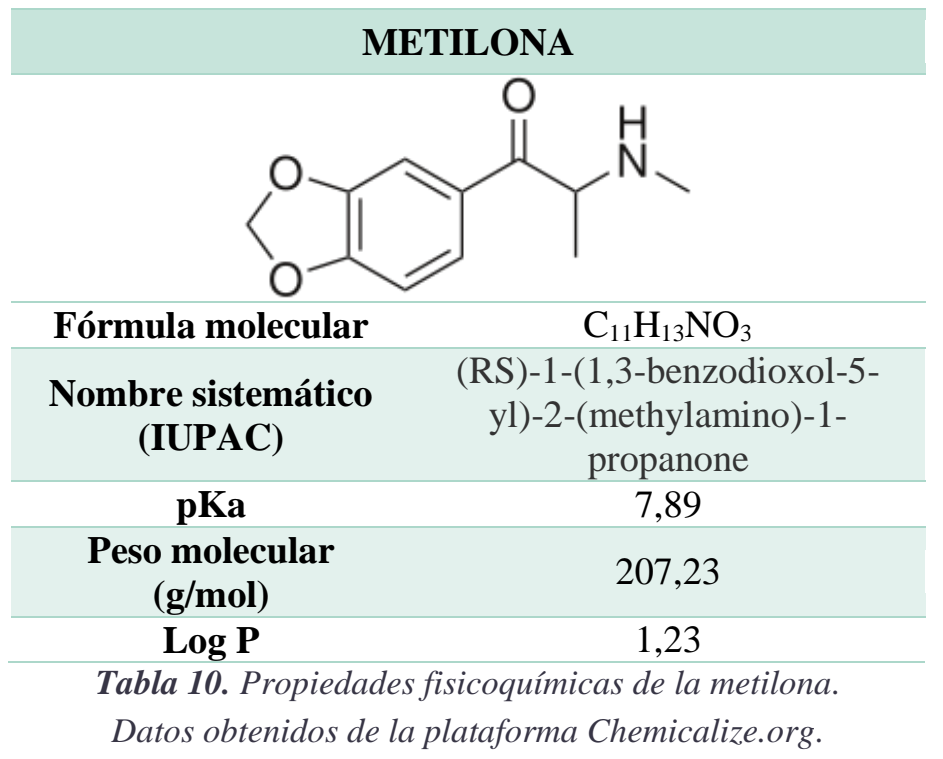

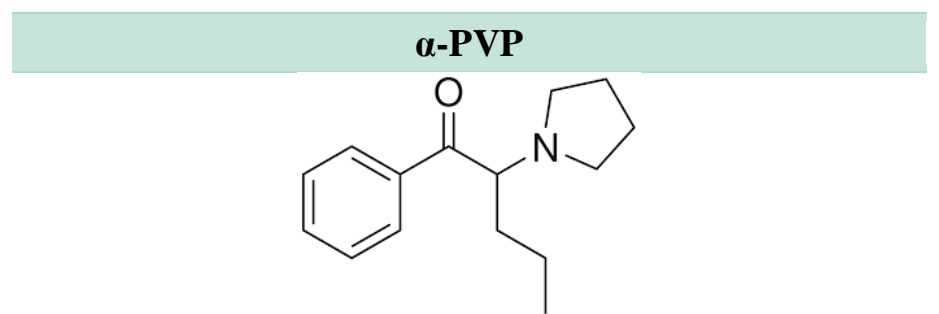

\begin{tabular}{|cc|}
\hline $\begin{array}{c}\text { Fórmula molecular } \\
\text { Nombre sistemático } \\
\text { (IUPAC) }\end{array}$ & $\begin{array}{c}\mathrm{C}_{11} \mathrm{H}_{13} \mathrm{NO}_{3} \\
\text { pKa }\end{array}$ \\
$\begin{array}{c}\text { Peso molecular } \\
\text { (g/mol) }\end{array}$ & 1 -pentanona \\
\hline Log P & 7,89 \\
\hline
\end{tabular}

Tabla 11. Propiedades fisicoquímicas del $\alpha$-pirrolidinpentiofenona $(\alpha-P V P)$.

Datos obtenidos de la plataforma Chemicalize.org.

Se puede comprobar que las dos catinonas sintéticas estudiadas tienen un valor de $\mathrm{pK}_{\mathrm{a}}$ cercano a la neutralidad, mientras que la cocaína (Tabla 4) muy frecuentemente presente en las muestras derivadas de un proceso de SQ, y por tanto, estudiadas conjuntamente con la metilona y $\alpha$-PVP, tiene un $\mathrm{pK}_{\mathrm{a}}$ más elevado, siendo estas drogas más estables en medio orgánico que en medio acuoso. Por otro lado, al igual que le ocurre a la cocaína, 
debido a sus valores de $\log \mathrm{P}$, estas drogas se pueden analizar por cromatografía líquida en fase reversa, siendo la metilona más polar que la cocaína y el $\alpha$-PVP.

\subsubsection{ACTIVIDAD DE LAS CATINONAS SINTÉTICAS}

Aunque aún no se sabe mucho acerca del mecanismo de acción de las catinonas sintéticas sobre el cerebro humano, debido a la estrecha relación estructural de las catinonas sintéticas con la metcatinona, MDMA y otras anfetaminas, se sabe que presentan una actividad similar, siendo potentes inhibidores de la monoaminatransferasa, dopamina transferasa (dopamina transferasa, noradrenalina transferasa y serotonina transferasa), de tal forma que su selectividad para actuar sobre una monoaminatransferasa y la potencia con la cual actúa, da lugar a la siguiente clasificación [29]:

Catinonas de cocaina-MDMA: mefedrona, metilona, etilona, butilona y nafirona. Son inhibidores no selectivos de la captación de monoaminatransferasa, similares a la cocaína, con una afinidad sobre la dopamina transferasa superior a la afinidad sobre la serotonina transferasa.

$>\quad$ Metanfetamina como catinona: catinona, metacatinona y flepedrona. Actúa de forma análoga a la metanfetamina y anfetamina inhibiendo la captación y liberación de dopamina.

Catinona pirovalerona: pirovalerona y MDPV. Son inhibidores de la absorción de dopamina más potentes que la cocaína. Debido a que los pocos estudios acerca de la farmacología del $\alpha$-PVP definen sus efectos similares a los del MDPV, se ha optado por clasificarlo en este grupo.

En cuanto al metabolismo que sufren este tipo de drogas parece ser complejo, de tal forma que tiene lugar una $\mathrm{N}$-desmetilación de la amina primaria, una reducción del grupo ceto a grupo hidroxilo y una oxidación parcial de los grupos alcoholes y ácidos carboxílicos, produciendo los diferentes síntomas que pueden tener lugar según la dosis administrada, normalmente por vía oral, pero también puede administrarse por vía intravenosa o por inhalación. 
Debido a que los efectos de estas sustancias se comparan con los producidos por el consumo de cocaína, anfetamina y MDMA, este nuevo tipo de sustancias psicoactivas incrementa los efectos sobre el estado de alerta, la motivación, energía, euforia, excitación, sociabilidad, intensificación sensorial de experiencias, moderación de la excitación sexual y reducción del apetito e insomnio.

Pero el uso de estas sustancias lleva asociado consecuencias cardiovasculares, consecuencias a nivel cognitivo, tales como la confusión y la desorientación, síntomas psiquiátricos como son la agresividad o incluso comportamiento criminal, síntomas neurológicos como pesadillas, hipertermia, mareos o insomnio, deshidratación, fallo renal y fallo de hígado, entre otras e incluso la muerte.

Las catinonas sintéticas empiezan a producir efecto entre los treinta y cuarenta y cinco minutos después de su administración y los efectos de deseo a partir de una hora tras la ingesta. Sin embargo, los efectos secundarios producidos por el consumo de estas sustancias psicoactivas pueden durar incluso días y por ello, se emplean cada vez más en la comisión de delitos, sobre todo en delitos de SQ en los que la víctima ingiere de forma involuntaria, normalmente disueltas en la bebida, una cantidad de estas drogas. La finalidad del agresor es diversa, como conseguir la firma de un documento o la agresión sexual $[29,31,33,34]$.

\subsubsection{METILONA}

La metilona es un derivado $\beta$-ceto del MDMA, cuya única diferencia es un grupo ceto en la posición $\beta$ del anillo fenetilamina (Imagen 8). Fue sintetizada por primera vez en 1994 por los químicos Peyton Jacob III y Alexander Shulgin como un antidepresivo y como droga contra el parkinson inhibiendo la captación de norepirefrina, dopamina y serotonina. Esta droga es uno de los principales componentes de las denominadas drogas legales comercializándose desde 2004 en internet y "smartshops" como sales de baño, abonos para las plantas, cachimbas y como ambientador con olor a vainilla, indicando<smiles>CNC(C)C(=O)c1ccc2c(c1)OCO2</smiles>

B)

Imagen 8. Estructura química de la Metilona y MDMA. 
que no es apto para consumo humano. Incluso, su vacío legal ha sido usado por narcotraficantes para adulterar o sustituir pastillas de MDMA, vendiéndose en muchos casos bajo este nombre.

Aunque en sus inicios se usaba como antidepresivo, se observó que su uso proporcionaba un bajón depresivo como efecto secundario en algunas personas y posteriormente se ha demostrado que su uso abusivo, empleándose normalmente mezclada con otras drogas, como la mefedrona, MDPV o la cocaína origina síntomas similares [35].

En 2005 esta sustancia empezó a estar restringida por el Ministerio de Salud Pública holandés, en tanto que en 2011 la Agencia de Control de Drogas (DEA, del inglés Drug Enforcement Administration), la clasificó en la Lista I de sustancias controladas temporalmente, junto con la mefedrona y MDPV, siendo en 2013 cuando quedaron incluidas permanentemente en dicha lista [17].

En cuanto a los efectos producidos por la metilona, como consecuencia de su consumo se ha comprobado que provoca taquicardia, agitación, alucinaciones, hipertensión e incluso la muerte.

\subsection{4 $\alpha$-PIRROLIDINPENTIOFENONA ( $\alpha$-PVP)}

La $\alpha$-pirrolidinopentiofenona ( $\alpha$-PVP), también conocida como Flakka, fue desarrollada y patentada en 1960 por Boehringer Ingelheim como un estimulante del sistema nervioso central, pero no se le ha prestado atención hasta hace unos años que empezó a introducirse de forma acelerada causando numerosas intoxicaciones.

La estructura química del $\alpha$-PVP es similar a la 3,4-metilendioxipirovalerona (MDPV), ya que es un derivado de ésta, y su única diferencia es la eliminación del grupo 3,4metilendioxi (Imagen 9). No hay muchos datos disponibles acerca de su toxicidad, pero ha sido detectada como una de las denominadas drogas legales, actuando como inhibidor de la recaptación de norepinefrina y dopamina, mostrando una inhibición de norepirefrina y un poder estimulante superior o igual al de la cocaína. Además de estos efectos, se sabe que provoca la aceleración de la velocidad cardiovascular, ansiedad, paranoia, psicosis, arritmia, deseo sexual, aumento del estado de alerta, infarto de miocardio e incluso la 
muerte, amnesia, dolor de cabeza, convulsiones, temblores, parkinson y espasmos musculares.

Los efectos ocurren aproximadamente tres cuartos de hora después de su ingesta (vía oral, nasal, intravenosa o incluso fumada) manteniéndose durante las siguientes ocho horas, o incluso días [34].

Los efectos causados, así como la rapidez con la que esta droga produce esos efectos junto con el bajo precio al cual se comercializa hace que habitualmente se emplee en fenómenos de SQ, ya sea sola o mezclada con otras catinonas sintéticas u otras drogas como la cocaína o el MDMA, por lo que es de gran interés forense el desarrollo de métodos sencillos y robustos para su determinación.

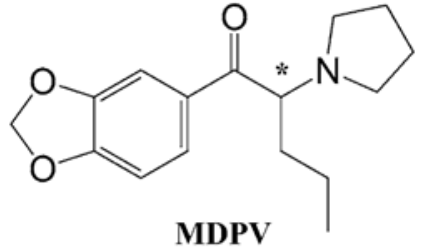

Imagen 9. Estructura química del MDPV y $\alpha-P V P$

Una vez la MDPV fue clasificada como droga ilegal por la DEA, se desarrolló como respuesta la $\alpha$-PVP, una catinona de segunda generación, produciendo una entrada repentina y explosiva dentro del mundo de las drogas ilícitas comercializadas como una alternativa legal no solo del MDPV, sino como alternativa a otras drogas como la cocaína, metanfetamina y MDMA. Este acontecimiento ha tenido especial incidencia en barrios pobres debido a su bajo precio, comercializándose normalmente en forma de polvos o cristal en cápsulas y en productos comerciales indicando que no son aptos para consumo humano $[34,36]$.

El abuso de esta droga se ha identificado tanto en Europa como en Estados Unidos, Australia, USA y Japón. Además, en Estados Unidos la DEA en 2014 clasificó esta droga temporalmente en la Lista I, ya que produce la misma acción farmacológica que el MDPV. Sin embargo, la Convención de las Naciones Unidas aún no la ha registrado en ninguna de las listas de las sustancias psicotrópicas prohibidas [34]. 


\subsection{MÉTODOS PARA LA DETERMINACIÓN DE CATINONAS SINTÉTICAS Y COCAÍNA}

En los últimos veinticinco años se han producido muchos avances en las técnicas de detección, identificación y cuantificación de estas sustancias en fluidos biológicos, teniendo como consecuencia la mejora de los resultados analíticos obtenidos. Algunas de las técnicas empleadas actualmente se muestran en la Tabla 12, siendo los métodos cromatográficos los más comunes en Toxicología Analítica aunque hay que tener en cuenta diversos factores a la hora de escoger el método analítico [37].

\begin{tabular}{|cc}
\hline $\begin{array}{c}\text { Principio } \\
\text { Químico }\end{array}$ & $\begin{array}{c}\text { Técnica } \\
\text { Test colorimétrico. }\end{array}$ \\
\hline Cromatográfico & $\begin{array}{r}\text { Cromatografía de gases }(\mathrm{GC}) \text {, cromatografía liquida de alta } \\
\text { resolución }(\mathrm{HPLC}), \text { cromatografía en capa fina (TLC). } \\
\text { Electroforesis capilar en zona (CZE), electrocromatografía }\end{array}$ \\
\hline Electroforético & $\begin{array}{c}\text { capilar (CEC), cromatografía capilar electrocinética micelar } \\
\text { (MEC). }\end{array}$ \\
\hline Inmunoensayo & Inmunoensayo ligado a enzimas (ELISA), inmunoensayo de \\
polarización fluorescente (FPIA), etc.
\end{tabular}

Tabla 12. Técnicas empleadas actualmente en el análisis de drogas de abuso.

La cromatografía de gases (GC) es la técnica analítica más empleada para el análisis de drogas y otros venenos orgánicos, sobre todo desde la introducción de detectores selectivos como el detector de ionización de llama (FID) o el de captura de electrones (ECD) y sobre todo acoplada a un detector de masas (MS) que permite identificar los compuestos de forma inequívoca.

Hay estudios mediante los cuales se determinan las catinonas sintéticas y sus derivados mediante cromatografía de gases acoplada a un detector de masas [38-40], siendo la cromatografía de gases la técnica más empleada para el análisis cuantitativo de las drogas legales, debido a la capacidad de volatilizarse de las mismas. Sin embargo, estos compuestos no siempre se detectan haciendo uso de ésta técnica debido al límite de detección que presenta y a la posible pérdida de la misma de la sustancia, e incluso esta técnica no es tan efectiva para aquellas drogas con una capacidad de volatilización menor, 
por lo que se ha ido ampliando su estudio empleando la cromatografía de líquidos [23,4148].

La cromatografía líquida de alta resolución (HPLC) ha ampliado en número los compuestos analizados en Toxicología Analítica desde 1970, ya que la cromatografía de gases se limita al análisis de compuestos volátiles y estables hasta una temperatura aproximada a $350^{\circ} \mathrm{C}[13]$.

Hay que destacar, que aunque el $\alpha$-PVP se conoce desde 1960, hasta hace pocos años no se le ha prestado mucha atención, por lo que en la actualidad hay pocos métodos sensibles y robustos que determinen esta sustancia psicoactiva. En la Tabla 13 se muestran métodos de análisis que se han llevado a cabo para la determinación de diferentes catinonas sintéticas y cocaína en muestras que presentan gran interés en fenómenos de SQ. 


\begin{tabular}{|c|c|c|c|c|c|}
\hline Analito & Matriz & Técnica & $\begin{array}{l}\text { Tratamiento de } \\
\text { muestra }\end{array}$ & LOD & Referencia \\
\hline Cocaína & Red Bull, Coca-Cola, Pepsi & EESI-MS/MS & $\begin{array}{l}\text { Sin tratamiento de } \\
\text { muestra }\end{array}$ & $\begin{array}{c}15,7,13 \\
(\mathrm{ng} / \mathrm{L}) \\
\text { (respectivame } \\
\text { nte) }\end{array}$ & [49] \\
\hline Cocaína, benzoilecgonina & Orina & HPLC-UV & $\begin{array}{l}\text { SPE y } \\
\text { LLE }\end{array}$ & $125(\mathrm{ng} / \mathrm{L})$ & [44] \\
\hline $\begin{array}{l}\text { Cocaína, benzoilecgonina, } \\
\text { 2-metilcocaína, 2- } \\
\text { metilbenzoilecgonina, } \\
\text { cocaetileno. }\end{array}$ & Orina & HPLC-UV & SPE & $20(\mathrm{ng} / \mathrm{L})$ & [23] \\
\hline $\begin{array}{l}\text { MDPV, Metilona, } \alpha \text {-PVP, } \\
\text { metedrona, mefedrona, } \\
\text { butilona y } \\
\text { 3-fluorocatinona }\end{array}$ & $\begin{array}{l}\text { Sangre, plasma, orina, humor } \\
\text { vítreo, fluido cerebroespinal, } \\
\text { bilis, tejidos homogeneizados }\end{array}$ & $\begin{array}{l}\text { GC-MS } \\
\text { LC-MS }\end{array}$ & $\begin{array}{c}\text { Digestión enzimática y } \\
\text { derivatización }\end{array}$ & - & [31] \\
\hline $\begin{array}{l}\text { MDPV, MDPBP, 4- FMC, } \\
\alpha-P V P, 4-\text { MEC, etcatinona, } \\
\text { 3-MPPP }\end{array}$ & $\begin{array}{l}\text { "White Rush", "White Gierls } \\
\text { Bath Salt" "JET", "Recharge", } \\
\text { "Ocean Burst", "Ivory Wave", } \\
\text { Doves Original", "Doves } \\
\text { Ultra" "Exotix Super Strong", } \\
\text { "Dynamite NRG" "Diablo } \\
\text { XXX" "Space Trips Ultra", } \\
\text { "Cosmic Blast" }\end{array}$ & $\begin{array}{c}\text { GC-FID } \\
\text { HPLC-MS/MS }\end{array}$ & $\begin{array}{l}\text { Extracción y disolución } \\
\text { en metanol. } \\
\text { Ajuste de pH con } \mathrm{HCl} \\
6 \mathrm{M} \text { y } \mathrm{NaOH} 1 \mathrm{M}\end{array}$ & - & [32] \\
\hline
\end{tabular}

Tabla 13. Métodos de análisis de catinonas sintéticas, sus metabolitos y cocaína, así como el tratamiento de muestra empleado y los límites de detección y cuantificación

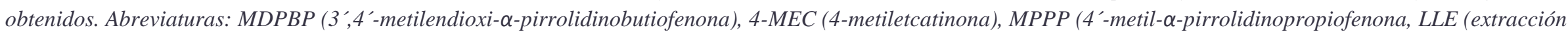
líquido-líquido), SPE (extracción en fase sólida). 


\begin{tabular}{|c|c|c|c|c|c|}
\hline $\begin{array}{c}\text { MDPV, 4- FMP } \\
\text { metoxetamina, } \\
\text { desoxypipradol, 4- FMC, } \\
\text { 4-MMH, 4-HO-MET, } \\
\text { MDAI, MABP, } \\
\text { metedrona }\end{array}$ & Orina & LC-MS/MS & Dilución & $0,1(\mathrm{ng} / \mathrm{L})$ & [46] \\
\hline $\begin{array}{l}\text { Diazepam, } \\
\text { fluitracezepam y } \\
\text { temazepam }\end{array}$ & $\begin{array}{l}\text { Licor, cerveza, vino blanco, } \\
\text { spirit y un refresco (J2O) }\end{array}$ & GC-MS & Dilución & $714(\mathrm{ng} / \mathrm{L})$ & [50] \\
\hline 9 Benzodiazepinas & $\begin{array}{c}\text { Bebida alcohólica basada en } \\
\text { crema de Whisky }\end{array}$ & LC-MS & $\begin{array}{l}\text { d-SPE con } \\
\text { QuEChERS }\end{array}$ & $\begin{array}{c}0,02-0,1 \\
(\mathrm{mg} / \mathrm{L})\end{array}$ & [47] \\
\hline $\begin{array}{l}\text { Metanfetamina, } \\
\text { metcatinona, bupedrona, } \\
\text { mefedrona, MDMA, } \\
\text { MDA, MDBD, metilona, } \\
\text { FMC, MDAI }\end{array}$ & Orina & GC-MS & Extracción con $\mathrm{KOH}$ & $25(\mu \mathrm{g} / \mathrm{L})$ & [10] \\
\hline $\begin{array}{l}\text { MDMA,feniciclidina, } \\
\text { LSD }\end{array}$ & Orina & CE-DAD & DLLME & $\begin{array}{c}1,00 ; \\
4,50 ; 4,40 \\
(\mathrm{ng} / \mathrm{mL})\end{array}$ & [51] \\
\hline MDPV, $\alpha-P V P, \alpha-P B P$ & Pelo & LC-MS & LLE & $\begin{array}{c}0,02 \mathrm{ng} / 10 \\
\mathrm{~mm}\end{array}$ & [48] \\
\hline $\begin{array}{c}\text { Cocaina, } \\
\text { benzoylecgonina, } \\
\text { ecgonina, cocaetileno }\end{array}$ & Orina & CE-ESI-MS & SPE & $\begin{array}{c}1,5-10 \\
(\mathrm{ng} / \mathrm{mL})\end{array}$ & {$[52]$} \\
\hline
\end{tabular}

Continuación Tabla 13. Métodos de análisis de catinonas sintéticas, sus metabolitos y cocaína, así como el tratamiento de muestra empleado y los límites de detección y cuantificación obtenidos. Abreviaturas:4-FMP (4-flluoranfetamina), FMC (3-fluormetcatinona), 4-OH-MET (4-hidroxi-N-metil-etiltriptamina), MABP ( $\alpha$-metilaminobutirofenona), MDAI (5,6-metilendioxi-2-aminoindano),MDA (tenamfetamina), MDBD (1,3-Benzodioxolil-N-metilbutnamina) $\alpha$-PBP ( $\alpha$-pirrolidinobutiofenona), d-SPE (extracción sólido-líquido dispersiva), EESI-MS/MS (Ionización por electroespraynanoextractiva con espectrometría de masas en tándem. 


\subsection{CROMATOGRAFÍA LÍQUIDA CAPILAR}

El problema de los sistemas de Toxicología Analítica es la detección fiable de un amplio rango de compuestos en una muestra pequeña (orina, sangre, restos de alimentos, tejidos, etc.) con una alta sensibilidad.

Hasta la fecha, la técnica más empleada para la cuantificación de drogas de abuso en los laboratorios forenses es el acoplamiento GC-MS y, en algunas ocasiones, el potente acoplamiento de la cromatografía de líquidos de alta resolución con espectrometría de masas (HPLC-MS) disponible en muy pocos laboratorios de referencia.

La LC presenta muchas ventajas en el análisis de drogas debido a su capacidad para acoplarse a distintos detectores y posibilidad de analizar muestras no volátiles. En la Tabla 14 se muestran las ventajas y desventajas que presenta la cromatografía de líquido en el análisis de drogas [37].

\section{Ventajas}

Separaciones rápidas y eficientes.

Permite el análisis de moléculas polares y de alto peso molecular que no pueden ser analizadas mediante GC

Sensible y selectivo empleando detectores no destructivos como UV y fluorescencia.

Permite la inyección de muestras acuosas

Bajo coste de análisis

\section{Técnica robusta debido a los} empaquetamientos de la columna basados en la sílice trabajando con eluyentes polares o apolares.

Relativamente fácil de automatizar

\section{Desventajas}

Alto precio de hardware e infraestructura.

Resuelve relativamente pocos picos en un rango de trabajo.*

Elución independiente del peso molecular.

El gradiente de elución a veces da problemas.

Sólo los detectores de ED, fluorescencia y

MS proporcionan una sensibilidad comparable a los detectores de GC aunque presentan buena selectividad.

Influencia de muchos factores externos en la eficiencia de la separación (volumen de inyección, disolvente de inyección, volumen muerto, etc.).

Problemas de coelución de compuestos.

Tabla 14. Ventajas y desventajas de la cromatografía líquida en el análisis de drogas. *Hoy en día este problema se ha solventado con la cromatografía de líquidos de ultra-alta eficacia (UHPLC).

La tendencia actual es recurrir a desarrollar métodos alternativos empleando técnicas miniaturizadas que van a consumir menos muestras y reactivos, por lo que, presentando 
las mismas prestaciones, serán más compatibles con la Química Verde. A lo largo de los años se han desarrollado diferentes columnas de LC con diferentes diámetros y longitudes dando lugar a la clasificación que se muestra en la Tabla 15 [53-56].

\begin{tabular}{|cc|}
\hline Clasificación & Diámetro interno $(\mathbf{m m})$ \\
\hline HPLC & $3-5$ \\
\hline$\mu$ HPLC & $0,5-1$ \\
\hline HPLC capilar & $0,1-0,5$ \\
\hline nano-HPLC & $0,01-0,1$ \\
\hline HPLC tubular abierta & $0,005-0,05$ \\
\hline
\end{tabular}

Tabla 15. Diferentes modalidades de la LC en función del diámetro interno de la columna.

La cromatografía líquida capilar es una técnica miniaturizada cuya principal característica es la reducción del diámetro interno de la columna con la consecuente disminución en el consumo de disolventes que componen la fase móvil y por tanto contribuyendo con los principios de la Química Verde [57]. Además, presenta otras ventajas frente a la cromatografía líquida convencional como es el aumento en la resolución de los picos y selectividad, así como límites de detección menores.

Las columnas de HPLC capilar se caracterizan por poseer diámetros internos que varían en el rango 0,1-0,5 mm. Esta reducción del diámetro frente al HPLC convencional, ha presentado como ventaja una disminución en el flujo de fase móvil que pasa a través de la misma y a que se consiguen altas presiones a temperaturas más bajas. Como consecuencia un aumento en la durabilidad de la columna, pues al pasar menos fase móvil se desgasta menos. Además, mejora la eficiencia de la columna cromatográfica debido a la baja dispersión que se produce y baja resistencia al flujo para la transferencia de masa.

Otra ventaja de la reducción del diámetro interno de la columna es la inyección de menor volumen de muestra sobre todo cuando se trabaja en casos de Toxicología forense, alimentaria o ambiental, inyectándose volúmenes de muestra en el rango de 1-100 $\mu \mathrm{L}$, según cuál sea el diámetro interno de la columna.

El sistema de bombeo de fase móvil proporciona un caudal preciso, reproducible y constante, además de una amplia gama de caudales.

En este trabajo se ha empleado un sistema Agilent basado en la serie 1200 que está compuesto por una bomba binaria que permite un caudal de flujo en columna máximo de $20 \mu \mathrm{L} / \mathrm{min}$. Además emplea un sistema de división de flujo o "Split" que desvía parte de 
la fase móvil que se está bombeando para que no llegue a la columna. El inconveniente es que el "Split" se produce una vez producida la mezcla de las fases móviles, por lo que no se puede reutilizar estos disolventes y pasan directamente al bidón de deshechos. Este tipo de bombas pueden mantener velocidades de flujo constantes independientemente de cuál sea la presión del sistema y por lo tanto permite trabajar en gradiente de concentración de fase móvil. En la Tabla 16 se muestra una comparativa entre la velocidad de flujo empleada en las distintas modalidades de cromatografía líquida.

\begin{tabular}{cc|}
\hline Clasificación & Caudal $(\boldsymbol{\mu} \mathbf{L} / \mathbf{m i n})$ \\
\hline HPLC & 2500 \\
\hline HPLC capilar & $(0,5-1)-100$ \\
\hline nanoHPLC & $(0,05-0-1)-1$ \\
\hline Tabla 16. Velocidad de flujo en función del tipo de LC.
\end{tabular}

La monitorización de la señal analítica obtenida tras la separación cromatográfica mediante cromatografía líquida capilar se puede llevar a cabo empleando los mismos detectores que para la cromatografía líquida convencional, siendo el detector de absorción UV/Vis uno de los más empleados debido al amplio rango de longitudes de onda que abarca (195-700 nm) y al bajo coste de esta técnica, siendo de fácil acceso por parte de los laboratorios de rutina. No obstante, presenta como desventaja el problema de la selectividad, siendo necesario por ello la aplicación de procedimientos de limpieza muy eficaces. Esta técnica, se emplea habitualmente en muchos campos como la industria alimentaria, farmacéutica y ambiental, entre otros [58-61].

Hasta la fecha esta técnica está poco desarrollada en el campo de la Toxicología Forense, pero debido a las grandes ventajas que presenta y a la necesidad de disponer de técnicas alternativas a las ya existentes para mejorar el consumo de disolventes y el coste que esto conlleva, es objetivo de este trabajo desarrollar un método de HPLC capilar empleando como sistema de detección un detector UV/Vis para la determinación de drogas de abuso en diferentes muestras de interés forense, como son las muestras alimentarias y biológicas. 


\subsection{TRATAMIENTO DE MUESTRA}

Una de las etapas más importantes del proceso analítico es el tratamiento de muestra, pues en la mayoría de las muestras hay muchos compuestos que interfieren en la medida analítica, siendo muy pocas las muestras que se pueden analizar directamente.

El tratamiento de muestra por lo tanto tiene un doble objetivo: la extracción de los analitos de la matriz estudiada para poder cuantificarlos y llevar a cabo una preconcentración de aquellos analitos que se encuentren en concentraciones traza y requieran de dicha preconcentración para poder cuantificarlo.

Dentro de los tratamientos de muestra empleados habitualmente para la determinación de catinonas sintéticas en muestras alimentarias y ambientales se encuentran la extracción en fase sólida (SPE) y la extracción líquido-líquido (LLE) [38].

La tendencia actual es el desarrollo y empleo de tratamientos de muestra rápidos, económicos y que consuman una menor cantidad de disolvente orgánico, disminuyendo así la contaminación ambiental y consiguiendo preconcentraciones mayores. Entre estas técnicas se encuentran principalmente la microextracción líquido-líquido dispersiva (DLLME) y la extracción mediante QuEChERS (del inglés Quick, Easy, Cheap, Effective, Rugged, y Safe, que significa Rápido, Fácil, Barato, Efectivo, Robusto y Seguro) [62].

En este trabajo se ha llevado a cabo el estudio comparativo de tres tratamientos de muestra para la determinación de las drogas de abuso objeto de estudio. Los procedimientos empleados han sido: SPE, DLLME y QuEChERS, ampliamente usadas para el análisis de tóxicos en muestras alimentarias, ambientales y biológicas.

\subsubsection{EXTRACCIÓN EN FASE SÓLIDA}

La SPE, es una de las técnicas más empleada como tratamiento de muestra para el análisis cromatográfico desde que se introdujo a finales de los años setenta, teniendo como objetivo llevar a cabo un proceso de preconcentración de trazas, así como eliminar interferencias presentes en la muestra mediante una etapa de limpieza (“clean-up") y almacenar compuestos en disolución o volátiles y permitir la derivatización de aquellos 
compuestos que lo necesiten. Esta técnica se basa en la retención, sobre un adsorbente sólido, de los analitos de interés, disueltos en una muestra líquida y se lleva a cabo en seis etapas: acondicionamiento del cartucho (activación de los grupos funcionales del adsorbente), lavado y equilibrado del cartucho, carga de la muestra, lavado, elución y secado.

La selectividad de una extracción está relacionada con la capacidad del adsorbente de discriminar entre los analitos de interés y los otros compuestos presentes en la matriz. Por lo tanto, la separación va a depender de: la estructura química del analito, las propiedades del adsorbente y la composición de la muestra [63].

Una de las ventajas de la SPE es la reducción del empleo de disolventes orgánicos respecto a otros tratamientos de muestra así como el evitar las emulsiones que se pueden generar mediante la extracción líquido-líquido. Aunque en los últimos años se han desarrollado técnicas miniaturizadas que emplean menor cantidad de disolvente orgánico que ésta. En la Tabla 17 se describen las etapas en las cuales tiene lugar la SPE [64].

\begin{tabular}{|cl}
\hline \multicolumn{1}{|c|}{ Etapa } & \multicolumn{1}{c}{ Principio } \\
\hline & $\begin{array}{l}\text { Activación de los grupos funcionales de adsorbente pasando un } \\
\text { disolvente o mezcla de ellos a través del cartucho. Los discos } \\
\text { fritados que contienen el adsorbente también se solvatan } \\
\text { convenientemente. Se lleva a cabo con un disolvente fuerte } \\
\text { (MeOH, MeCN, normalmente) seguido de un disolvente débil } \\
\text { cartucho } \\
\text { (disolvente en el cual se ha preparado la muestra) para equilibrar } \\
\text { la fase estacionaria. }\end{array}$ \\
\hline \multirow{3}{*}{ Carga de la muestra } & $\begin{array}{l}\text { Tras la adición de la muestra, los analitos quedan retenidos en la } \\
\text { superficie del adsorbente, mientras que los interferentes quedan } \\
\text { menos retenidos o incluso nada. }\end{array}$ \\
\hline Lavado del cartucho & $\begin{array}{l}\text { Pasar un disolvente o mezcla de los mismos a través del cartucho } \\
\text { para eliminar cualquier interferente. }\end{array}$ \\
\hline \multirow{3}{*}{ Elución de los analitos } & $\begin{array}{l}\text { Eliminación de la interacción analito-adsorbente pasando un } \\
\text { disolvente que interaccione mucho con el analito y poco con los } \\
\text { interferentes. }\end{array}$ \\
\hline Secado de la muestra & $\begin{array}{l}\text { y posteriormente se recompone en un disolvente apropiado para } \\
\text { el análisis. }\end{array}$ \\
\hline
\end{tabular}

Tabla 17. Etapas de la SPE. 


\subsubsection{EXTRACCIÓN LÍQUIDO-LÍQUIDO DISPERSIVA}

En los últimos años, el interés por la miniaturización de los tratamientos de muestra se ha incrementado notablemente. Dicho interés se traduce en el empleo de disolventes menos contaminantes y en el empleo cantidades más pequeñas de disolventes orgánicos, cumpliendo de esta forma con los principios de la Química Verde, y por lo tanto, aumentando la seguridad y disminuyendo el coste de los procesos en comparación a los métodos convencionales de extracción líquido-líquido.

DLLME fue introducida por Assadi y colaboradores en 2006 [65] y desde entonces ha sido ampliamente usada para el análisis de tóxicos orgánicos como los pesticidas y las drogas de abuso en distintas matrices entre las que se encuentran las matrices alimentarias y biológicas [38, 51, 58, 60, 66-70] debido a que es una técnica simple, rápida, con bajo consumo de disolventes y reactivos. Además, este tratamiento de muestra permite obtener valores altos de recuperación de los analitos, así como llevar a cabo una preconcentración de los mismos, lo cual es muy beneficioso para el análisis de elementos traza. Por todo ello, la DLLME tiene un gran interés en el campo de la Química Analítica.

La extracción líquido-líquido se basa en la inyección rápida de una muestra acuosa que contiene a los analitos en un disolvente extractante y un disolvente dispersante, en proporciones adecuadas. Esta inyección produce una dispersión que origina la formación de gotas de extractante dispersas en la muestra acuosa, facilitando así la extracción de los analitos ya que la transferencia de éstos de la fase acuosa a la fase orgánica se ve favorecida por la creación de las gotas de extractante que da lugar a una gran área superficial entre éste y la fase orgánica. Posteriormente las dos fases se separan por centrifugación, ya que ambas fases tienen distinta densidad, pudiéndose recoger la fase orgánica conteniendo a los analitos [71-72].

\subsubsection{MÉTODO QuEChERS}

El método QuEChERS es otra de las técnicas miniaturizadas que está teniendo gran interés en la actualidad. 
Fue introducida por Anastassides y colaboradores en el 2003 publicando un método que reducía notablemente el número de pasos en el desarrollo de la extracción y consumo de materiales y disolvente, en comparación a los métodos convencionales, para el análisis de plaguicidas en vegetales. El nombre de esta técnica es un acrónimo que refleja sus principales ventajas: rápida, sencilla, barata, efectiva, robusta y segura [73].

El método QuEChERS es un sistema de extracción en fase sólida dispersiva (dSPE) que se lleva a cabo en dos etapas principalmente: la primera consiste en una extracción simple y la segunda, en una limpieza mediante extracción en fase sólida dispersiva (dSPE) [74].

\section{$1^{\circ}$ Etapa: Extracción simple}

Se lleva a cabo una extracción con un disolvente orgánico en presencia de diferentes sales, normalmente sulfato de magnesio anhidro $\left(\mathrm{MgSO}_{4}\right)$ y cloruro sódico $(\mathrm{NaCl})$, que proporcionan una adecuada separación de fases. A continuación se lleva a cabo la centrifugación para separar físicamente las dos fases.

\section{$2^{\circ}$ Etapa: dSPE}

La segunda etapa del procedimiento corresponde a una etapa de limpieza o "clean-up" que se lleva a cabo mediante la dSPE, de tal forma que se trata la muestra obtenida de la primera etapa con sales y un adsorbente que retiene los componentes de la matriz sin retener los componentes de interés, es decir, limpia la matriz de interferentes. Se agitan en un vórtex para homogeneizar y facilitar la separación. Mediante centrifugación, se separa el adsorbente de la disolución.

\section{$3^{\circ}$ Etapa: Ajuste de $\mathbf{p H}$}

Algunas muestras requieren un ajuste de $\mathrm{pH}$ previo a su análisis mediante GC-MS o LCMS para proporcionar una mejor sensibilidad, no siendo necesario para otros tipos de detectores.

Hasta la fecha se han publicado estudios que emplean este tratamiento de muestra no solo en vegetales, sino también en muestras alimentarias procedentes de los animales y muestras biológicas, entre otras. Además, gracias al éxito de esta técnica para la extracción de plaguicidas en una amplia gama de frutas y verduras, se ha adoptado un método normalizado europeo para la determinación de plaguicidas [75]. Además, este 
método está siendo evaluado por multitud de laboratorios para validar métodos para un gran número de analitos en una gran variedad de muestras, entre los que se encuentran las drogas de abuso [47, 76-78].

Como se deduce de lo tratado hasta el momento, en el campo de la Toxicología Analítica, bien enfocada a la Toxicología Alimentaria o Forense, la puesta a punto de métodos rápidos, sencillos y económicos para el análisis de sustancias tóxicas, como las drogas legales ampliamente utilizadas en la sociedad actual, son de vital importancia. 


\section{REACTIVOS Y MATERIAL}

Todos los reactivos empleados en este trabajo son de grado analítico y los disolventes de grado HPLC. El ácido fórmico (98-100\% v/v) fue suministrado por Merck (Darmstadt, Alemania), mientras que el acetonitrilo $(\mathrm{MeCN})$, metanol $(\mathrm{MeOH})$, cloroformo, acetona y 2-butanol se adquirieron en VWR International (West Chester, Pensilvania, EE.UU). El ácido acético, tetracloroetileno, el diclorometano y el dibromometano se adquirieron en Sigma-Aldrich (St. Luis, MO, USA). El amoniaco $\left(\mathrm{NH}_{3}\right)$ fue suministrado por Panreac (Castellar del Vallés, Barcelona, España). El cloruro sódico $(\mathrm{NaCl})$ y el sulfato magnésico $\left(\mathrm{MgSO}_{4}\right)$ fueron suministrados por Panreac-Química (Madrid, España). Además, los sorbentes empleados en la extracción d-SPE han sido C18 y PSA, suministrados por Agilent Technologies (Waldbronn, Germany), y Z-Sep ${ }^{+}$, suministrado por Supelco (Bellafonte PA, USA). El agua empleada a lo largo de todo el trabajo ha sido agua ultrapura (18,2 m $\left.\Omega \mathrm{cm}^{-1}\right)$ obtenida mediante un sistema Milli-Q (Millipore, Bedford, MA, EEUU).

Los compuestos objeto de estudio en este trabajo, metilona (2- metilamino-1-(3,4metilendioxifenil)propano-1-ona), $\alpha$-PVP (1-fenil-2-(pirrolidin-1-il)pentan-1-ona) y cocaína ((1R,2R,3S,5S)-3-(benzoiloxi)-8-metil-8-azabiciclo[3.2.1.]octano-2-carboxilato de metilo) se adquirieron en Sigma-Aldrich (Tres Cantos, Madrid, España).

A partir de disoluciones estándar de $1000 \mu \mathrm{g} / \mathrm{mL}$ de cada catinona en MeOH y de cocaína en $\mathrm{MeCN}$, se preparó una disolución intermedia en $\mathrm{MeOH}$ que contenía $100 \mu \mathrm{g} / \mathrm{mL}$ de cada compuesto. Esta disolución se conservó a $4^{\circ} \mathrm{C}$ en un frasco de vidrio topacio para evitar su exposición a la luz.

Las muestras de bebidas alcohólicas (ron, vodka y whisky) objeto de análisis se adquirieron en un establecimiento comercial de Granada.

Para la evaluación del tratamiento de SPE, se emplearon cartuchos Oasis® HLB de 60 $\mathrm{mg}$ de relleno, $3 \mathrm{~mL}$ de capacidad de carga de muestra y $30 \mu \mathrm{m}$ de diámetro de partícula. Se adquirieron en Waters (Miliford, Masachusetts, EE.UU).

El filtrado de todas las muestras se ha llevado a cabo en filtros de nylon $(0,22 \mu \mathrm{m}$ x 13 $\mathrm{mm}$ ) suministrados por Bonna-Agela Technologies (Wilmington, DE, USA). Durante el 
tratamiento de muestra se emplearon tubos falcon de $15 \mathrm{~mL}$ de capacidad y viales de 4 mL, ambos suministrados por VWR International (West Chester, Pensilvania, EE.UU). 


\section{INSTRUMENTACIÓN Y SOFTWARE}

El método de separación de las catinonas sintéticas en presencia de cocaína se ha llevado a cabo en un equipo de HPLC capilar serie 1200 acoplado a un detector de UV/Vis (Imagen 10) comercializado por Agilent Technologies (Santa Clara, CA, USA). Los datos fueron tratados con el software HP ChemStation (versión A.09.01) y los cromatogramas obtenidos fueron editados con el software Grapher (versión 8.7.844).

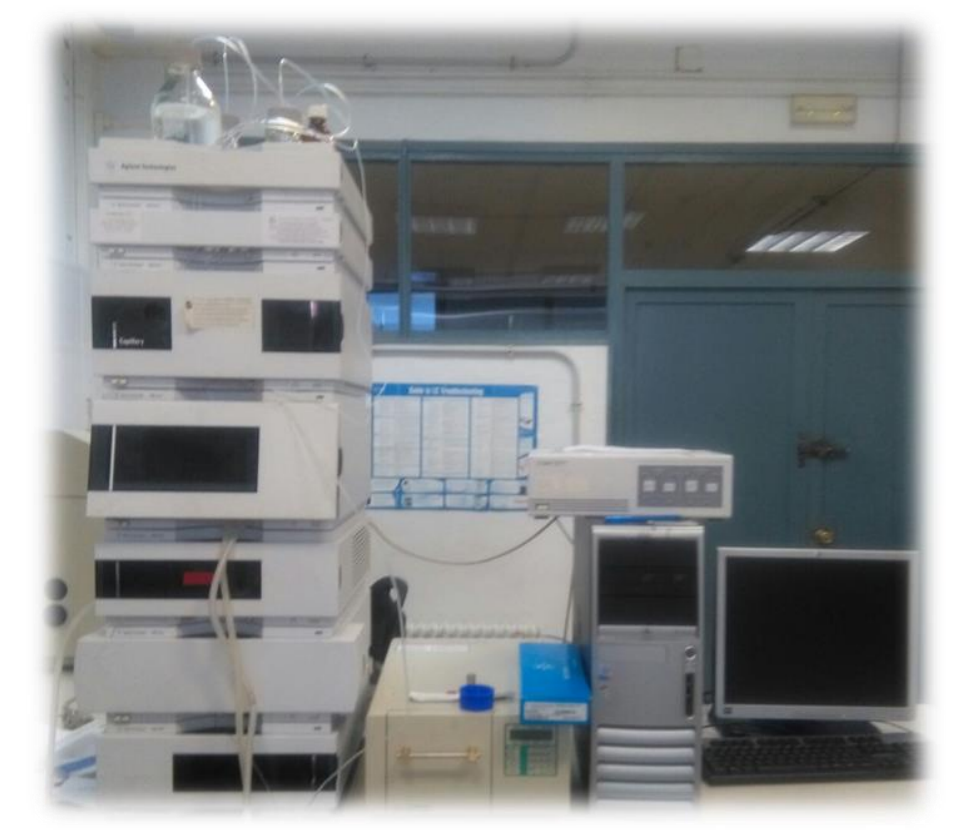

Imagen 10. Sistema HPLC capilar acoplado a un detector UV/Vis.

Además se ha empleado una columna de fase reversa Zorbax XDB-C18 (150 x 0,5, mm, $5 \mu \mathrm{m}$ de tamaño de partícula) suministrada por Agilent Technologies.

Tanto para la preparación de las disoluciones de patrones, como para el tratamiento de muestras, se ha empleado un agitador Vórtex-2 Genie (Scientific Industries, Bohemia, NY, EE.UU). Además para el tratamiento de muestras de orina se ha empleado una centrifugadora Universal 320R (Hettich Zentrifugen, Tuttlingen, Germany), un agitador mecánico (modelo 384 de Vibromatic; Noblesville, USA) y un sistema de evaporación de nitrógeno EVA lift (VLM GmbH, Bielefeld, Alemania). 


\section{RESULTADOS Y DISCUSIÓN}

\subsection{IDENTIFICACIÓN DE LOS PICOS CROMATOGRÁFICOS}

Para llevar a cabo la separación cromatográfica de las tres drogas de abuso objeto de este trabajo se ha empleado una columna Zorbax XDB-C18 $(150 \mathrm{~mm} ; 0,5 \mathrm{~mm} ; 5 \mu \mathrm{m})$. Inicialmente se procedió a la identificación de los tres analitos (metilona, $\alpha$-PVP y cocaína) en el cromatograma obtenido en las condiciones establecidas inicialmente a partir de los espectros de absorción UV obtenido para cada uno de los picos cromatográficos registrados. Se propuso el gradiente de separación indicado en la Tabla 18 en el cual se emplea agua como fase acuosa (A) y acetonitrilo $(\mathrm{MeCN})$ como fase orgánica (B), variando el porcentaje de $\mathrm{MeCN}$ desde un 5\% hasta un 95\% en 20 minutos, y volviendo a las condiciones iniciales consiguiendo la elución de los analitos en 30 minutos.

\begin{tabular}{ccc|}
\hline $\begin{array}{c}\text { Tiempo } \\
\text { (min) }\end{array}$ & \%A & \% B \\
\hline 0,00 & 95,00 & 5,00 \\
\hline 5,00 & 95,00 & 5,00 \\
\hline 8,00 & 80,00 & 20,00 \\
\hline 10,00 & 50,00 & 50,00 \\
\hline 15,00 & 30,00 & 70,00 \\
\hline 20,00 & 5,00 & 95,00 \\
\hline 24,00 & 5,00 & 95,00 \\
\hline 26,00 & 95,00 & 5,00 \\
\hline 30,00 & 95,00 & 5,00 \\
\hline
\end{tabular}

Tabla 18. Gradiente inicial seleccionado.

La velocidad de flujo se estableció en $7 \mu \mathrm{L} / \mathrm{min}$ y el volumen de inyección en $5 \mu \mathrm{L}$, manteniendo la columna termostatizada a $20^{\circ} \mathrm{C}$. Para la monitorización de la señal se empleó un detector UV seleccionando como longitud de onda $230 \mathrm{~nm}$ para la cocaína y la metilona y $254 \mathrm{~nm}$ para la monitorización del $\alpha$-PVP $[79,80]$.

En la Tabla 19 se muestran los espectros UV obtenidos tras la inyección individual de un patrón de cada analito conteniendo una concentración de $3 \mu \mathrm{g} / \mathrm{mL}$, comprobándose que la 
metilona y la cocaína presentan su máximo de absorción a $230 \mathrm{~nm}$, mientras que el $\alpha$ PVP lo presenta a $254 \mathrm{~nm}$.

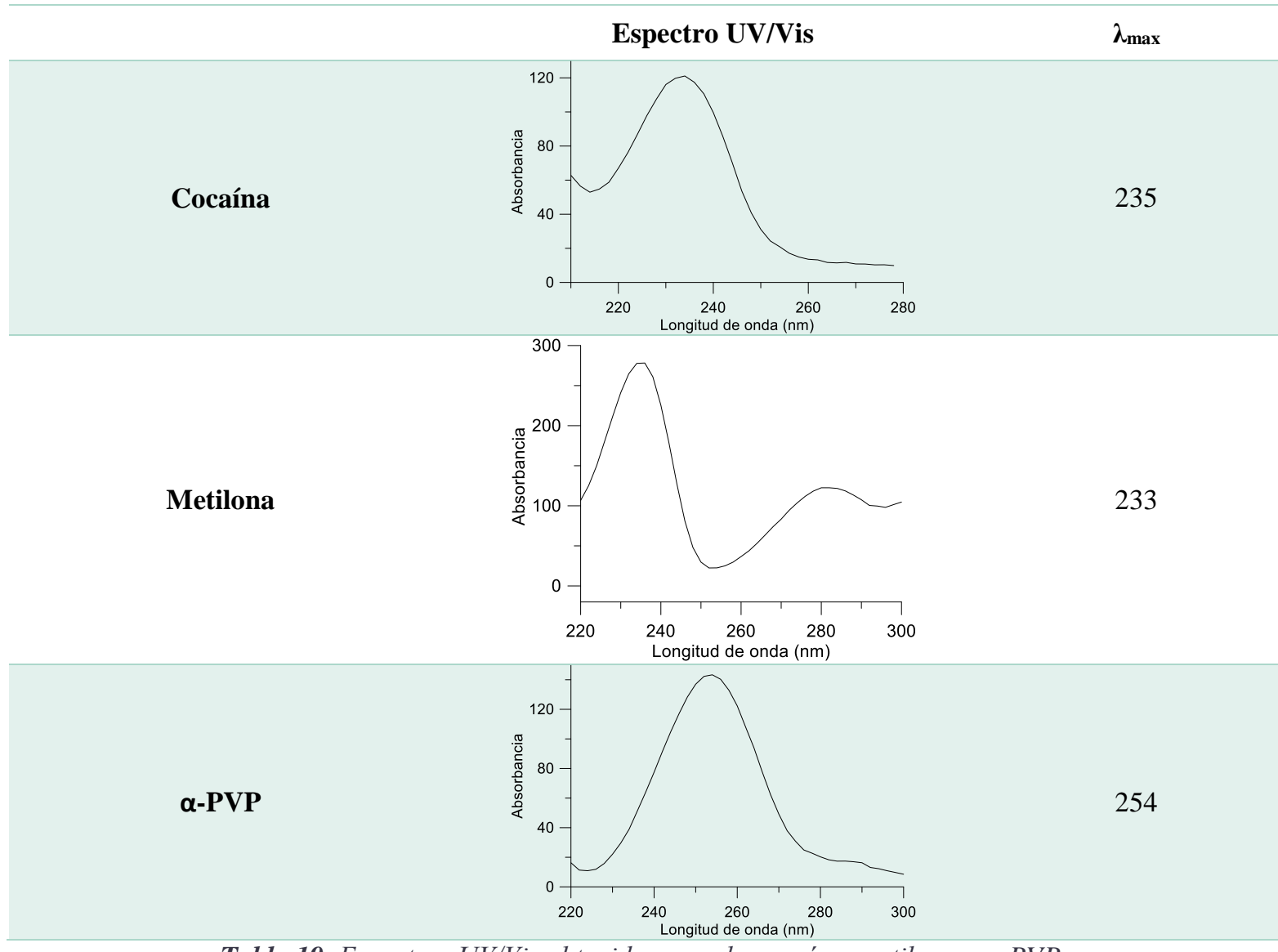

Tabla 19. Espectros UV/Vis obtenidos para la cocaina, metilona y $\alpha$-PVP.

Para confirmar la identificación de cada analito en el cromatograma obtenido bajo estas condiciones de separación, se llevó a cabo la inyección de patrones individuales con una concentración de $3 \mu \mathrm{g} / \mathrm{mL}$ y se comparó el tiempo de elución obtenido con el cromatograma inyectando la mezcla de analitos.

Con este gradiente de elución se consiguió la separación cromatográfica mostrada en la Imagen 11 identificándose las tres drogas objeto de estudio en este trabajo. 


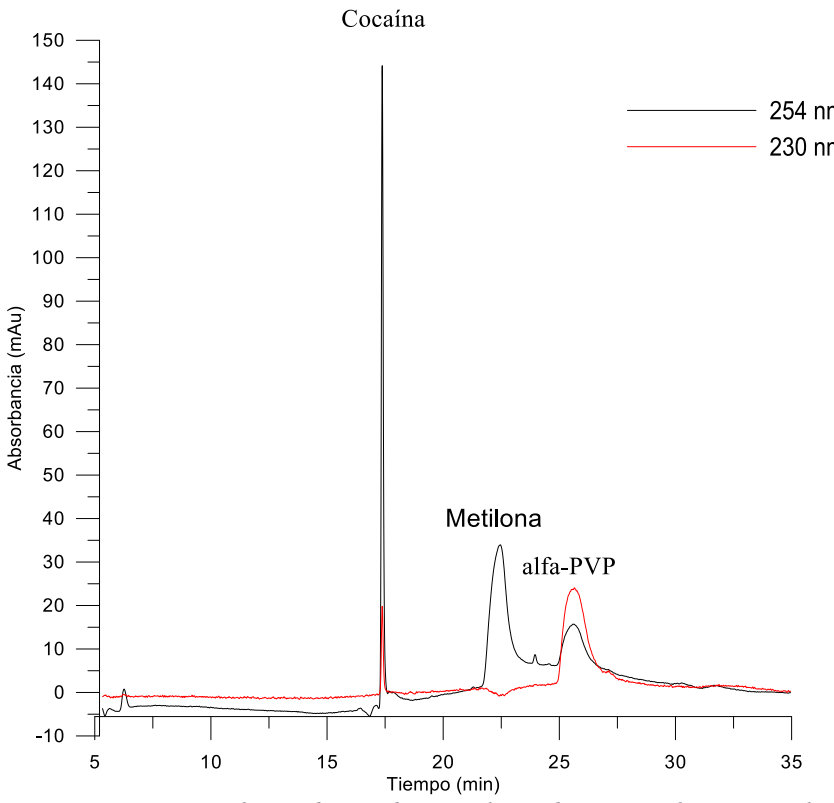

Imagen 11. Separación cromatográfica obtenida empleando como fase móvil acuosa (A) agua y como fase móvil orgánica (B) $\mathrm{MeCN}$.

\subsection{OPTIMIZACIÓN DE LA SEPARACIÓN CROMATOGRÁFICA}

Con el objetivo de conseguir una separación con buena resolución de las tres drogas de abuso objeto de estudio, así como un método analítico robusto, se optimizaron los parámetros que afectan a la separación cromatográfica: gradiente, fase móvil, volumen de inyección, velocidad de flujo y temperatura.

Como criterio para seleccionar los valores óptimos se evaluó la eficacia de pico obtenida en el estudio de cada una de las variables estudiadas.

\subsubsection{ESTUDIO DE LA COMPOSICIÓN DE LA FASE MÓVIL}

\section{a) Estudio de la presencia de ácido en la fase móvil acuosa.}

Con el objetivo de conseguir una separación eficaz, se evaluó la presencia de un ácido, así como el porcentaje en volumen del mismo, en la fase móvil. Debido a la gran diferencia en la naturaleza de las drogas objeto de estudio, la fase móvil orgánica escogida ha sido el MeCN y el gradiente con el que se ha evaluado la presencia de ácido en la fase móvil es el mostrado en la Tabla 18. 
En primer lugar se evaluó la naturaleza del ácido a emplear, comparando la eficacia de los picos obtenidos, que viene definida por los platos teóricos $(\mathrm{N})$ obtenidos, cuando se emplean ácidos de distinta fortaleza. Por un lado se estudió la adición de 0,05\% de ácido acético $\left(\mathrm{pK}_{\mathrm{a}}=4,76\right)$ en la fase acuosa, en tanto que también se evaluó la adición de $0,05 \%$ de ácido fórmico $\left(\mathrm{pK}_{\mathrm{a}}=3,74\right)$ en la fase acuosa. Los resultados obtenidos se muestran en el Gráfico 1, observando, que en presencia de ácido, la eficacia de la cocaína y $\alpha$-PVP es mayor, mientras que la eficacia de la metilona es mayor en ausencia de ácido. De los ácidos evaluados, el ácido fórmico es el que proporciona mejores resultados. Además, en la Imagen 12 se comprueba que en presencia de ácido el orden de elución de la cocaína y la metilona se invierten, en comparación a la Imagen 11.

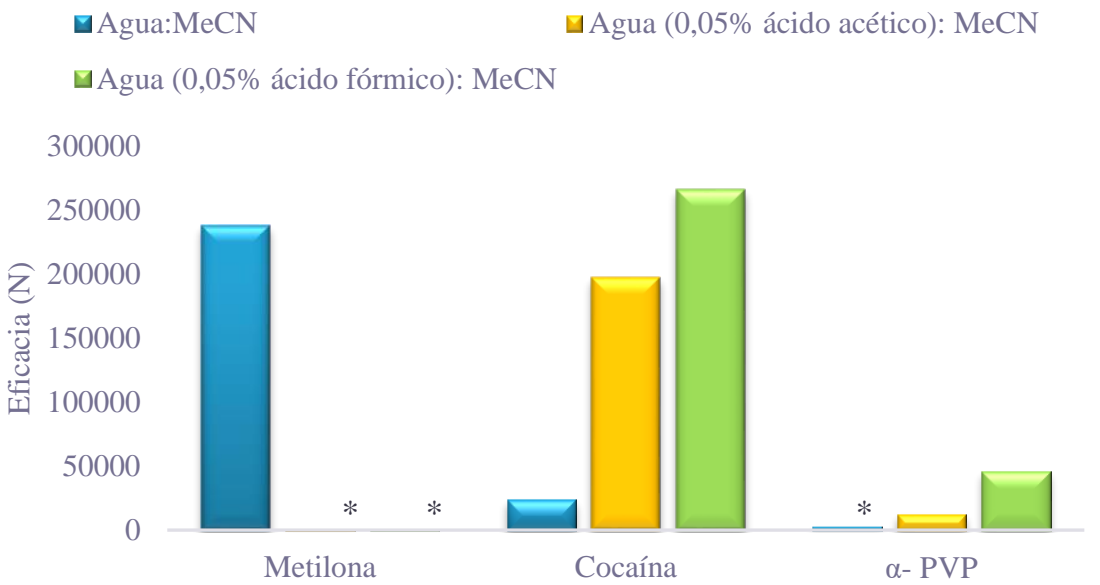

Gráfico 1. Comparación de la eficacia de los picos obtenida empleando como fase móvil: agua y MeCN; agua conteniendo 0,05\% (v/v) ácido acético y MeCN; y agua conteniendo 0,05\% (v/v) ácido fórmico y MeCN. *Eficacia obtenida inferior a 10000 platos teóricos. 


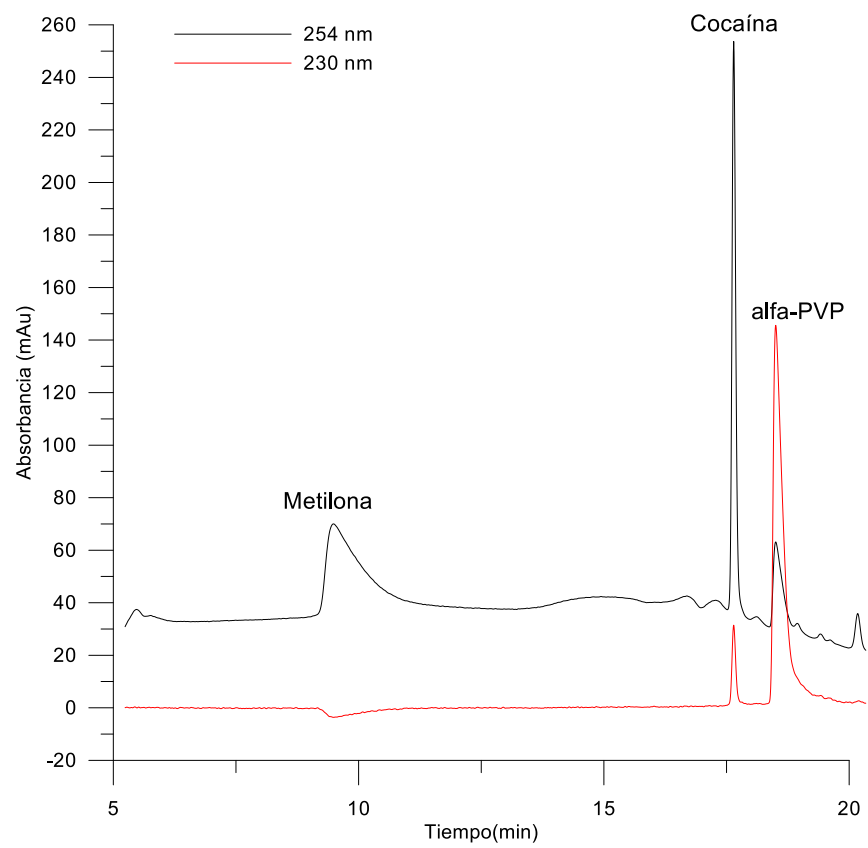

Imagen 12. Separación cromatográfica de las dos catinonas sintéticas y la cocaína cuando se emplea como fase móvil (A): agua conteniendo 0,05\% ácido fórmico (v/v) y (B): MeCN. La señal se ha registrado a $230 \mathrm{~nm}$ (cromatograma negro) y $254 \mathrm{~nm}$ (cromatograma rojo).

A la vista de los resultados obtenidos y llegando a un compromiso entre las eficacias observadas, se procede a emplear ácido fórmico adicionado a la fase acuosa.

b) Optimización del porcentaje de ácido fórmico presente en la fase móvil acuosa.

Dado que se ha seleccionado el ácido fórmico para adicionarlo a la fase acuosa en la separación de los tres analitos, se procede a la optimización del porcentaje del mismo.

Para ello, se evaluaron los siguientes porcentajes en volumen de ácido fórmico en la fase acuosa: $0,01 \%, 0,05 \%, 0,10 \%, 0,25 \%$ y $0,50 \%$.

Los resultados obtenidos se muestran en el Gráfico 2, observando que a mayor porcentaje de ácido la eficacia de los picos es mayor. Sin embargo, al adicionar un 0,50\% de ácido fórmico, el pico cromatográfico de la metilona no se resuelve prácticamente en el cromatograma obtenido del análisis de un patrón de $2 \mu \mathrm{g} / \mathrm{mL}$ en agua.

Por lo tanto, la concentración óptima de ácido fórmico seleccionada para adicionar a la fase acuosa ha sido del 0,25\% (v/v). 

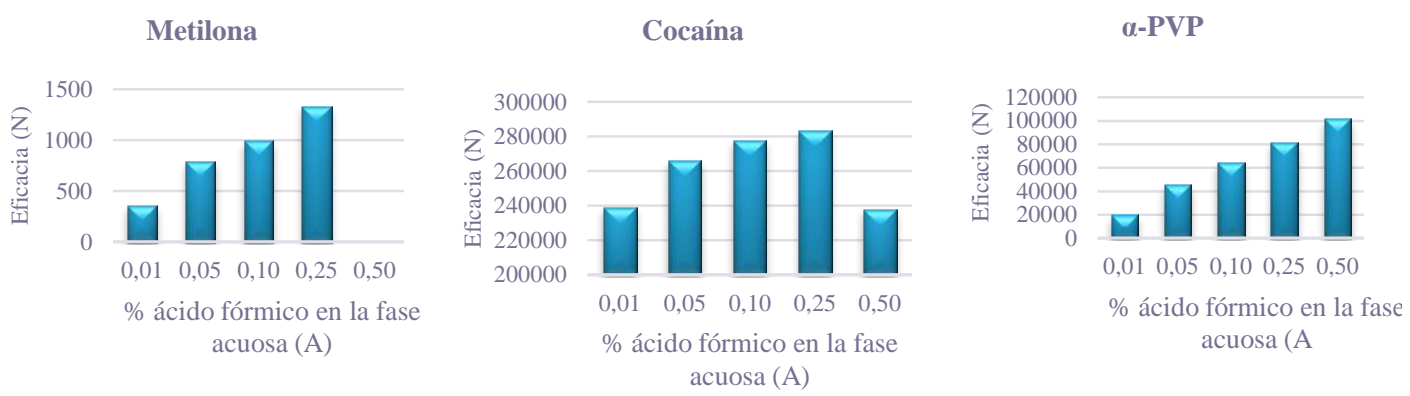

Gráfico 2. Eficacia obtenida en la evaluación del porcentaje de ácido en la fase móvil acuosa (A) para la metilona, cocaína y $\alpha$-PVP. La eficacia de la metilona cuando se emplea 0,50 \% ácido fórmico $(v / v)$ no se тиеstra puesto que no se consigue resolver su pico cromatográfico.

\section{c) Evaluación de la presencia de ácido en la fase móvil orgánica.}

Una vez optimizada la concentración de ácido fórmico presente en la fase acuosa, 0,25\% (v/v) se estudió la posibilidad de añadir esta misma concentración a la fase orgánica. El principal objetivo de esto es mantener constante la concentración de ácido a lo largo del análisis, ya que si no se añade ácido a la fase orgánica, la concentración de ácido variará según varíe el gradiente de elución. Para ello, se comprueba la eficacia de los picos cromatográficos correspondientes a los tres analitos, en presencia de un 0,25\% (v/v) de ácido fórmico, también en la fase orgánica. Como se observa en el Gráfico 3, se obtuvieron resultados de eficacia similares, aunque los de la metilona y $\alpha$-PVP aumentaban y la cocaína perdía algo de eficacia. Por lo tanto, se optó por trabajar en presencia de un 0,25\% (v/v) de ácido fórmico tanto en la fase acuosa como en la fase orgánica de MeCN. En la Imagen 13 se muestra la separación cromatográfica obtenida empleando la fase móvil establecida para las condiciones iniciales de gradiente, flujo, temperatura y volumen de inyección propuestas inicialmente.
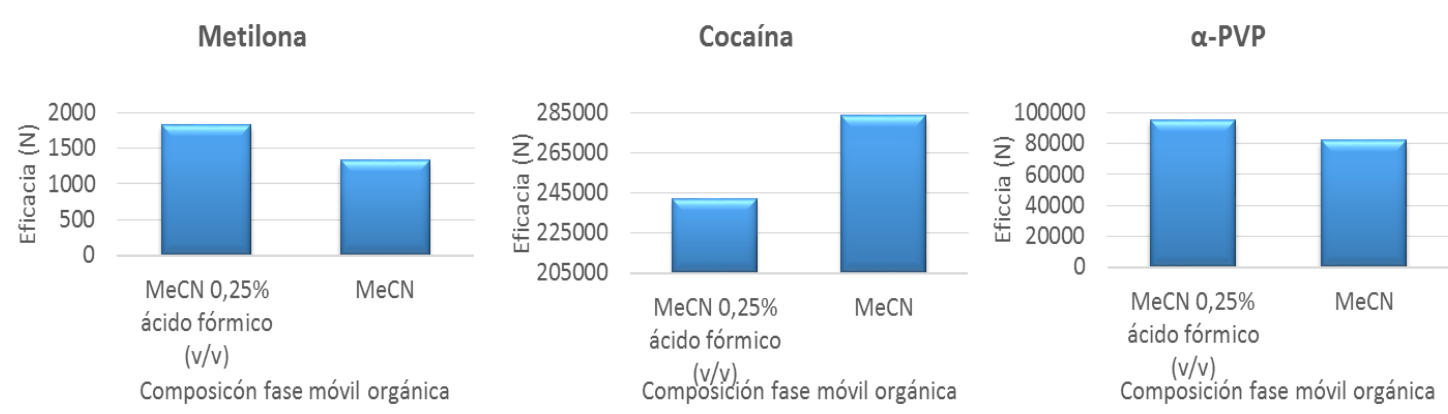

Gráfico 3. Comparación del número de platos teóricos obtenidos $(N)$ para cada una de las catinonas sintéticas y para la cocaína cuando se emplea como fase móvil orgánica MeCN y MeCN conteniendo $0,25 \%(v / v)$ ácido fórmico. 


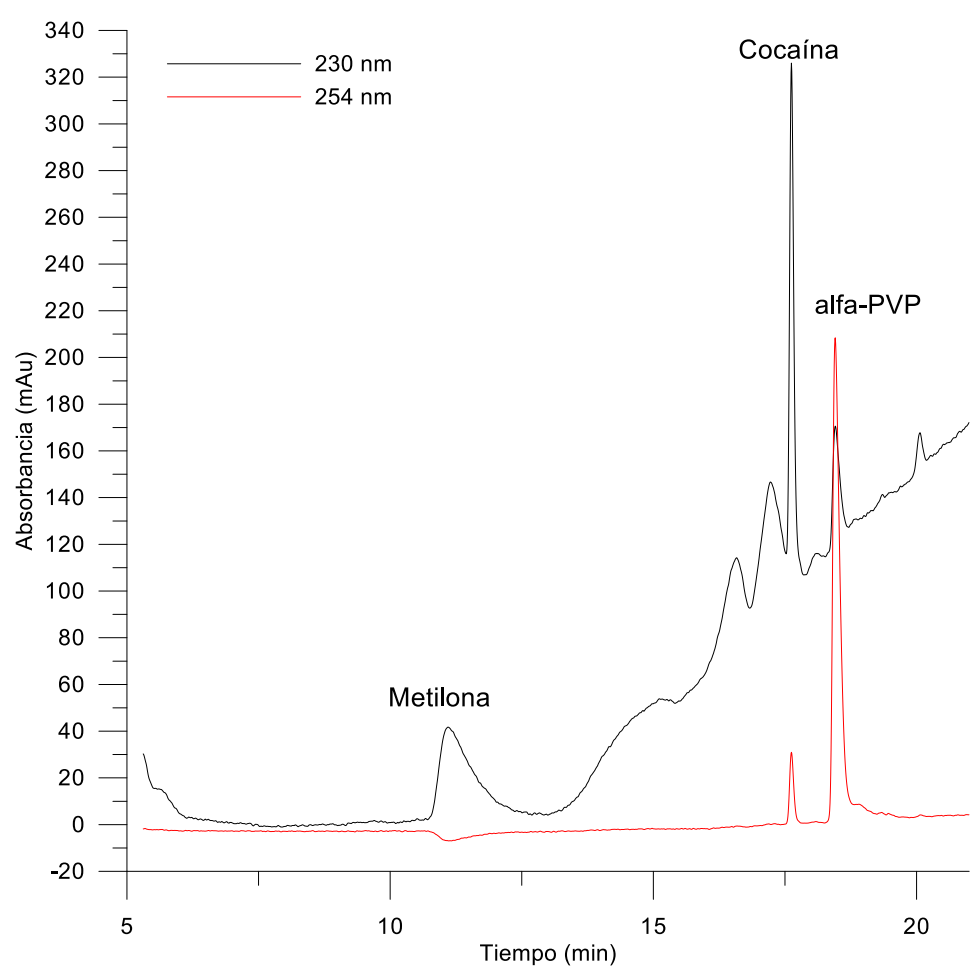

Imagen 13. Separación cromatográfica obtenida cuando se emplea como fase móvil (A) agua conteniendo 0,25\% (v/v) ácido fórmico y como fase móvil (B) MeCN conteniendo 0,25\% (v/v) ácido fórmico. La señal se ha registrado a $230 \mathrm{~nm}$ (cromatograma negro) y a $254 \mathrm{~nm}$ (cromatograma rojo).

\subsubsection{ESTUDIO DEL GRADIENTE DE ELUCIÓN}

Con la fase móvil consistente en una fase acuosa conteniendo un $0,25 \%$ (v/v) de ácido fórmico y la fase orgánica compuesta por $\mathrm{MeCN}$ conteniendo un 0,25\% (v/v) de ácido fórmico, se procedió a estudiar el gradiente de elución que permita separar los analitos con una alta eficiencia y en el menor tiempo posible. Las condiciones cromatograficas empleadas para este estudio fueron las iniciales: un flujo de $7 \mu \mathrm{L} / \mathrm{min}, 20^{\circ} \mathrm{C}$ y $5 \mu \mathrm{L}$ de volumen de inyección.

De este estudio se concluyó que las condiciones de inicio del gradiente de elución afectan mucho a la eficacia de la metilona, de tal forma que cuando las condiciones iniciales contienen un porcentaje igual o superior a un $10 \%$ de fase orgánica, este analito eluye con mayor eficacia, incrementando la eficacia con el incremento del porcentaje de fase orgánica inicial. Por otro lado se observa que la cocaína y el $\alpha$-PVP no eluyen hasta que en el gradiente de elución se alcanza un $95 \%$ de fase orgánica, así como la cocaína coeyluye con un pico interferente presente en un blanco de muestra. Debido a que los analitos estudiados presentan una naturaleza química distinta, el principal objetivo del 
estudio del gradiente es alcanzar una buena separación cromatográfica en el menor tiempo posible, así como separar la cocaína del pico presente en el blanco con el que eluía.

Además, y debido a que el tiempo que tarda en alcanzarse el equilibrio de distribución del sistema tras cada análisis es muy importante para la reproducibilidad de la separación cromatográfica, se procedió a evaluar el tiempo de equilibrado comprobando que la presión al principio y al final del análisis fuera la misma. De esta forma se consiguió el equilibrado en 36 minutos.

De los estudios del gradiente de fase móvil durante la separación, se obtuvo que la mejor separación cromatográfica se alcanzaba empleando el gradiente mostrado en la Tabla 20. Por tanto, la separación comienza con un flujo de fase móvil con un 10\% de fase orgánica (B) que se mantiene durante los cinco primeros minutos, un porcentaje de B que se incrementa a lo largo del análisis hasta llegar al 95\% de B a los veinte minutos. Estas condiciones se mantienen durante cuatro minutos para lograr la elución total de los compuestos estudiados. Posteriormente, el \% de B se disminuye a las condiciones iniciales, manteniéndose durante diez minutos, el cual es el tiempo requerido para el reequilibrado de la columna. En la Imagen 14 se muestra la separación cromatográfica obtenida en estas condiciones.

\begin{tabular}{cccc}
\hline $\begin{array}{c}\text { Tiempo } \\
(\mathbf{m i n})\end{array}$ & $\% \mathbf{B}$ & $\begin{array}{c}\text { Flujo } \\
(\boldsymbol{\mu} \mathbf{L} / \mathbf{m i n})\end{array}$ & $\begin{array}{c}\text { Presión máxima } \\
(\mathbf{b a r})\end{array}$ \\
\hline 0 & 10 & 7 & 400 \\
\hline 5 & 10 & 7 & 400 \\
\hline 8 & 20 & 7 & 400 \\
\hline 10 & 50 & 7 & 400 \\
\hline 15 & 70 & 7 & 400 \\
\hline 20 & 95 & 7 & 400 \\
\hline 24 & 95 & 7 & 400 \\
\hline 26 & 10 & 7 & 400 \\
\hline 36 & 10 & 7 & 400 \\
\hline
\end{tabular}

Tabla 20. Gradiente de elución de los analitos en la separación cromatográfica. 


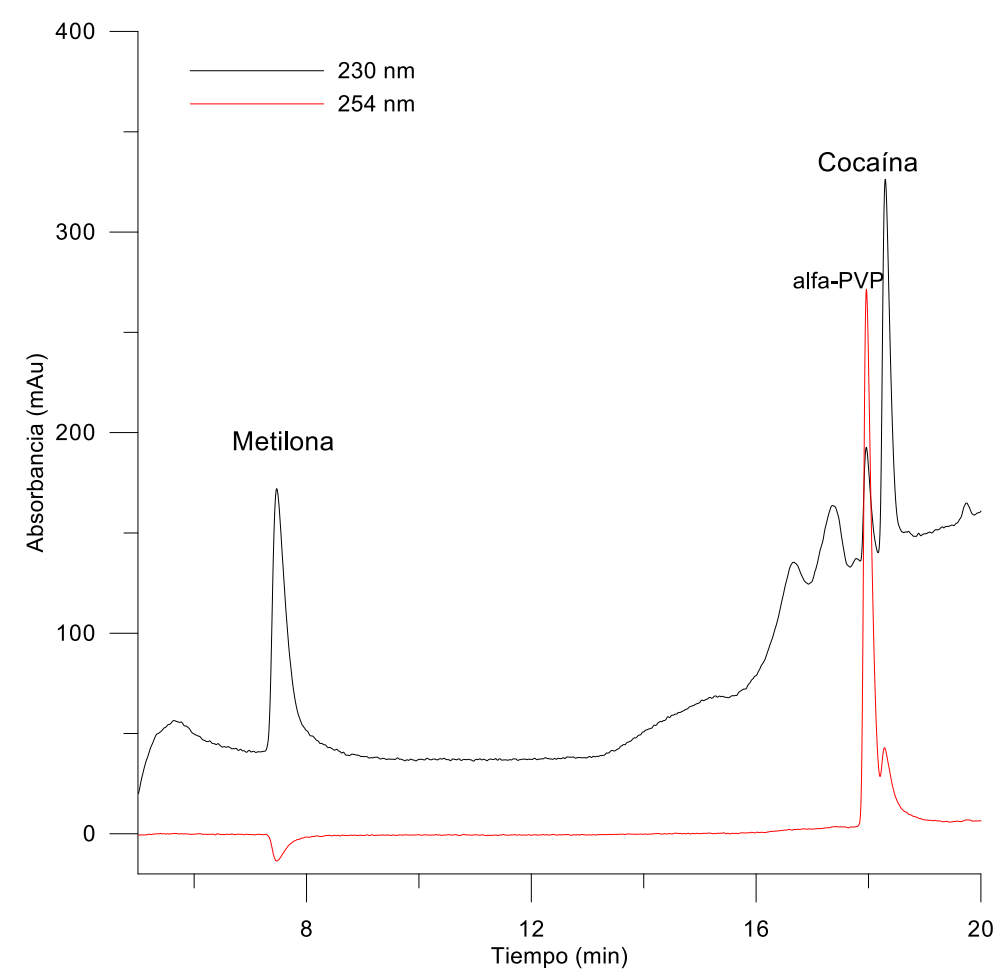

Imagen 14. Cromatograma obtenido para las tres drogas de abuso empleando el gradiente de concentraciones escogido y registrándose la señal a $230 \mathrm{~nm}$ (cromatograma negro) y a $254 \mathrm{~nm}$ (cromatograma rojo).

Por otro lado, y con objeto de establecer un método sencillo, también se evaluó la posibilidad de trabajar en modo isocrático, en vez de emplear un gradiente de concentración de la fase móvil durante la separación. Para ello, se estudió la separación de los analitos manteniendo constante el porcentaje de fase orgánica (MeCN conteniendo 0,25\% (v/v) ácido fórmico) durante todo el análisis, de tal forma que se evaluó la separación cromatográfica trabajando con un $60 \%$ y un $70 \%$ de fase orgánica, respectivamente.

Trabajando en modo isocrático los analitos no eluían debido a la naturaleza de los mismos y a la gran cantidad de disolvente orgánico que necesitan. Por lo tanto, finalmente, se optó por llevar a cabo la separación de estos compuestos empleando un gradiente de concentración de la fase móvil.

\subsubsection{OPTIMIZACIÓN DEL CAUDAL DE FASE MÓVIL}

La velocidad de desplazamiento de los analitos a través de la fase estacionaria juega un papel muy importante para definir el ensanchamiento de los picos y por tanto, la eficacia 
del sistema cromatográfico. Con el objetivo de optimizar este parámetro, se llevó a cabo un estudio de la eficiencia de los picos cromatográficos obtenidos cuando se emplean caudales de 6,7, 8, 10 y $12 \mu \mathrm{L} / \mathrm{min}$ de fase móvil, manteniendo constantes las condiciones iniciales de temperatura y volumen de inyección $\left(20^{\circ} \mathrm{C}\right.$ y $5 \mu \mathrm{L}$, respectivamente) y empleando el gradiente de elución y la composición de fase móvil optimizados previamente.

Para este estudio se empleó una disolución acuosa conteniendo a los tres analitos en una concentración de $2 \mu \mathrm{g} / \mathrm{mL}$, así como se midió un blanco de agua aplicando los distintos caudales de fase móvil estudiados para comprobar si el interferente que anteriormente coeluía con la cocaína eluye en tiempos distintos cuando se modifica dicho caudal.

En el Gráfico 4 se muestran las eficacias obtenidas para cada uno de los analitos a los distintos caudales de fase móvil estudiados. Los resultados obtenidos muestran que al aumentar el caudal de la fase móvil la eficacia de pico de la metilona empeora, a la vez que mejora la eficacia del $\alpha$-PVP y la cocaína, teniendo como valor óptimo un caudal de $10 \mu \mathrm{L} / \min$ y $8 \mu \mathrm{L} / \mathrm{min}$, respectivamente, ya que la cocaína a partir de un flujo de 10 $\mu \mathrm{L} /$ min coeluye con el interferente. Este interferente sólo aparece cuando la señal se monitoriza a $230 \mathrm{~nm}$. Por tanto, no importa que coeluya con el $\alpha$-PVP, dado que la señal analítica para este analito se monitoriza a $254 \mathrm{~nm}$. Debido a que se observó que cada analito presentaba una eficacia de pico óptima a un flujo distinto, fue necesario llegar a una opción de compromiso entre las eficacias de los mismos. Dado que la eficacia de pico de la metilona era inferior en todos los casos, se seleccionó ésta como factor limitante.
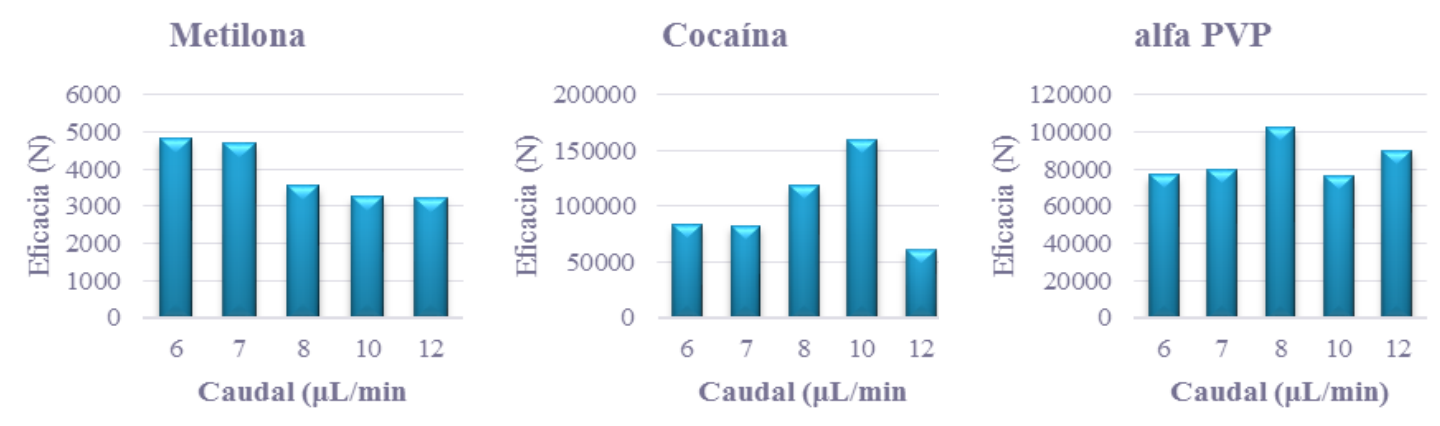

Gráfico 4. Eficacias de los picos obtenidas para cada uno de los analitos cuando a distintos caudales de fase móvil.

En la Tabla 21 se muestra como disminuyen los tiempos de retención de los tres analitos a medida que se incrementa el caudal de la fase móvil. 


\begin{tabular}{cccccc}
\hline & \multicolumn{5}{c}{$\mathbf{T}_{\mathrm{R}}(\mathbf{m i n})$} \\
\hline & $\mathbf{6} \boldsymbol{\mu} \mathbf{L} / \mathbf{m i n}$ & $\mathbf{7} \boldsymbol{\mu L} / \mathbf{m i n}$ & $\mathbf{8} \boldsymbol{\mu} \mathbf{L} / \mathbf{m i n}$ & $\mathbf{1 0} \boldsymbol{\mu L} / \mathbf{m i n}$ & $\mathbf{1 2} \boldsymbol{\mu L} / \mathbf{m i n}$ \\
\cline { 2 - 6 } Metilona & 7,07 & 7,47 & 6,25 & 5,57 & 4,92 \\
$\boldsymbol{\alpha}-P V P$ & 19,24 & 18,30 & 17,06 & 15,74 & 14,82 \\
Cocaína & 18,86 & 17,97 & 16,77 & 15,41 & 14,45 \\
\hline
\end{tabular}

Tabla 21. Variación de los tiempos de retención $\left(T_{R}\right)$ en función del caudal aplicado.

Por otro lado, de la medida de los blancos se observa que la línea base es la misma y el interferente siempre eluye al mismo tiempo de retención, por lo que, teniendo en cuenta estos resultados y llegando a un compromiso entre los mismos, se estima como caudal de fase móvil óptimo $8 \mu \mathrm{L} / \mathrm{min}$, ya que con este caudal, aunque la metilona pierde un poco de eficacia con respecto a los caudales de 6 y $7 \mu \mathrm{L} / \mathrm{min}$, la cocaína y el $\alpha$-PVP consiguen un aumento notable de la eficacia. En la Imagen 15 se muestra el cromatograma obtenido cuando se aplica el caudal óptimo elegido de $8 \mu \mathrm{L} / \mathrm{min}$.

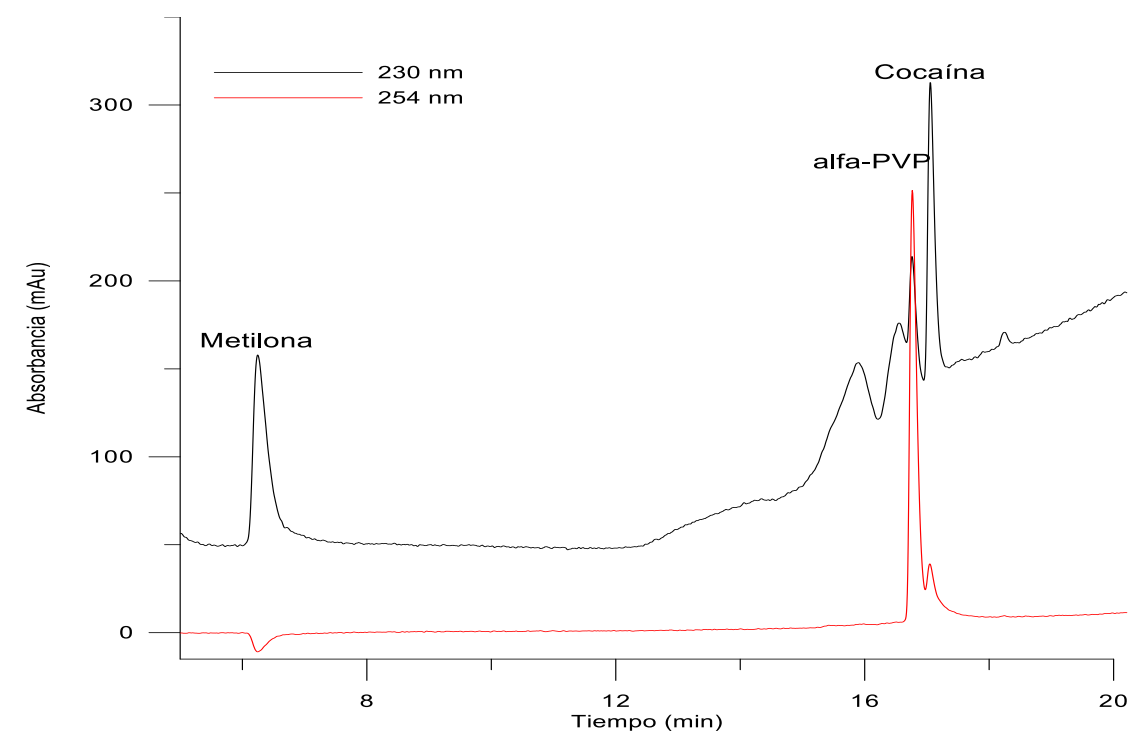

Imagen 15. Separación cromatográfica obtenida cuando se emplean $8 \mu \mathrm{L} / \mathrm{min}$ como flujo de fase móvil, regristrándose la señal a $254 \mathrm{~nm}$ (cromatograma rojo) y $230 \mathrm{~nm}$ (cromatograma negro).

\subsubsection{OPTIMIZACIÓN DE LA TEMPERATURA}

La temperatura de la columna puede afectar a los parámetros cromatográficos de la separación, como es el tiempo de retención y la eficacia de pico. Por ello, es un factor a evaluar en la optimización de un método.

Inicialmente, se propuso que la columna estuviera termostatizada a $20^{\circ} \mathrm{C}$ y su estudio se llevó a cabo analizando una disolución patrón de $2 \mu \mathrm{g} / \mathrm{mL}$ en agua, empleando como fase 
móvil acuosa agua con $0,25 \%$ (v/v) de ácido fórmico y como fase orgánica, MeCN con 0,25\% (v/v) del mismo ácido, $8 \mu \mathrm{L} / \mathrm{min}$ de caudal de fase móvil e inyectando $5 \mu \mathrm{L}$ de disolución patrón en el equipo.

En un principio, se estudió el efecto de la temperatura cada $5^{\circ} \mathrm{C}$ en el rango de temperaturas entre $20-35^{\circ} \mathrm{C}$, observándose que la eficacia de pico de la metilona y la cocaína aumenta cuando aumenta la temperatura, mientras que la eficacia del $\alpha$-PVP disminuye a partir de $25^{\circ} \mathrm{C}$, tal y como se muestra en el Gráfico 5 .
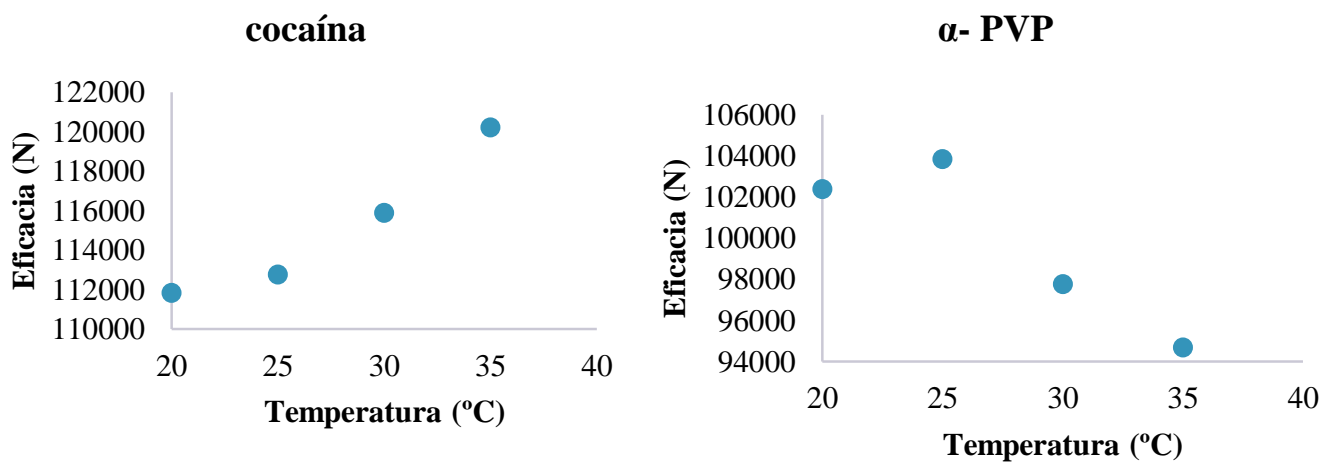

metilona

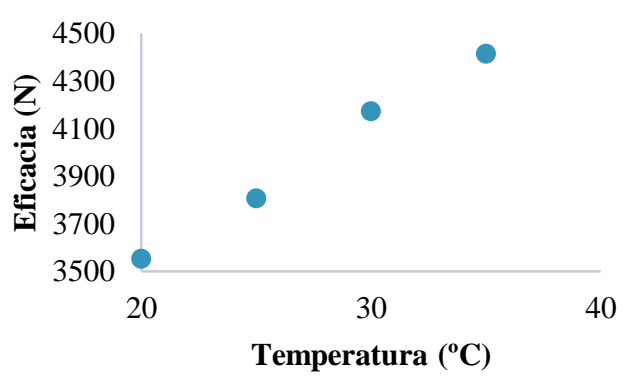

Gráfico 5. Efecto de la temperatura en la eficacia de los picos cromatográficos correspondientes a los tres analitos.

Teniendo en cuenta los resultados obtenidos, hay que llegar a un compromiso entre el aumento de la eficacia de pico de la metilona y la cocaína a altas temperaturas y la pérdida de eficacia de pico que conlleva esta condición para el $\alpha$-PVP. Además, se observó en análisis sucesivos que una alta temperatura provocaba la degradación de la cocaína. A pesar de que la eficacia de la cocaína y la metilona aumenta con la temperatura, con objetivo de evitar la degradación de la cocaína, se va a mantener la columna a $20^{\circ} \mathrm{C}$, es decir, la misma que se había escogido como temperatura de partida para la optimización del método. 


\subsubsection{REOPTIMIZACIÓN DEL GRADIENTE DE ELUCIÓN}

El gradiente de elución establecido previamente (Tabla 20), se modificó tras la optimización de los parámetros cromatográficos con el objetivo de simplificar el gradiente de concentración de la fase móvil. De tal forma que el gradiente final es el que se muestra en la Tabla 22, alcanzando el 95\% de fase orgánica en 20 minutos y alargando el análisis hasta los 36 minutos para conseguir el reequilibrado de la columna. En la Imagen 16 se muestra la rampa del gradiente de composición de fase móvil a lo largo del análisis.

\begin{tabular}{ccc}
$\begin{array}{c}\text { tiempo } \\
\text { (min) }\end{array}$ & $\begin{array}{c}\text { \% fase } \\
\text { orgánica }\end{array}$ & $\begin{array}{c}\text { \% fase } \\
\text { acuosa }\end{array}$ \\
\hline 0 & 10 & 90 \\
\hline 5 & 10 & 90 \\
10 & 50 & 50 \\
15 & 50 & 50 \\
\hline 21 & 95 & 5 \\
\hline 24 & 95 & 5 \\
\hline 26 & 10 & 90 \\
\hline 36 & 10 & 90 \\
\hline
\end{tabular}

Tabla 22. Gradiente de concentraciones óptimo para la separación cromatográfica de metilona, $\alpha-P V P$ y

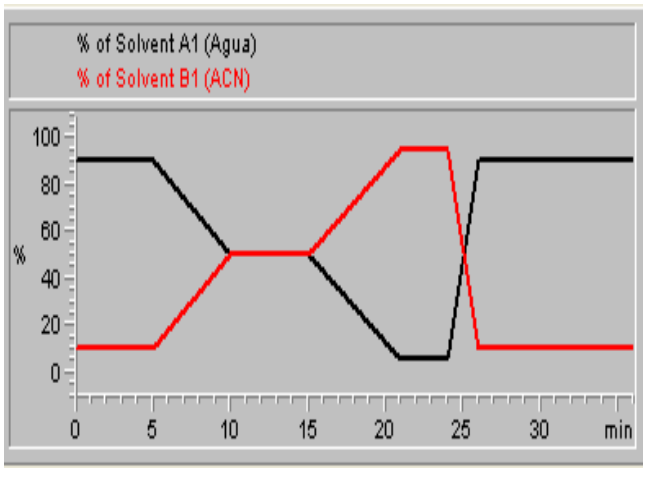

Imagen 16. Rampa del gradiente de composición, donde se muestra el porcentaje de cada fase móvil durante todo el análisis.

\subsubsection{EVALUACIÓN DEL MEDIO DE INYECCIÓN}

Una vez optimizado el gradiente, se evaluó la influencia del medio de inyección de la muestra en la señal analítica. Para ello, se inyectó la muestra en las condiciones iniciales del método, es decir, 90:10 (v/v) de agua:MeCN conteniendo 0,25\% (v/v) ácido fórmico, observándose que la señal analítica de la metilona empeora bastante, por lo tanto, se mantiene el agua como medio de inyección. 


\subsubsection{OPTIMIZACIÓN DEL VOLUMEN DE INYECCIÓN}

El volumen de inyección se evaluó con el objetivo de incrementarla altura de los picos para la misma concentración de analito, mejorando la sensibilidad del método. Para ello, se analizó con las condiciones de gradiente, flujo y temperatura óptimos, una disolución estándar de $200 \mu \mathrm{g} / \mathrm{L}$ de cada uno de los analitos, evaluando los volúmenes de inyección siguientes: 4, 5, 6, 7 y $8 \mu \mathrm{L}$ Los resultados obtenidos se muestran en el Gráfico 6, observándose un aumento lineal de la altura de pico al aumentar el volumen de inyección. Debido a esto, y a que no se observan pérdidas en la eficacia de pico, el volumen de inyección óptimo se fijó en $8 \mu \mathrm{L} / \mathrm{min}$.

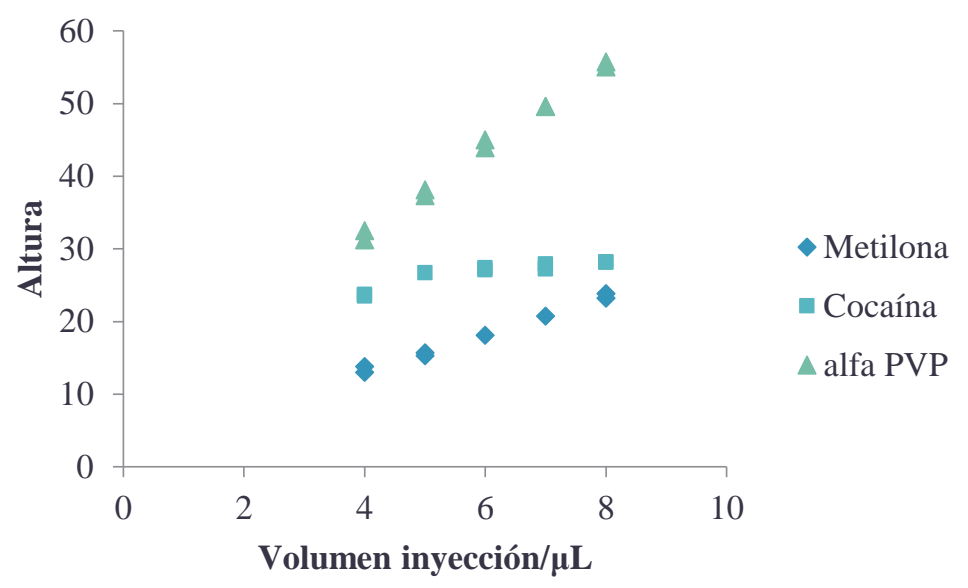

Gráfico 6. Representación de la altura de pico obtenida cuando se inyectan 4; 5; 6; 7 y $8 \mu \mathrm{L}$ de muestra.

\subsubsection{RESUMEN DE LA OPTIMIZACIÓN DE VARIABLES DEL MÉTODO CROMATOGRÁFICO}

Llevado a cabo todo el proceso de optimización de las variables que afectan a la separación cromatográfica, en la siguiente tabla (Tabla 23) se presenta un resumen de todos los valores óptimos fijados para la separación y determinación simultánea de las tres drogas de abuso en estudio. 


\begin{tabular}{|c|c|}
\hline Columna & Zorbax XDB Diox C18 (150 mm x $0,5 \mathrm{~mm}$ x $5 \mu \mathrm{m})$ \\
\hline $\begin{array}{l}\text { Temperatura de la columna } \\
\left({ }^{\circ} \mathrm{C}\right)\end{array}$ & 20 \\
\hline Caudal $(\mu \mathrm{L} / \mathrm{min})$ & 8 \\
\hline Volumen de inyección $(\mu \mathrm{L})$ & 8 \\
\hline Composición de la fase móvil & $\begin{array}{l}\text { A: Agua }(0,25 \%(\mathrm{v} / \mathrm{v}) \text { ácido fórmico); } \\
\mathrm{B}: \operatorname{MeCN}(0,25 \%(\mathrm{v} / \mathrm{v}) \text { ácido fórmico) }\end{array}$ \\
\hline Gradiente de elución & $\begin{array}{c}0-5 \min (10 \% \mathrm{~B}) ; 5-10 \min (10-50 \% \mathrm{~B}) ; 10-15 \\
\min (50 \% \mathrm{~B}) ; 15-21 \min (50-95 \% \mathrm{~B}) ; 21-24 \\
(95 \% \mathrm{~B}) ; 24-26 \min (95-10 \% \mathrm{~B}) ; 26-36 \min \\
(10 \% \mathrm{~B})\end{array}$ \\
\hline $\begin{array}{l}\text { Longitud de onda }(\mathrm{nm}) \text { de } \\
\text { monitorización de la señal }\end{array}$ & $\begin{array}{c}230 \text { (cocaína y metilona); } \\
254 \text { ( } \alpha \text {-PVP) }\end{array}$ \\
\hline
\end{tabular}

Tabla 23. Resumen de lo valores óptimos para el establecimiento del método de cromatografía liquida capilar con detección UV para la separación cromatográfica de metilona, $\alpha-P V P$ y cocaína.

\subsection{CARACTERIZACIÓN DEL MÉTODO CROMATOGRÁFICO EN MUESTRAS ALIMENTARIAS}

Aunque las muestras biológicas sean las más analizadas en fenómenos de SQ, debido a la baja permanencia de las drogas en el organismo y a la gran variedad de drogas de abuso que se pueden emplear, distintas asociaciones de Toxicología Analítica están haciendo hincapié en recoger además de las muestras biológicas, muestras de la bebida o alimento sospechoso de ser contaminado, si la víctima puede aportarlos, pues puede resultar clave para la resolución del caso [5]. Por ello, se va a evaluar la aplicabilidad del método desarrollado en bebidas alcohólicas, que es el medio más común para llevar a cabo delitos de SQ, ya que el alcohol potencia los efectos de las drogas, además de enmascararlos.

Para demostrar la validez del método y su aplicabilidad para el análisis de estas drogas de abuso en bebidas alcohólicas, se estableció la recta de calibrado con patrones y en presencia de matriz, con muestras fortificadas de ron, así como los parámetros de calidad de dicho método: límite de detección (LOD), límite de cuantificación (LOQ), rango lineal, precisión y veracidad. 


\subsubsection{ESTABLECIMIENTO DE LA CURVA DE CALIBRADO Y PARÁMETROS DE}

\section{CALIDAD}

En primer lugar se estableció la función de calibrado empleando patrones conteniendo las tres drogas de abuso objeto de estudio. Así mismo, se establecieron los parámetros de calidad del método: LOD, LOQ y rango lineal.

Las curvas de calibrado (Gráfico 7) se determinaron a partir de las señales analíticas obtenidas (áreas de pico) en el análisis de disoluciones estándar a cinco niveles de concentración: 80;160;320; 800 y $1600 \mu \mathrm{g} / \mathrm{L}$. Dichos niveles de concentración se escogieron de acuerdo a los niveles estudiados en la bibliografía [38, 47, 50] y las disoluciones se prepararon a partir de la disolución intermedia de $100 \mu \mathrm{g} / \mathrm{mL}$ de cada analito, preparándose dos disoluciones estándar por cada nivel de concentración e inyectándose cada una por triplicado.

\section{$\alpha-P V P$}

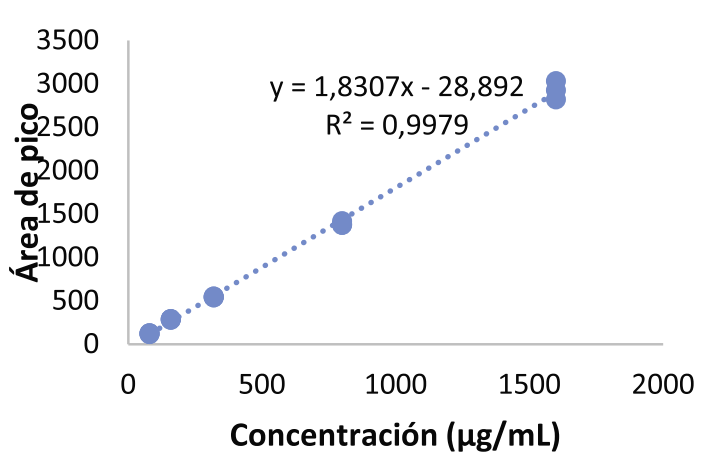

METILONA

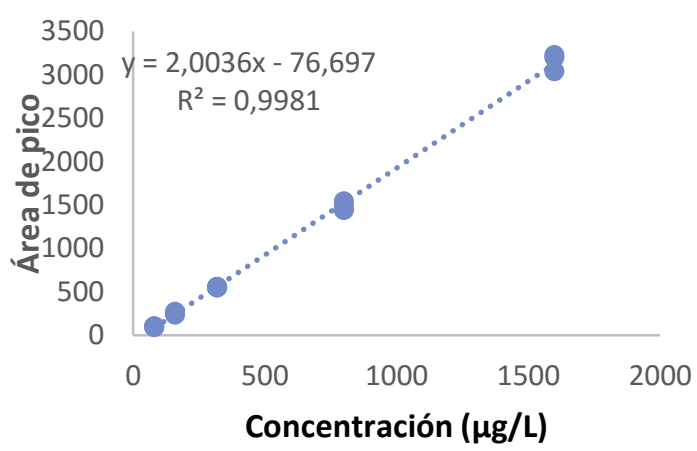

COCAÍNA

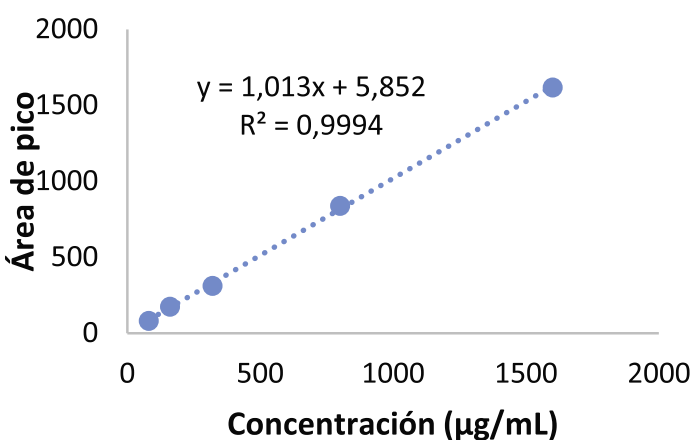

Gráfico 7. Rectas de calibrado en patrones.

Los parámetros estadísticos calculados mediante regresión por mínimos cuadrados, así como los valores del rango lineal, LOD y LOQ se muestran en la Tabla 24. Los LODs y 
LOQs se obtuvieron considerando las siguientes relaciones: 3 veces la relación señal/ruido $(\mathrm{S} / \mathrm{R})$ y 10 veces la relación $\mathrm{S} / \mathrm{R}$, respectivamente.

\begin{tabular}{ccccccc}
\hline Analito & Ordenada & Pendiente & $\mathbf{R}^{2}$ & $\begin{array}{c}\text { LOD } \\
(\boldsymbol{\mu g} / \mathbf{L})\end{array}$ & $\begin{array}{c}\text { LOQ } \\
(\boldsymbol{\mu g} / \mathbf{L})\end{array}$ & $\begin{array}{c}\text { Rango lineal } \\
(\boldsymbol{\mu g} / \mathbf{L})\end{array}$ \\
\hline Metilona & $-76,70$ & 2,00 & 0,998 & 6,65 & 22,18 & $22,18-1600$ \\
\hline Cocaína & 5,85 & 1,01 & 0,999 & 4,07 & 13,56 & $13,56-1600$ \\
$\mathbf{\alpha - P V P}$ & $-28,89$ & 1,83 & 0,998 & 1,66 & 5,52 & $5,52-1600$ \\
\hline
\end{tabular}

Tabla 24. Parámetros estadísticos y de calidad del método cromatográfico propuesto.

Los límites de detección y cuantificación alcanzados con este método varían entre 1,66,6 y 5,5-22,2 $\mu \mathrm{g} / \mathrm{L}$, respectivamente. Además, el coeficiente de determinación $\left(\mathrm{R}^{2}\right)$ obtenido para cada una de las drogas de abuso estudiadas confirma la relación lineal de la señal analítica obtenida (área de pico) en el rango de concentraciones estudiado.

Los resultados obtenidos muestran que el método propuesto para la determinación de cocaína y catinonas sintéticas posee una gran sensibilidad a pesar de emplear un sistema de detección UV/Vis, el cual se considera tradicionalmente como un sistema de detección poco sensible.

También se establecieron las rectas de calibrado en presencia de matriz, empleando para ello muestras de ron dopadas, a cinco niveles de concentración: 1,6; 3,2; 6,4; 16; y 32 $\mu \mathrm{g} / \mathrm{mL}$. Las muestras se doparon con concentraciones relativamente altas de analitos, de acuerdo a la bibliografía consultada, debido a que, para que las drogas produzcan efecto con fines de SQ, las concentraciones presentes en ellas no pueden ser demasiado bajas y hay que estudiar la linealidad a niveles altos de concentración [47, 50].

Teniendo en cuenta que las muestras eran diluidas 20 veces antes de ser analizadas, las concentraciones finales en los viales analizados fueron: 80, 160, 320, 800 y $1600 \mu \mathrm{g} / \mathrm{L}$, respectivamente. Se prepararon dos réplicas por nivel de concentración y cada una fue analizada por duplicado. La función de calibrado se estableció considerando las áreas de pico en función de la concentración de cada analito en la muestra y en el vial de análisis. En el Gráfico 8 se muestran las rectas de calibrado obtenidas, comprobándose que, el coeficiente de determinación $\left(\mathrm{R}^{2}\right)$ en los tres casos es superior a 0,99 . 


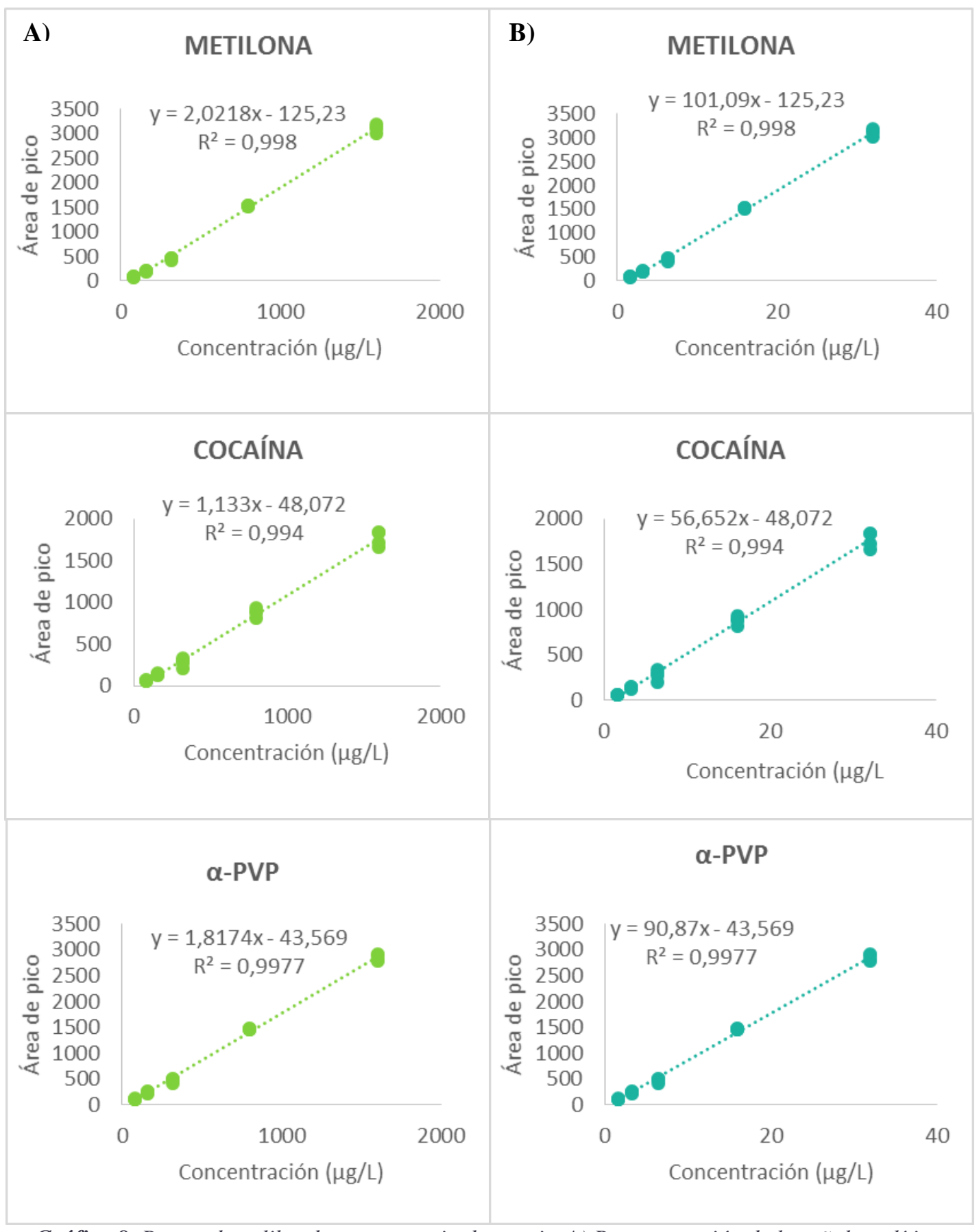

Gráfico 8. Rectas de calibrado en presencia de matriz. A) Representación de la señal analítica frente a la concentración de drogas en disolución. B) Representación de la señal analítica frente a la concentración de drogas presente en la muestra.

Los parámetros estadísticos y los parámetros de calidad se han calculado de forma similar al calibrado en patrones. Los resultados obtenidos para el calibrado en presencia de matriz teniendo en cuenta la concentración de analitos en el vial de análisis se muestran en la Tabla 25. 


\begin{tabular}{ccccccc}
\hline Analito & Ordenada & Pendiente & $\mathbf{R}^{2}$ & $\begin{array}{c}\text { LOD } \\
(\boldsymbol{\mu g} / \mathbf{L})\end{array}$ & $\begin{array}{c}\text { LOQ } \\
(\boldsymbol{\mu g} / \mathbf{L})\end{array}$ & $\begin{array}{c}\text { Rango lineal } \\
(\boldsymbol{\mu g} / \mathbf{L})\end{array}$ \\
\hline Metilona & $-125,23$ & 2,02 & 0,998 & 8,95 & 29,84 & $29,84-1600$ \\
\hline Cocaína & $-48,07$ & 1,13 & 0,994 & 5,03 & 16,77 & $16,77-1600$ \\
\hline $\boldsymbol{\alpha - P V P}$ & $-43,57$ & 1,82 & 0,998 & 3,11 & 10,37 & $10,37-1600$ \\
\hline
\end{tabular}

Tabla 25. Parámetros estadísticos y de calidad del método cromatográfico propuesto en presencia matriz. teniendo en cuenta la concentración de analitos en el vial de análisis.

El estudio del efecto matriz se ha realizado mediante cálculos estadísticos comparando la pendiente, ordenada y varianzas de las rectas de calibrado establecidas con patrones y en presencia de matriz. Del estudio estadístico se obtiene que las pendientes son iguales. Sin embargo, para la metilona, las varianzas no se consideran iguales y para el $\alpha$-PVP las ordenadas de ambas rectas tampoco se consideran iguales. Por lo tanto, para el estudio de la veracidad se ha decidido emplear la recta de calibrado establecida en muestras de ron, con el fin de descartar la existencia del efecto matriz.

\subsubsection{ESTUDIO DE LA PRECISIÓN DEL MÉTODO}

La precisión del método se evaluó en términos de repetitividad y reproducibilidad. La repetitividad proporciona la precisión intradía y se evaluó en un mismo día aplicando el procedimiento cromatográfico establecido a tres muestras de ron (réplicas experimentales), a tres niveles de concentración, y cada una de ellas analizada por triplicado (réplicas instrumentales). Los niveles de concentración de cada analito evaluados para este estudio fueron 80,320 y $1600 \mu \mathrm{g} / \mathrm{L}$.

La reproducibilidad del método proporciona la precisión interdía y se evaluó durante cinco días distintos aplicando el procedimiento cromatográfico cada uno de los días a una muestra de ron (réplica experimental), a los mismos niveles de concentración a los que se estudió a repetitividad del método, y analizando esta muestra por triplicado (réplicas instrumentales). En la Tabla 26 se muestran los resultados expresados en términos de desviación estándar relativa (DER) de las áreas de pico. Se observa que tanto para la precisión interdía como para la precisión intradía los resultados obtenidos fueron inferiores al 10\%, por lo que se considera que el método proporciona resultados muy buenos. 


\begin{tabular}{|c|c|c|c|}
\hline & Metilona & $\alpha-P V P$ & Cocaína \\
\hline & \multicolumn{3}{|c|}{ Repetibilidad (DER\%) (n=9) } \\
\hline $80 \mu \mathrm{g} / \mathrm{L}$ & 4,72 & 3,81 & 3,66 \\
\hline $320 \mu \mathrm{g} / \mathrm{L}$ & 1,22 & 1,03 & 4,18 \\
\hline \multirow[t]{2}{*}{$1600 \mu \mathrm{g} / \mathrm{L}$} & 1,76 & 1,93 & 1,29 \\
\hline & \multicolumn{3}{|c|}{ Precisión interdía (DER\%) $(n=15)$} \\
\hline $80 \mu \mathrm{g} / \mathrm{L}$ & 6,24 & 5,95 & 7,95 \\
\hline $320 \mu \mathrm{g} / \mathrm{L}$ & 6,96 & 5,40 & 7,62 \\
\hline $1600 \mu \mathrm{g} / \mathrm{L}$ & 8,09 & 8,50 & 7,53 \\
\hline
\end{tabular}

Tabla 26. Estudio de precisión para el método propuesto.

\subsection{ESTUDIO DE LA VERACIDAD DEL MÉTODO}

Para evaluar la veracidad del método se llevaron a cabo estudios de recuperación de estas drogas de abuso en diferentes bebidas alcohólicas ampliamente utilizadas en fenómenos de SQ. Las bebidas estudiadas fueron un ron procedente de dos fabricantes distintos, siendo uno de ellos el empleado para caracterizar el método; además de vodka y whisky.

Los estudios de recuperación se llevaron a cabo dopando estas muestras con una mezcla de las tres drogas objeto de estudio en dos rangos de concentraciones $(6,4$ y $32 \mu \mathrm{g} / \mathrm{mL})$, siendo la concentración en el vial 320 y $1600 \mu \mathrm{g} / \mathrm{mL}$. Cada nivel de concentración se preparó por duplicado e inyectó tres veces cada uno. Las recuperaciones se calcularon en términos de veracidad, mediante la comparación de la concentración obtenida, calculada mediante la recta de calibrado en presencia de matriz, con las concentraciones teóricas que deberían tener tras haber aplicado la dilución correspondiente. Dichas recuperaciones dependerán de la variabilidad del método, aceptándose las recuperaciones cuyo rango de incertidumbre sea $\pm 20 \%$ en la concentración más baja y $\pm 15 \%$ en la concentración más alta [81].

En la Tabla 27 se muestran las recuperaciones obtenidas para cada una de las bebidas estudiadas a los diferentes niveles de concentración. Considerando que la recuperación ideal es del 100\%, se obtienen valores aceptables, ya que todos se encuentran dentro de los límites que establece la ley, que son $\pm 20 \%$ en el nivel de concentración más alto y $\pm 15 \%$ en el nivel de concentración más bajo [81], a excepción del whisky que, en el nivel más alto de concentración no se encuentra dentro del rango establecido. 


\begin{tabular}{ccccc}
\hline & & \multicolumn{3}{c}{ Recuperaciones (\%) } \\
\hline \multirow{2}{*}{ Ron (fabricante 1) } & Concentración $(\boldsymbol{\mu g} / \mathbf{L})$ & Metilona & $\boldsymbol{\alpha - P V P}$ & Cocaína \\
\cline { 2 - 5 } & 320 & $96,82 \pm 6,97$ & $110,00 \pm 6,01$ & $109,28 \pm 2,12$ \\
\hline \multirow{2}{*}{ Ron (fabricante 2) } & 1600 & $108,97 \pm 6,71$ & $105,47 \pm 7,21$ & $109,81 \pm 0,64$ \\
\hline \multirow{2}{*}{ Vodka } & 320 & $92,35 \pm 5,50$ & $101,48 \pm 4,52$ & $104,37 \pm 8,28$ \\
\hline \multirow{2}{*}{ Whisky } & 1600 & $101,36 \pm 3,74$ & $96,48 \pm 6,92$ & $102,04 \pm 10,88$ \\
\hline & 320 & $88,99 \pm 1,69$ & $107,31 \pm 4,51$ & $107,47 \pm 0,63$ \\
\hline & 1600 & $95,92 \pm 2,90$ & $102,11 \pm 6,72$ & $107,06 \pm 7,28$ \\
\hline
\end{tabular}

Tabla 27. Recuperaciones obtenidas en muestras de Ron, Vodka y Whisky dopados con distintas concentraciones de metilona, $\alpha-P V P$ y cocaína.

En la Imagen 17 se muestran los cromatogramas obtenidos del análisis cromatográfico de cocaína y catinonas sintéticas en muestras de ron, whisky y vodka, respectivamente.
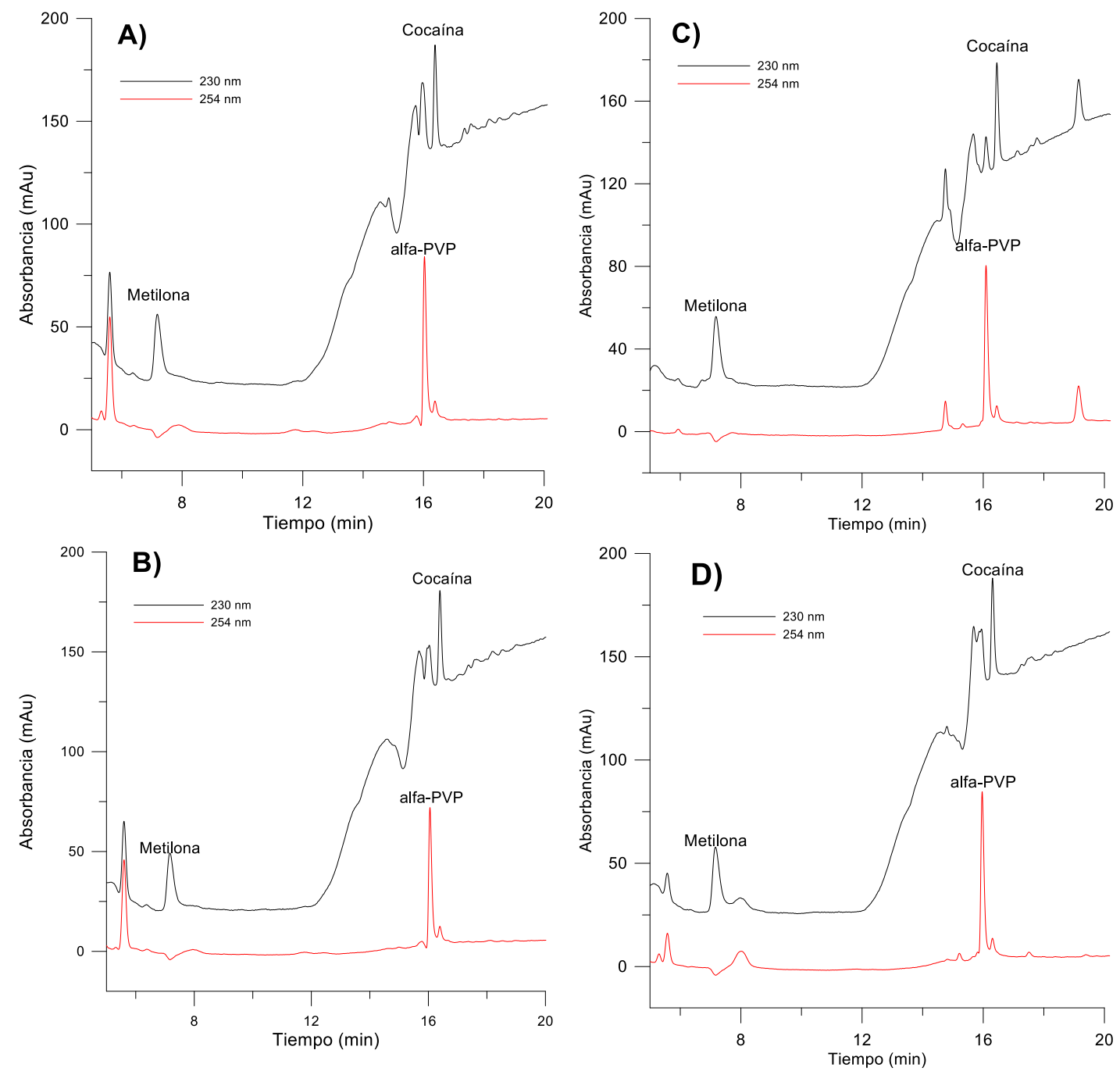

Imagen 17. Cromatogramas obtenidos del análisis de catinonas sintéticas y cocaína mediante HPLC capilar-UV/Vis a $254 \mathrm{~nm}$ (cromatograma rojo) y $230 \mathrm{~nm}$ (cromatograma negro), en diferentes bebidas alcohólicas: A) Ron (fabricante 1); B) Ron (fabricante 2); C) Vodka; D) Whisky. 


\subsection{ENSAYOS PRELIMINARES PARA LA APLICACIÓN DEL MÉTODO PROPUESTO A LA DETERMINACIÓN DE LAS DROGAS DE ABUSO EN MUESTRAS BIOLÓGICAS}

Las muestras biológicas (sangre, orina, saliva) son las matrices más empleadas para el análisis de drogas en fenómenos de SQ, ya que además de su disponibilidad y fácil acceso, informan del consumo reciente de dichas drogas. La orina, además presenta la ventaja de tener una ventana de detección más amplia. Por ello, en 1999 la Sociedad de Toxicólogos Forenses estadounidense (SOFT, del inglés Society of Forensic Toxicologists) propuso la orina como muestra de elección en estos casos, aunque tiene la limitación de ser detectada sólo en un periodo que oscila entre 12 horas y 5 días [5].

Teniendo en cuenta esto, que la orina es la matriz biológica más analizada en fenómenos de SQ, se ha aplicado el método desarrollado para el análisis de catinonas sintéticas en presencia de cocaína a esta muestra.

Debido a que en la orina las drogas se encuentran ya metabolizadas, la concentración de las mismas en esta muestra será muy inferior a la cantidad consumida. Es por ello, que, además de un método sensible y robusto para la determinación de las mismas, el tratamiento de muestra es uno de los aspectos críticos para la determinación de estos compuestos a niveles de traza. El empleo de sorbentes permite llevar a cabo una preconcentración de los analitos en muestras complejas, así como una extracción rápida y reproducible.

Teniendo en cuenta la importancia del tratamiento de muestra, en este trabajo se evaluaron distintos procedimientos de extracción y se realizaron estudios para una futura optimización de un tratamiento de microextracción líquido-líquido dispersiva (DLLME) en orina, para el análisis de las dos catinonas sintéticas objeto de nuestro estudio en presencia de cocaína, una droga de consumo habitual junto con las anteriores en fenómenos de SQ.

Los estudios de tratamiento de muestra se llevaron a cabo evaluando las recuperaciones obtenidas, teniendo en cuenta que no siempre serán del $100 \%$ ya que la recuperación dependerá de la eficacia de la extracción de los analitos. Además, en toxicología forense, 
el porcentaje de recuperación no es tan fundamental como que tenga una precisión muy buena, es decir, que sea reproducible y tenga unos límites de detección y cuantificación bajos, aceptándose recuperaciones, normalmente superiores al $80 \%$ y cuya DER sea inferior a $\pm 15 \%[81]$.

\subsubsection{EVALUACIÓN DEL TRATAMIENTO DE MUESTRA}

Para el análisis cromatográfico de las drogas de abuso objeto de estudio se evaluaron los siguientes tratamientos de muestra: SPE, extracción empleando el método QuEChERS y DLLME.

El estudio del tratamiento de muestra, para los tres procedimientos indicados, se llevó a cabo aplicando cada procedimiento a dos muestras de orina dopadas con $500 \mu \mathrm{g} / \mathrm{L}$, un blanco y un blanco dopado, que consiste en un blanco de orina que tras el tratamiento de muestra se dopa con la concentración de analitos que posee la muestra al final de dicho tratamiento. Tanto el blanco dopado como las muestras se doparon con la disolución intermedia que contenía los analitos.

Con el objetivo de poder llevar a cabo un estudio comparativo de los tratamientos de muestra estudiados, el volumen de muestra tratada fue la misma en los tres estudios, así como la concentración con la cual se dopó la muestra y el volumen en el cual la muestras se reconstituyeron tras el análisis.

Los procedimientos llevados a cabo para la evaluación de los tres tratamientos de muestra estudiados se describen a continuación.

\section{a) Procedimiento SPE}

Este tratamiento de muestra se llevó a cabo empleando cartuchos de balance hidrofílicolipofílico Oasis ${ }^{\circledR}$ HLB de $60 \mathrm{mg}$ de partícula y $3 \mathrm{~mL}$ de capacidad. En la Imagen 18 se muestra un esquema del procedimiento SPE. 


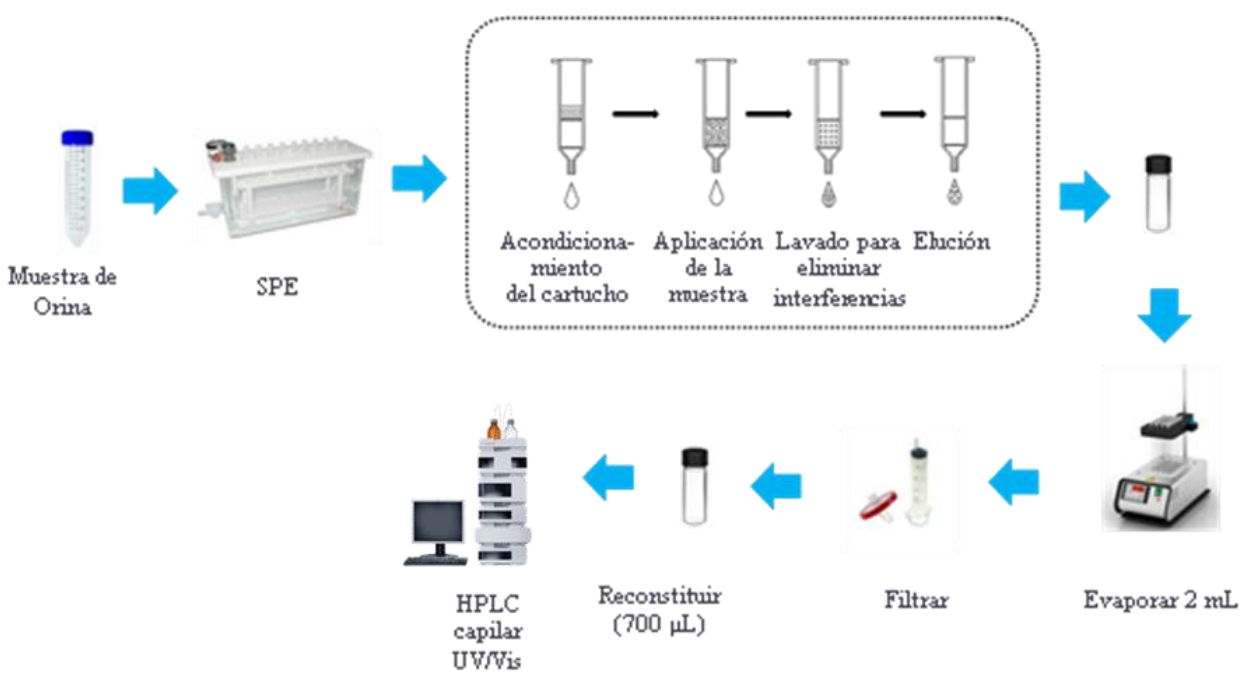

Imagen 18. Esquema del procedimiento SPE.

En primer lugar, se acondicionó el cartucho con $1 \mathrm{~mL}$ de $\mathrm{MeOH}$ y $1 \mathrm{~mL}$ de agua. Posteriormente se procedió a cargar $2 \mathrm{~mL}$ de la muestra de orina dopada con los analitos con una concentración de $500 \mu \mathrm{g} / \mathrm{L}$. Para el lavado del cartucho se adicionó al mismo una mezcla de agua y $\mathrm{MeOH}$ en una proporción 95:5 (v/v) y la elución de los analitos se realizó adicionando $2 \mathrm{~mL}$ de $\mathrm{MeOH}$ que se recogieron en viales de $4 \mathrm{~mL}$ y se secaron en una corriente de nitrógeno líquido a $40^{\circ} \mathrm{C}$. Posteriormente se recostituyeron en $700 \mu \mathrm{L}$ de agua. Una vez reconstituida la muestra, ésta se filtró en un vial de cromatografía empleando un filtro de nylon de $0,22 \mu \mathrm{m}$ de tamaño de poro y $13 \mathrm{~mm}$ de tamaño de filtro, y se llevó a cabo el análisis en el equipo de HPLC capilar-UV/Vis.

Empleando este tratamiento de muestra, la muestra aparece muy sucia (Imagen 19) y no se pueden identificar los analitos, por lo que este tratamiento de muestra queda descartado para posteriores estudios. 


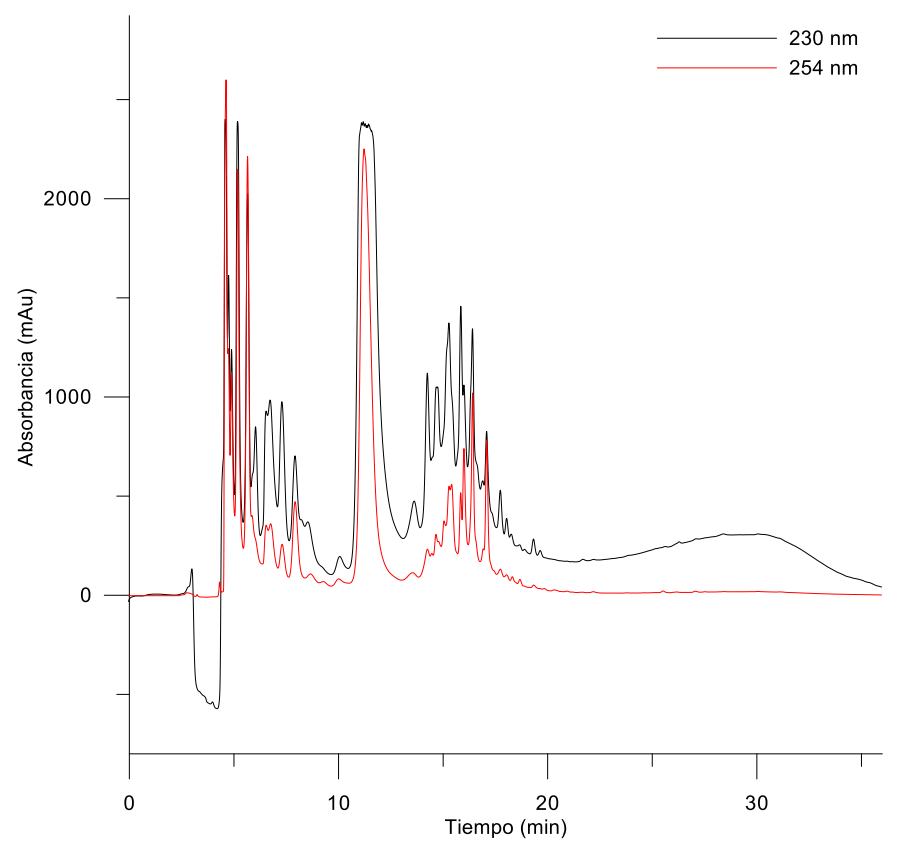

Imagen 19. Cromatograma obtenido del análisis cromatográfico de las catinonas sintététicas y la cocaína cuando se emplea SPE como tratamiento de muestra y registrándose la señal a $254 \mathrm{~nm}$ (cromatograma rojo) y $230 \mathrm{~nm}$ (cromatograma negro).

\section{b) Procedimiento QuEChERS}

Este tratamiento se lleva a cabo en dos etapas: en la primera se produce la extracción de los analitos gracias a la adición de sales y un disolvente orgánico y la segunda etapa es una etapa de limpieza ("clean-up") en la cual se emplea un sorbente para mejorar la eficacia de la extracción y limpieza de la muestra (Imagen 20). 


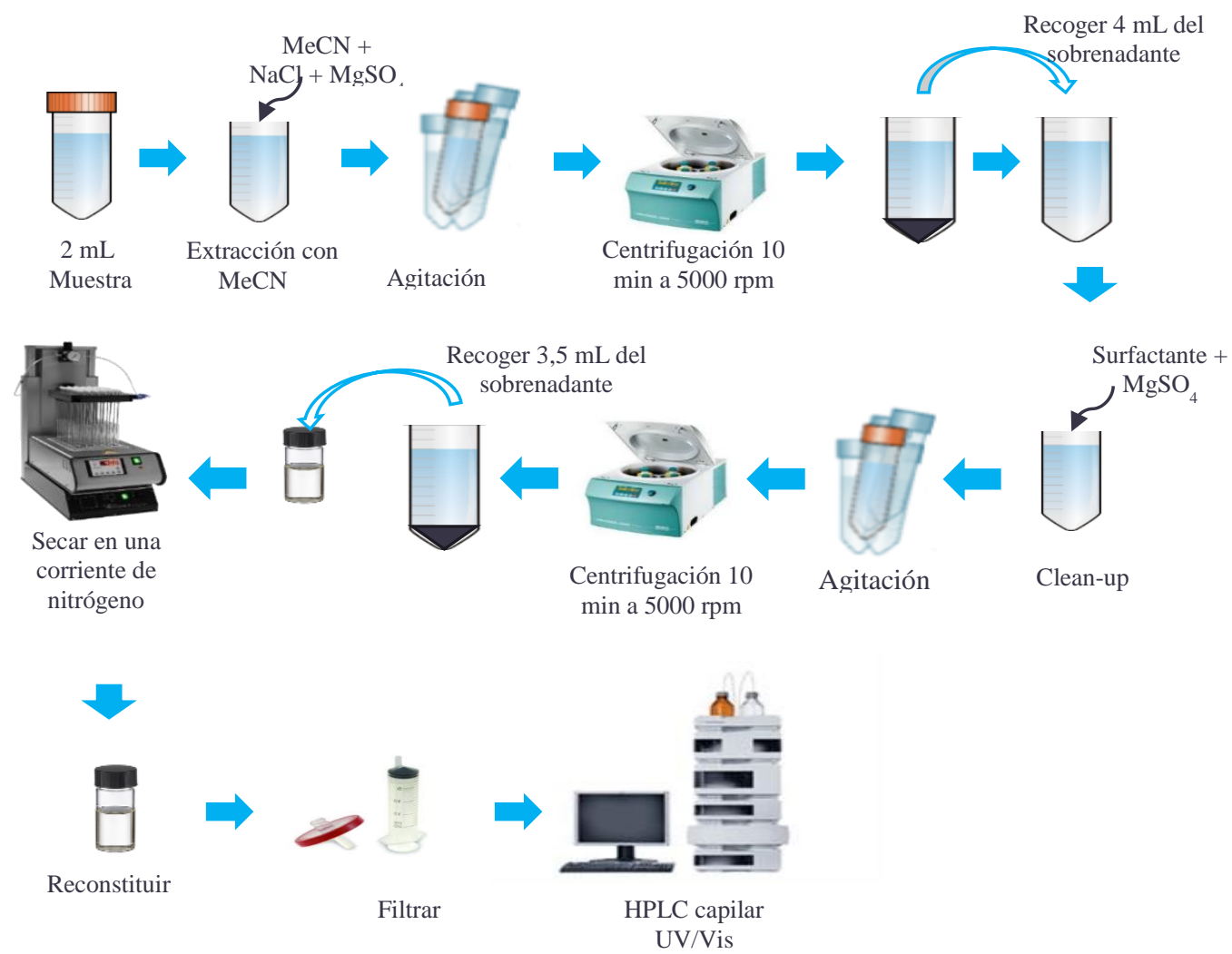

Imagen 20. Esquema del procedimiento QuEChERS llevado a cabo.

Se trataron dos muestras de orina dopadas con los analitos y dos blancos de orina, uno de ellos se dopó al final del tratamiento para estudiar la recuperación de los analitos obtenida empleando este tratamiento de muestra.

En primer lugar se adicionó a un tubo falcon de $15 \mathrm{~mL}$ de capacidad $2 \mathrm{~mL}$ de orina, en el caso de los dos blancos, y $2 \mathrm{~mL}$ dopada con $500 \mu \mathrm{g} / \mathrm{L}$ de cada analito en el caso del análisis de las dos muestras dopadas. A continuación se adicionaron $5 \mathrm{~mL}$ de $\mathrm{MeCN}$ como disolvente extractante y una mezcla de sales $\left(0,5 \mathrm{~g} \mathrm{NaCl}\right.$ y $0,5 \mathrm{~g}$ de $\left.\mathrm{MgSO}_{4}\right)$ para deshidratar y favorecer el intercambio de los analitos de la fase acuosa a la fase orgánica. Posteriormente se agitaron las mezclas durante 30 segundos y se centrifugaron a 5000 rpm durante 10 minutos.

La etapa de limpieza se llevó a cabo adicionando $150 \mathrm{mg}$ de $\mathrm{MgSO}_{4}$ y $25 \mathrm{mg}$ de un sorbente $\left(\mathrm{C} 18\right.$, PSA o Z-Sep $\left.{ }^{+}\right)$a $4 \mathrm{~mL}$ del sobrenadante obtenido tras la centrifugación. Posteriormente, cada uno de los tubos se agitó mecánicamente durante 5 minutos y se centrifugaron durante 10 minutos a $5000 \mathrm{rpm}$.

Por último, se recogieron $3,5 \mathrm{~mL}$ del sobrenadante que se secaron en una corriente de $\mathrm{N}_{2}$ a $40^{\circ} \mathrm{C}$, se reconstituyeron en $700 \mu \mathrm{L}$ de agua y se filtraron en viales de cromatografía 
empleando filtros de nylon de $0,22 \mu \mathrm{m}$ de tamaño de poro y $13 \mathrm{~mm}$ de tamaño de filtro previamente al análisis cromatográfico.

Con el objetivo de estudiar la eficacia de este tratamiento de muestra, así como estudiar la eficacia de aplicar la etapa de limpieza se realizaron los siguientes estudios:

$>\quad$ Se aplicó el procedimiento QuEChERs explicado anteriormente empleando tres sorbentes distintos: $\mathrm{C}_{18}$, PSA (Primary Secondary Amine) y Z-sep ${ }^{+}$.

$>\quad$ Se aplicó el procedimiento QuEChERs eliminando la etapa de limpieza, es decir, se aplicó solo la primera etapa del procedimiento explicado.

Del estudio de este tratamiento de muestra se observó que sólo se conseguían recuperar el $\alpha$-PVP y la cocaína. Además, del estudio de la eficacia de la etapa de limpieza se comprueba que empleando en esta etapa PSA o Z-sep ${ }^{+}$como sorbente el efecto matriz disminuye obteniéndose cromatogramas más limpios. Sin embargo, empleando $\mathrm{C}_{18}$ como sorbente en la etapa de limpieza, los resultados no mejoran. Del estudio de los sorbentes se comprueba que el Z-sep ${ }^{+}$es el que consigue una mayor limpieza de la muestra, aunque al igual que el PSA y $\mathrm{C}_{18}$ no consigue limpiar la muestra de los compuestos más polares que coeluyen en los primeros diez minutos con la metilona. En la Imagen 21 se muestran los cromatogramas obtenidos en este estudio donde se comprueba que el sorbente que consigue una mejor limpieza de la muestra es el Z-Sep ${ }^{+}$. 

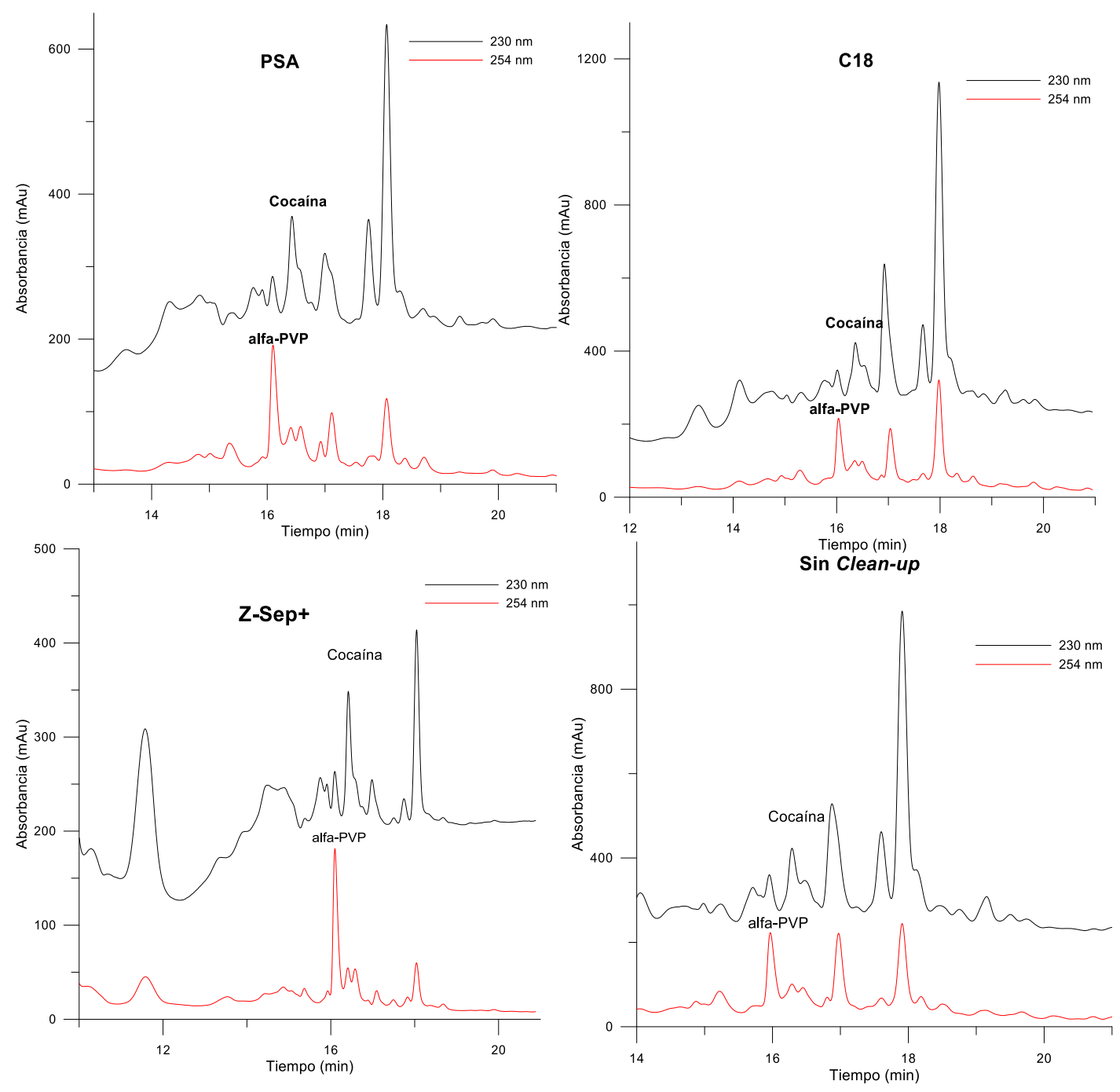

Imagen 21. Cromatogramas obtenidos del análisis cromatográfico de una muestra de orina dopada con los analitos empleando el método QuEChERS como tratamiento de muestra y empleando diferentes surfactantes y registrando la señal a $254 \mathrm{~nm}$ (cromatograma rojo) y $230 \mathrm{~nm}$ (cromatograma negro).

\section{c) Procedimiento DLLME}

El procedimiento DLLME [82] estudiado se muestra en la Imagen 22. Se llevó a cabo añadiendo $2 \mathrm{~mL}$ de orina dopada con $500 \mu \mathrm{g} / \mathrm{L}$ cada analito, a excepción del blanco en el que se empleó orina en ausencia de drogas de abuos, en un falcon de $15 \mathrm{~mL}$ al cual se adicionaron $2 \mathrm{~mL}$ de agua y $1 \mathrm{~mL}$ de amoniaco, este último para evitar la precipitación de sustancias presentes en las muestras de orina.

A continuación, se procedió a formar la dispersión añadiendo rápidamente, con una aguja, una mezcla que contenía $800 \mu \mathrm{L}$ de cloroformo (disolvente extractante) y 1,5 $\mu \mathrm{L}$ de $\mathrm{MeOH}$ (disolvente dispersante). Posteriormente se agitó y centrifugó durante 10 minutos a $5000 \mathrm{rpm}$ y $25^{\circ} \mathrm{C}$ para separar la fase acuosa de la orgánica con los analitos extraídos. 
Una vez separadas ambas fases, se recogieron los $800 \mu \mathrm{L}$ de fase orgánica conteniendo los analitos y se secaron en una corriente de $\mathrm{N}_{2}$ a $40^{\circ} \mathrm{C}$. Finalmente la muestra se reconstituyó en $700 \mu \mathrm{L}$ de agua y se filtró en viales de cromatografía utilizando filtros de nylon de 0,22 $\mu \mathrm{m}$ de tamaño de poro y $13 \mathrm{~mm}$ de tamaño de filtro. Finalmente se llevó a análisis en el cromatógrafo de líquidos capilar acoplado a un detector UV/Vis y se monitorizó la separación a 254 nm y 230 nm.

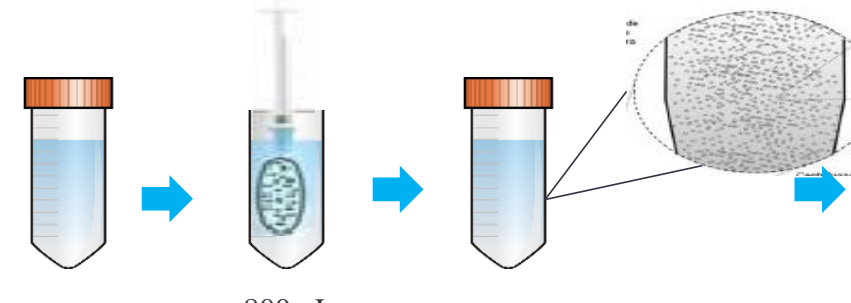

$2 \mathrm{~mL}$

Orina

$800 \mu \mathrm{L}$

Cloroformo +

$1,5 \mu \mathrm{L} \mathrm{MeOH}$

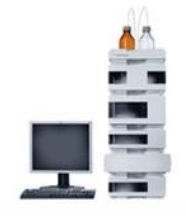

HPLC

capilar

$\mathrm{UV} / \mathrm{Vis}$

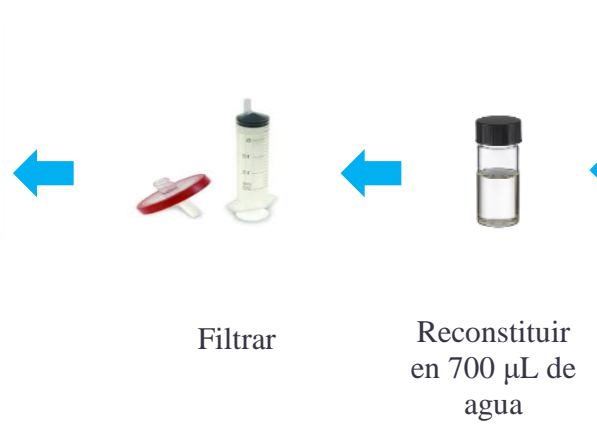

Formación

dispersión
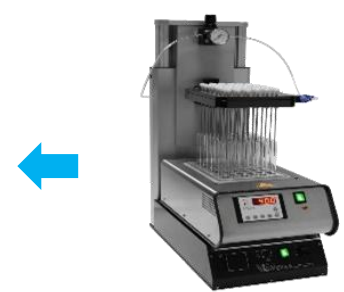

Secado de la muestra en una corriente de N2 a $40{ }^{\circ} \mathrm{C}$
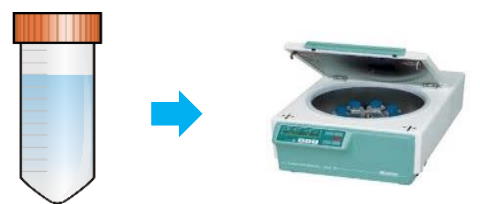

Centrifugación $5000 \mathrm{rpm}, 10 \mathrm{~min}$

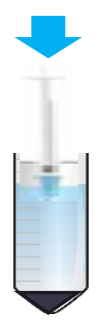

Recogida de la fase orgánica con los analitos

Imagen 22. Esquema del procedimiento DLLME llevado a cabo.

Empleando este tratamiento de muestra se consiguió recuperar los tres analitos objeto de estudio, así como una mayor limpieza de la muestra. En la Imagen 23 se muestra un cromatograma de un blanco de orina y una muestra dopada, en el cual se pueden ver los tres analitos en estudio. 


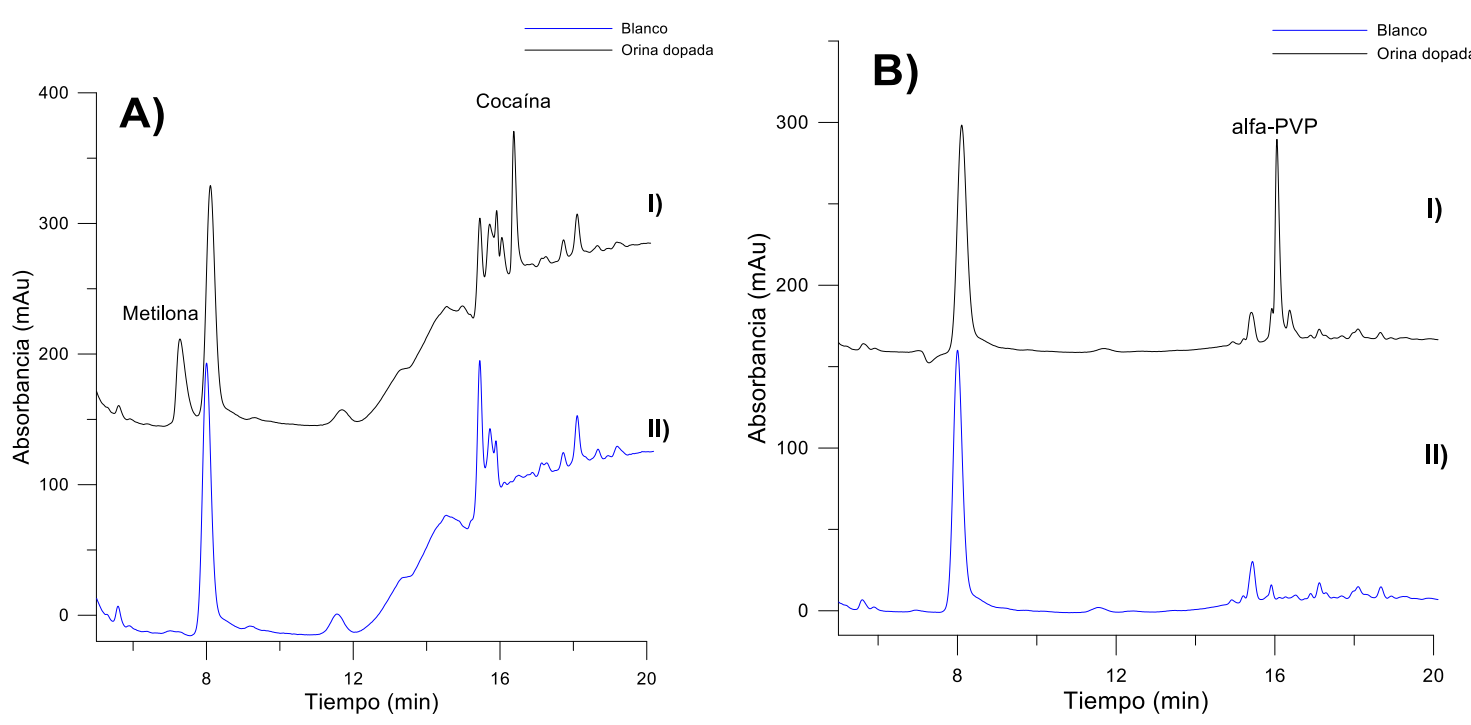

Imagen 23. Cromatogramas obtenidos del análisis cromatográfico cuando se emplea DLLME como tratamiento de muestra, monitorizando la señal a A) $230 \mathrm{~nm}$ y B) $254 \mathrm{~nm}$. I) Muestra de orina dopada y II) Blanco de orina.

La elección del tratamiento de muestra a seguir se llevó a cabo atendiendo a las ventajas y desventajas de cada uno de las técnicas estudiadas, así como las recuperaciones y limpieza obtenidas.

En la Tabla 28 se muestran las diferentes características de cada una de las técnicas estudiadas y los resultados obtenidos, observándose que sólo se consiguen recuperar los tres analitos empleando como tratamiento de muestra la DLLME además de conseguirse una matriz mucho más limpia que empleando la SPE o QuEChERS.

A la vista de los resultados obtenidos, en este trabajo se ha realizado un estudio para mejorar un tratamiento DLLME para el análisis mediante cromatografía líquida capilar de catinonas sintéticas en presencia de cocaína en muestras de orina empleando como detector un sistema de detección UV/Vis. 


\begin{tabular}{|c|c|c|c|c|c|}
\hline & $\begin{array}{c}\text { Duración } \\
\text { tratamiento* } \\
(\text { min })\end{array}$ & Contaminación & $\begin{array}{c}\text { Recuperación } \\
\text { analitos }\end{array}$ & $\begin{array}{c}\text { Coste del } \\
\text { tratamiento }\end{array}$ & Limpieza \\
\hline $\begin{array}{c}\text { SPE } \\
\text { (Empleando } \\
\text { cartuchos } \\
\text { Oasis }{ }^{\circledR} \\
\text { HLB 60 mg; } \\
3 \text { mL) }\end{array}$ & $\approx 25$ & Media & - & Coste medio & $\begin{array}{c}\text { Muestra } \\
\text { poco limpia }\end{array}$ \\
\hline QuEChERS & $\approx 35$ & Baja & $\begin{array}{l}\alpha \text {-PVP y } \\
\text { cocaína }\end{array}$ & $\begin{array}{c}\text { Bajo coste del } \\
\text { material y } \\
\text { disolventes }\end{array}$ & $\begin{array}{c}\text { Muestra } \\
\text { poco limpia } \\
\text { durante los } \\
\text { primeros } 8 \\
\text { minutos a } \\
\lambda=230 \mathrm{~nm}\end{array}$ \\
\hline DLLME & $\approx 35$ & Muy baja & $\begin{array}{l}\alpha-P V P, \\
\text { metilona y } \\
\text { cocaína }\end{array}$ & $\begin{array}{c}\text { Bajo coste del } \\
\text { material y } \\
\text { disolventes }\end{array}$ & $\begin{array}{c}\text { Mayor } \\
\text { limpieza de } \\
\text { la muestra }\end{array}$ \\
\hline
\end{tabular}

\subsubsection{ESTUDIOS REALIZADOS DE DLLME}

Los factores que más afectan a la eficacia de la extracción de la DLLME son la naturaleza y volumen del disolvente de extracción y del disolvente dispersante, así como la presencia de sales que dificultan la solubilidad de los analitos en la fase acuosa dando lugar a una extracción más eficaz.

En este trabajo se han llevado a cabo algunos estudios previos a la optimización de este tratamiento de muestra para analizar catinonas sintéticas en orina mediante $\mu$ HPLCUV/Vis, tales como la naturaleza del disolvente extractante y del disolvente dispersante.

Se evaluó la naturaleza del disolvente de extracción aplicando el tratamiento de muestra explicado en el apartado 5.4.1 empleando diferentes disolventes de extracción: cloroformo $\left(\mathrm{CH}_{3} \mathrm{Cl}\right)$, diclorometano $\left(\mathrm{CH}_{2} \mathrm{Cl}_{2}\right)$, dibromometano $\left(\mathrm{CH}_{2} \mathrm{Br}_{2}\right)$, diyodometano $\left(\mathrm{CH}_{2} \mathrm{I}_{2}\right)$ y tetracloroetileno $\left(\mathrm{C}_{2} \mathrm{Cl}_{4}\right)$.

La elección del mejor disolvente de extracción se llevó a cabo estudiando las recuperaciones de cada uno de los analitos obtenidas mediante comparación del área de pico obtenida tras el tratamiento de la muestra y el área de pico obtenida para un blanco dopado. 
El $\mathrm{CH}_{2} \mathrm{I}_{2}$ se descartó debido a que la muestra recolectada tardaba mucho en secarse bajo la corriente de $\mathrm{N}_{2}$ (aproximadamente 4 horas) lo cual incrementaba notablemente el tiempo de tratamiento de muestra. Además, una vez secado, su reconstitución en agua no era total.

En el Gráfico 9 se muestran las recuperaciones obtenidas para cada analito empleando los disolventes de extracción estudiados. Se observa en este gráfico que las mejores recuperaciones se alcanzaron empleando el $\mathrm{C}_{2} \mathrm{Cl}_{4}$ como disolvente. Además, empleando este disolvente se consigue una limpieza mayor de la muestra en comparación a la obtenida con el resto de disolventes estudiados, ya que en los cromatogramas se observan menos picos provenientes de la matriz de estudio. Por lo tanto, los siguientes estudios se llevaron a cabo empleando $\mathrm{C}_{2} \mathrm{Cl}_{4}$ como disolvente de extracción.

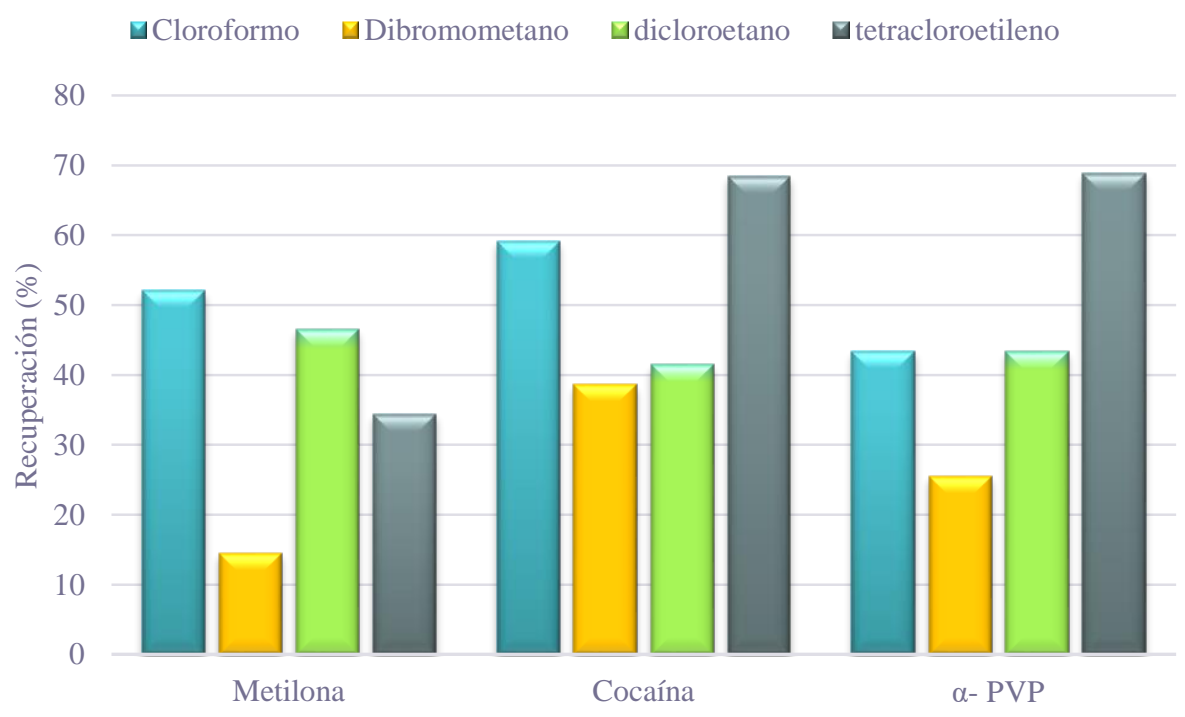

Gráfico 9. Recuperaciones obtenidas empleando diferentes disolventes de extracción en el tratamiento DLLME.

También se evaluó la naturaleza del disolvente dispersante. Para ello, se eligen una serie de disolventes miscibles tanto con la fase acuosa como con la orgánica, ya que su función es la de formar gotas del disolvente de extracción rodeadas de la fase acuosa facilitando de esta forma el intercambio de los analitos de la fase acuosa a la fase orgánica, y consecuentemente, incrementando la eficacia de la extracción. El estudio se realizó aplicando el procedimiento desarrollado en el apartado 5.4.1 empleando diferentes disolventes dispersantes: $\mathrm{MeOH}, \mathrm{MeCN}, 2-$ butanol y acetona. 
En el Gráfico 10 se muestran las recuperaciones obtenidas para cada uno de los disolventes dispersantes empleados, observándose que con el MeCN se obtienen mejores recuperaciones para la metilona y el $\alpha$-PVP, mientras que con el $\mathrm{MeOH}$ se consigue una recuperación mayor para la cocaína. Llegando a un compro7miso entre las recuperaciones obtenidas, se concluye que el disolvente de dispersión óptimo para la extracción de los tres analitos estudiados es el MeCN.

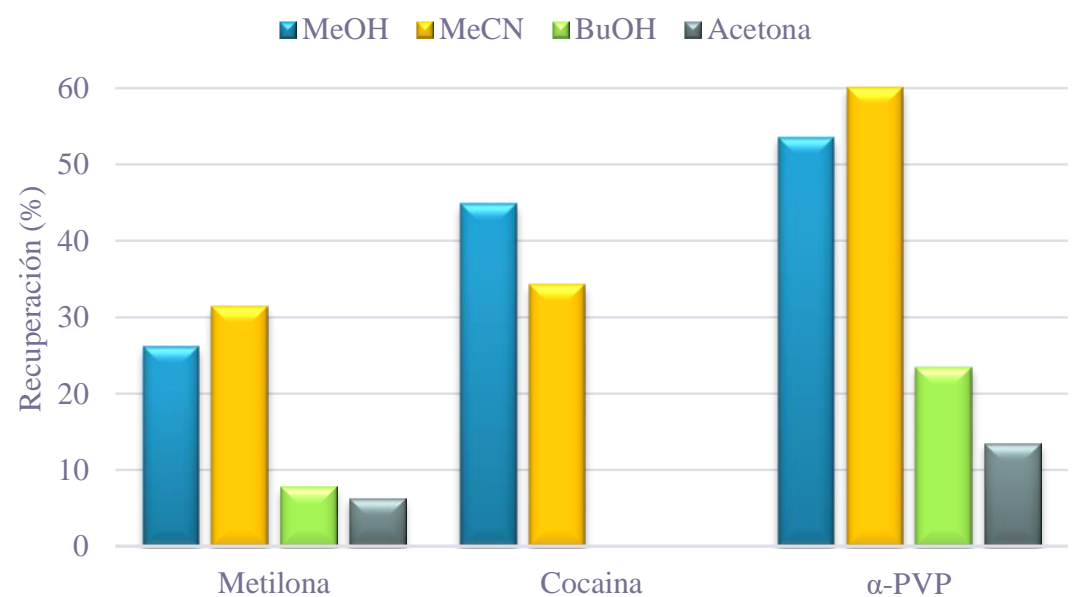

Gráfico 10. Recuperaciones obtenidas del estudio del disolvente de dispersión.

En la Imagen 24, se muestra el cromatograma obtenido tras optimizar el disolvente de extracción y el disolvente dispersante.

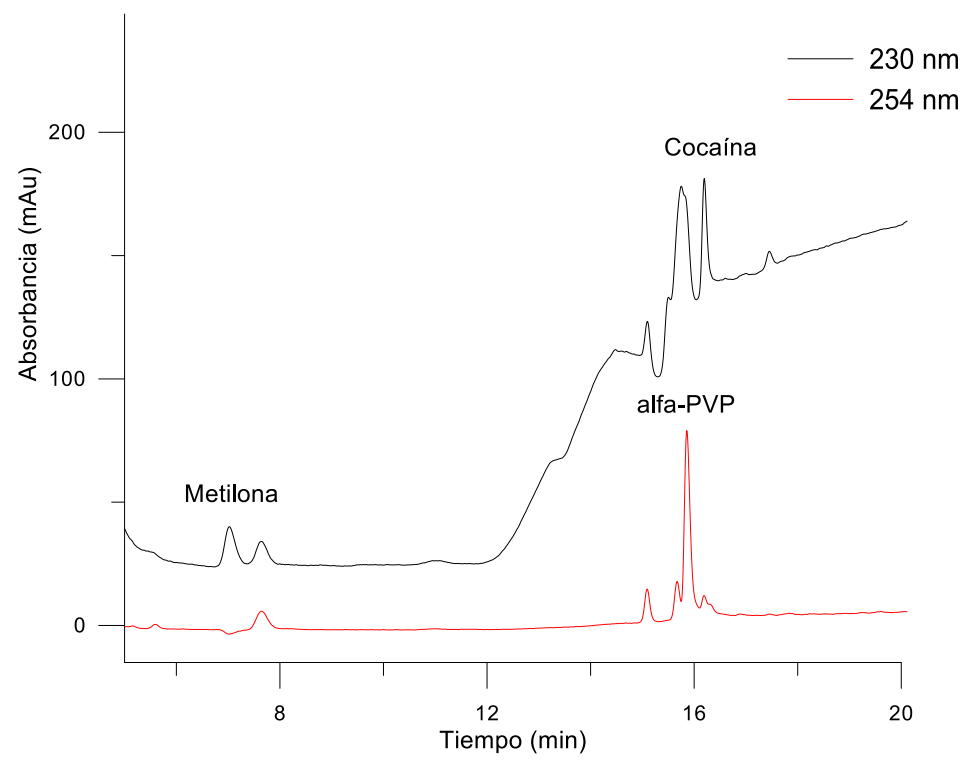

Imagen 24. Cromatograma obtenido del análisis cromatrográfico de las catinonas sintéticas y cocaína cuando se emplea MeCN como disolvente de dispersión en el tratamiento de muestra DLLME.

Los pasos posteriores para optimizar por completo el tratamiento de muestra y obtener recuperaciones mayores serían la evaluación de la mejora de la eficacia tras añadir sales 
que favorezcan la extracción, así como optimizar el volumen de cada uno de los disolventes empleados y en el caso de que la adición de sales mejore la eficacia de la extracción también habría que optimizar la cantidad de sales a emplear. 


\section{CONCLUSIONES}

En este trabajo se ha desarrollado y caracterizado un método de HPLC-capilar acoplado a un detector UV/Vis para la detección y cuantificación de catinonas sintéticas y cocaína en diferentes bebidas alcohólicas obteniéndose las siguientes conclusiones:

Se ha conseguido la separación simultánea de la cocaína, la metilona y el $\alpha$-PVP en un tiempo de 17 minutos.

Se ha evaluado la presencia del efecto matriz comparando una muestra de ron con los resultados obtenidos con patrones, obteniendo un efecto matriz positivo.

$>\quad$ Se ha caracterizado el método analítico en muestras de ron en términos de precisión, veracidad así como se han determinado los límites de detección, límites de cuantificación y rango dinámico lineal.

Los límites de detección y cuantificación varían en el rango (3,1-8,9 ㅆg/L) y (10,329,8 $\mu \mathrm{g} / \mathrm{L})$, respectivamente, siendo éstos inferiores a los encontrados en la bibliografía.

Los valores de precisión interdía e intermedia $(1,3-4,7 \%$; 5,4-8,5\%; respectivamente) obtenidos son aceptables y están dentro de lo que recomienda la legislación actual $( \pm 15 \%)$.

$>\quad$ Los ensayos de recuperación realizados en diferentes bebidas alcohólicas (dos tipos de ron, vodka y whisky) muestran que el método analítico ofrece porcentajes de recuperación, en términos de veracidad, satisfactorios así como DER aceptables, garantizando la aplicación del método a dichas matrices.

De los tratamientos de muestra evaluados para la extracción de los analitos en muestras de orina, la DLLME es la única que ha conseguido extraer los tres analitos objeto de estudio, dejándose abierto el estudio de optimización de este tratamiento de muestra para futuras investigaciones.

A la vista del trabajo de investigación realizado, se puede concluir que la técnica de HPLC-capilar constituye una alternativa muy interesante para establecer como técnica de análisis de drogas de abuso en los laboratorios forenses. 


\section{ACRÓNIMOS}

$\alpha$-PBP - $\alpha$-pirrolidinobutiofenona

$\alpha$-PVP - $\alpha$-pirrolidinopentiofenona

$\mu$ HPLC . Micro-Cromatografía líquida de alta eficacia.

CE - Electroforesis capilar

CEC - Electrocromatografía Capilar

CSA - Ley de Sustancias Controladas

CZE - Electroforesis Capilar en Zona

DEA - Agencia de Control de Drogas

DER - Desviación Estándar Relativa

DFSA

DL $_{50}$ - Dosis Letal Media

DLLME - Microextracción Líquido-

Líquido Dispersiva

d-SPE - Extracción sólido-líquido

dispersiva

ECD - Detector de Cáptura de Electrones

EESI-MS/MS - Ionización por

electroespraynanoextractiva con

espectrometría de masas en tándem.

ELISA - Inmunoensayo ligado a enzimas

EMCDDA - Centro de Control de Drogas y

Adicción

ESI - Ionización por electrospray

$\mathrm{EtOH}-\mathrm{Etanol}$

EWS - Sistema de Alerta Temprana

FID - Detector de Ionización de Llama

FMC - Fluorometcatinona

FMP - flluoranfetamina

FPIA - Inmunoensayo de Polarización

Fluorescente
GC - Cromatografía de Gases

GHB - Ácido oxibico

HPLC - Cromatografía líquida de alta resolución

ISRS - Inhibidores Selectivos de la

Recaptación de Serotonina

LLE - Extracción líquido-líquido

LOD - Límite de detección

LOQ - Límite de cuantificación

LSD - Ácido Lisérgico de dDietilamida

MABP - $\alpha$-metilamino-butirofenona

MDA - tenamfetamina

MDAI - 5,6-metilendioxi-2-aminoindano

MDBD - 1,3-Benzodioxolil-N-

metilbutnamina

MDMA - Éxtasis

MDPBP - 3',4'-metilendioxi- $\alpha$ -

pirrolidinobutiofenona)

MDPV - 3,4-metilendioxipirovalerona

MEC - metiletcatinona

MECC - Cromatografía Capilar

Electrocinética Micelar

$\mathrm{MeCN}$-Acetonitrilo

$\mathrm{MeOH}-$ Metanol

MPPP - metil- $\alpha$-pirrolidinopropiofenona,

MRPL - Límite Mínimo de

Funcionamiento Exigido.

MS- Espectrometría de Masas

nHPLC - nano-Cromatografía Líquida de alta Eficacia

NPDs - Nuevas Sustancias Psicoactivas 
OH-MET - hidrox-N-metil-etiltriptamina

OMS - Organización Mundial de la Salud

PCP - penciclina

PSA - Primary Sencondary Amine

QuEChERS - del inglés: Quick, Easy,

Cheap, Effective, Rugged, y Safe

$\mathrm{R}^{2}$ - Coeficiente de Determinación

SNC - Sistema Nervioso Central

SOFT - Sociedad de Toxicólogos Forenses

estadounidenses

SPE - Extracción en Fase Sólida
SQ - Sumisión Química

TLC - Cromatografía en Capa $\mu$ HPLC

Fina

TOFs - Compuestos Orgánicos Fijos

UHPLC - Cromatografía líquida de ultra alta resolución

UV/Vis - Ultravioleta/visible

v/v - Relación de volúmenes 


\section{BIBLIOGRAFÍA}

[1] A. Buquet, Manual de criminalística moderna: La ciencia y la investigación de la prueba, SIGLO XXI (MEXICO), 2006.

[2] P. Kintz, M. Villain, V. Dumestre-Toulet, B. Capoleghi y V. Crimele, «Methadone as a chemical weapon: two fatal cases involving babies,» Therapeutic Drug Monitoring, $\mathrm{n}^{\circ}$ 27, pp. 741-743, 2005.

[3] C. Maraveilas, M. Stefanidou, A. Dona, S. Athanaselis y C. Spiliopoulou, «Drugfacilitated sexual assault provoked by the victim's religious beliefs: a case report,» Journal of Academic Forensic Medicine Pathology, no 33, pp. 384-385, 2009.

[4] Y. Gaillard, M. Masson-Seyer, M. Giroud y J. Prevosto, «A case of drug facilitated sexual assault leading to death by chloroform poisoning,» International Journal of Legal Medicine, $\mathrm{n}^{\mathrm{o}}$ 120, pp. 241-245, 2006.

[5] R. García-Repetto y M. L. Soria, «Sumisión química: reto para el toxicólogo forense,» Revista Española de Medicina Legal, vol. 3, n 37, pp. 105-12, 2011.

[6] O. Quintela, A. Cruz-Landeira y C. García- Caballero, «La Sumisión Química en el laboratorio de Toxicología Forense, caracterización de los casos recibidos en el Instituto Nacional de Toxicología y Ciencias Forenses,» Revista de Toxicología, vol. 30, nº 1 , pp. 30-31, 2013.

[7] A. G. Mellado, «Drogas más usadas en la sumisión Química,» Moleqla, nº 17, pp. 58-61, 2015.

[8] M. I. Forgal y A. R. Boubeta, «Drug facilitated sexual assault and chemical submission,» Health and Adictions, vol. 15, n 2, pp. 137-150, 2015.

[9] Oficina de las Naciones Unidas Contra la Droga y el Delito (UNODC), «Directrices para el análisis forense de sustancias que facilitan la agresión sexual y otros actos delictivos,» Viena, 2013.

[10] K. S. Hagan y R. Lisa, «Detection of synthetic cathinones in victims of sexual assault,» Journal of Forensic Science International, nº 257, pp. 71-75, 2015. 
[11] A. C. Ponce, Manual de Química Forense, Editorial Comares, 2009.

[12] J. Marsh, Relato de un método para separar pequeñas cantidades de arsénico de las sustancias con las que se pueden mezclar, vol. 21, Edimburgo: Nuevo Diario Filosófico, 1836, pp. 229-236.

[13] G. Cooper y A. Negrusz, Clarke’s Analytical Forensic Toxicology, Pharmaceutical Press, 2013.

[14] P. M. Caro, Manual de Química Forense, Argentina: Ediciones la Roca, 2004.

[15] R. Rosenstingl, El alcoholismo en la prehistoria. En Gasull M. La enfermedad alcohólica, Barcelona: Químicos Unidos S.A., 1978.

[16] «Convención Única de 1961 sobre Estupefacientes, enmendada por el Protocolo de modificación de 1972 de Modificación de la Convención Única sobre Estupefacientes.».

[17] Naciones Unidas, «Convenio sobre Sustancias Sicotrópicas de1971».

[18] BOE, «Instrumento de ratificación de la Convención de las Naciones Unidas contra el tráfico ilícito de estupefacientes y sustancias sicotrópicas,» n 270, pp. 33062 33074, 10 Noviembre 1990.

[19] «The Controlled Substances Act (CSA),» 1970.

[20] E. Ochoa Mangado, «Drogas de Diseño,» Medicina Clínica, vol. 10, nº 119, pp. 375-376, 2002.

[21] E. Stashenko y J. R. Martínez, «GC-MS: herramienta fundamental para el análisis de drogas de uso ilícito,» Scientia Chromatographica, vol. 1, nº 4, pp. 21-33, 2012.

[22] M. Gold, Cocaine and crack: Clinical aspect, Baltimore. Williams \& Wilkins , 1997.

[23] K. M. Clauwaert, J. F. V. Bocxlaer, W. E. Lambert y A. P. D. Leenheer, «Analysis of Cocaine, Benzoylecgonine, and Cocaethylene in Urine by HPLC with Diode Array Detection,» Analyticall Chemistry, nº 68, pp. 3021-3028, 1996.

[24] Oficina de las Naciones Unidas contra las Drogas y el Desarrollo (UNDOC), «Métodos recomendados para la identificación y el análisis de cocaína en materiales incautados,» New York, 2012. 
[25] D. Zuba, «Identification of cathinones and other active components of "legal highs" by mass spectrometric methods,» Trends in Analytical Chemistry, vol. 32, pp. 15$30,2012$.

[26] European Monitoring Centre for Drugs, Drugs Addiction (EMCDDA), «latest update on 'new drugs' from EU Early Warning System,» 2015.

[27] Observatorio Europeo de las Drogas y las Toxicomanías, «Informe Europeo sobre Drogas,» 2016.

[28] G. Cooper y A. Negrusz, Clarrke’s Analytical Forensic Toxicology, Pharmaceutical Press, 2013.

[29] J. B. Zawiska y J. Wojcieszak, «Designer cathinones-An emerging class of novel recreational drugs,» Forensic Science International, nº 231, pp. 42-53, 2013.

[30] Observatorio Europeo de las Drogas y la Toxicomanía, «Informe sobre los Mercados de Drogas en la UE,» 2016.

[31] L. J. Marinetti y H. M. Antonides, «Analysis of synthetic Cathinones Commonly Found in Bath Salts in Human Performance and Postmortem Toxicology: Method Development, Drug Distribution and Interpretation of Results,» Journal of analytical Toxicology, pp. 1-12, 2013.

[32] A.M. Leffler, P. B. Smith, A. de Armas y F. L. Dorman, «The analytical investigation of synthetic street drugs containing cathinone analogs,» Forensic Science International, $\mathrm{n}^{\mathrm{o}}$ 234, pp. 50-56, 2014.

[33] C. L. German, A. E. Fleckenstein y G. R. Hanson, «Bath salts and synthetic cathinones: An emerging designer drug phenomenon,» Life Sciences, n 97, pp. 28, 2014.

[34] M. Katselou, I. Papoutsis, P. Nikolaou y C. Spiliopoulou, « $\alpha-P V P$ ("flakka"): a new synthetic catinone invades the drug arena. Review,» Journal of Forensic Toxicology, pp. 1-10, 2015.

[35] I. M. McIntyre, C. E. Hamm, L. Aldrdge y C. L. Nelson, «Acute methylone intoxication in an accidental drowning-A case report,» Forensic Science International, pp. e1-e3, 2013.

[36] K. G. Shanks, T. Dahn, G. Behonic y A. Terrell, «Analysis of First and Second Generation Legal Highs for Synthetic Cannabinoids and Synthetic Stimulants by 
Ultra-Performance Liquid Chromatography and Time of flight Mass Spectrometry,» Journal of Analytical Toxicology, n 36, pp. 360-371, 2012.

[37] R. J. Flanagan, A. Taylor, I. D. Watson y R. Whelpton, Fundamental of analytical toxicology, West Sussex (England): Wiley, 2007.

[38] A. Namera, M. Kawamura, A. Nakamoto, T. Saito y M. Nagao, «Comprehensive review of the detection methods for synthetic cannabinoids and cathinones,» Journal of Forensic Toxicology, nº 33, pp. 175-194, 2015.

[39] K. Savagi, N. N. Daeid, D. Ramsay, C. Halland y O. Sutcliffe, «Development of gas chromatography-mass spectrometry (GC-MS) and ther rapid screening methods for the analysis of 16 "legal hihg" cathinone derivatives,» Science and Justice, $\mathrm{n}^{\circ}$ 54, pp. 21-31, 2014.

[40] S. Brandt, H. Sumnall, F. Measham y J. Cole, «Analyses of second-generation "legal high" in the UK: initial findigs,» Drug Testing and Analysis, $\mathrm{n}^{\circ}$ 2, pp. $377-$ $382,2010$.

[41] M. Concheiro, S. Anizan, K. Ellefse y M. A. Huestis, «Simultaneous quantification of 28 synthetic cathinones and metabolites in urine by liquid chromatography-high resolution mass spectrometry,» Analytical and Bioanalytical Chemistry, vol. 405, pp. 9437-9448, 2013.

[42] A. de Castro, E. Lendoiroa, H. Fernández-Vega, S. Steinmeyer, M. LópezRivadulla y A. Cruza, «Liquid chromatography tandem mass spectrometry determination of selected synthetic cathinones and two piperazines in oral fluid. Cross reactivity study with an on-site immunoassay device,» Journal of Chromatography A, vol. 2014, nº 1374, pp. 93-101, 2014.

[43] P. Amaratunga, B. Lorenz-Lemberg y D. Lemberg, «Quantitative Measurement of Synthetic Cathinones in Oral Fluid,» Journal of Analytical Toxicology, n $\mathrm{n}^{\circ}$ 37, pp. 622-628, 2013.

[44] S. Torres, D. Peraza, A. Linares y A. Novoa, «Aislamiento de cocaína y benzoilecgonina en muestras de orina por extracción líquido-líquido y en fase sólida y confirmación por cromatografía líquida de alta resolución (HPLC),» Revista Española de Drogodependencia, vol. 31, nº 3-4, pp. 271-283, 2006. 
[45] S. Odoardia , M. Fisichella, F. Saverio-Romolo y S. Strano-Rossia, «Highthroughput screening for new psychoactive substances (NPS) in whole blood by DLLME extraction and UHPLC-MS/MS analysis,» Journal of Chromatography B, no 1000, pp. 57-68, 2015.

[46] Y. Al-Saffar, N. N. Stephanson y O. Beck, «Multicomponent LC-MS/MS screening method for detection of new psychoactive drugs, legal highs, in urine-Experience from the Swedish population,» Journal of Chromatography B, nº 930, pp. 112-120, 2013.

[47] G. Famiglini, F. Capriotti, P. Palma, V. Termopoli y A. Cappiello, «The Rapid Measurement of Benzodiazepines in a Milk-Based Alcoholic Beverage Using QuEChERS Extraction and GC-MS Analysis,» Journal of Analytical Toxicology, $n^{\text {o } 39, p p . ~ 306-312, ~} 2015$.

[48] A. Namera, S. Urabe, T. Saito, A. Torikoshi-Hatano, A. Shiraishi, Y. Arima y M. Nagao, «A fatal case of 3,4-methilenedioxypyrovalerone poisoning: coexistence of $\alpha$-pyrrolidinobutiophenone y $\alpha$-pirrolidinovalerophenone in blood and/or hair,» Journal of Forensic Toxicology, nº 31, pp. 338-343, 2013.

[49] B. Hu, X. Peng, S. Yang, H. Gu, H. Chen, Y. Huan, T. Zhang y X. Qiao, «Fast Quantitative Detection of Cocaine in Beverages Using Nanoextrative Electrospray Ionitation Tandem Mass Sprectrometry,» Journal of American Society for Mass Spectrometry, vol. 2, no 21, pp. 290-293, 2010.

[50] L. Gautam, S. D. Sharratt y M. D. Cole, «Drug Faclitated Sexual Assault: Detection and Stability of Benzodiazepines in Spiked Drinks Using Gas ChromatographyMass Spectrometry,» PLOS ONE, vol. 9, n² 2, pp. 1-7, 2014.

[51] D. Airado-Rodríguez, C. Cruces-Blanco y A. M. García-Campaña, «Dispersive liquid-liquid microextraction prior to field-amplified sample injection for the sensitive analysis of 3,4-methylenedioxymetamphetamine, phencyclidine and lysergic acid diethylamide by capillary electrophoresis in human urine,» Journal of Chromatography A, vol. 1267, pp. 189-197, 2012.

[52] V. Hezinov, Z. Aturki, K. Kleparn, G. D’Orazio, F. Foret y S. Fanali, «Simultaneous analysis of cocaine and its metabolites in urine by capillary electrophoresis- 
electrospray mass spectrometry using a pressurized liquid junction nanoflow interface,» Electrophoresis, vol. 33, p. 653-660, 2012.

[53] J. R. Vissers, H. A. Claessens y C. A. Cramers, «Microcolumn liquid chromatography: instrumentation, detection and applications,» Journal of Chromatography A, no 779, pp. 1-28, 1997.

[54] N. Milos, «Recent Advances in Microcolumn Liquid chromatography,» Journal of Analytical Chemistry, $\mathrm{n}^{\circ}$ 60, pp. 500A-510A, 1988.

[55] Y. Saito, K. Jinno y . T. Greibrokk, «Capillary columns in liquid chromatography: between conventional columns and microchips,» Journal of Separation Science, $\mathrm{n}^{\circ}$ 27, pp. 1379-1390, 2004.

[56] C. E. Nazarioa, M. R. Silva, M. S. Franco y F. M. Fernando M. Lanc, «Evolution in miniaturized column liquid chromatography instrumentation and applications: an overview,» Journal of Chromatography A 1421 , n 1421, pp. 18-37, 2015.

[57] N. Nudelman, «Química Sustentable,» UNL, 2004. [En línea]. Available: http://www.fcn.unp.edu.ar/sitio/quimicageneral/wp-content/uploads/2009/06/12principios.pdf. [Último acceso: 09/06/2016].

[58] N. Arroyo-Manzanares, A. M. García-Campaña y L. Gamiz-García, «Comparison of different sample treatments for the analysis of ochratoxin A in wine by capillary HPLC with laser-induced fluorescence detection,» Analytical and Bioanalytical Chemistry, no 401, pp. 2987-2994, 2011.

[59] M. Lombardo-Agüí, L. Gámiz-García, C. Cruces-Blanco y A. M. García-Campaña, «Comparison of different sample treatments for the analysis of quinolones in milk by capillary-liquid chromatography with laser induced fluorescence detection,» Journal of Chromatography A, $\mathrm{n}^{\circ}$ 1218, pp. 4966-4971, 2011.

[60] A. Gure, F. J. Lara, N. Megersa, M. del Olmo-Iruela y A. M. García-Campaña, «Dispersive liquid-liquid microextraction followed by capillary high-performance liquid chromatography for the determination of six sulfonylurea herbicides in fruit juices,» Food Analytical Method, no 7, pp. 1465-1473, 2014.

[61] M. Bailón-Perez, A. García-Campaña, M. del Olmo-Iruela, L. Gámiz-García y C. Cruces-Blanco, Journal of Chromatography A, 1216 (2009) 8355-8361. 
[62] L. Ramos, «Critical overview of selected contemporary sample preparation techniques,» Journal of Chromatography A, n 1221, pp. 84-98, 2012.

[63] K. Schug, «Applications, and innovations in solid-phase extraction, LCGC Blog,» 2014.

[64] «Extracción en fase sólida EFS-SPE,» Cromlab. SL, [En línea]. Available: http://www.cromlab.es/EFS_Principal.htm. [Último acceso: 09/06/2016].

[65] M. Rezaee, Y. Assadi, M. Milani-Hosseini, E. Aghaee, F. Ahmadi y S. Berijani, «Determination of organic compounds in water using dispersive liquid-liquid microextraction,» Journal of Chromatography A, Vols. 1-2, nº 1116, pp. 1-9, 2006.

[66] N. Arroyo-Manzanares, L. Gámiz-García y A. M. García-Campaña, «Alternative sample treatments for the determination of sulfonamides in milk by HPLC with fluorescence detection».

[67] M. Mehdi, K. Vahid, S. Waqif-Husain y S. M. Khoeini, «Analysis of chlorpheniramine in human urine samples using dispersive liquid-liquid microextraction combined with high performance liquid chromatography,» Brazilian Journal of Pharmaceutical Sciences, vol. 50, nº 3, pp. 551-558, 2014.

[68] V. Sharifi, A. Abbasi y N. Anahita, «Application of hollow fiber liquid phase microextraction and dispersive liquideliquid microextraction techniques in analytical toxicology,» Journal of food and Drugs Analysis, vol. 24, pp. 264-276, 2016.

[69] P. Fernández, M. Regenjo, A. M. Bermejo, A. M. Fernández, R. A. Lorenzo y A. M. Carro, «Analysis of drugs of abuse in human plasma by dispersive liquid-liquid microextraction and high-performance liquid chromatography,» Journal of Applied Toxicology, 2014.

[70] P. Fernández, M. Regenjo, A. M. Fernández, R. A. Lorenzo y A. M. Carrot, «Optimization of ultrasound-assisted dispersive liquid-liquid microextraction for ultraperformance liquid chromatography determination of benzodiacepines in urine and hospital wastewater,» Analytical Methods, vol. 6, pp. 8239-8246, 2014.

[71] M. Rezaee, Y. Yamini y M. Faraji, «Review: Evolution of dispersive liquid-liquid microextraction method,» Journal of Chromatography A, n 1217, pp. 2342-2357, 2010. 
[72] C. Bosh-Ojeda y F. Sánchez-Rojas, «Separation and Preconcentration by Dispersive Liquid-Liquid Microextraction Procedure: A Review,» Food Control, n ${ }^{\circ}$ 18, pp. 530-534, 2007.

[73] M. Anastassiades, S. Lehotay, D. Stajnbaher y F. Schenc, «Fast and easy multiresidue method employing acetonitrile extraction/partitioning and "dispersive solid-phase extraction" for the determination of pesticide residues in produce,» Journal of AOAC International, vol. 2, nº 86, pp. 412-31, 2003.

[74] Cromlab S.L., [En línea]. Available:

http://www.cromlab.es/EFS_INT_Quechers.htm. [Último acceso: 10/06/2016]

[75] S. Lehotay, Journal of AOAC International, nº 90, p. 485, 2007.

[76] K. Usui, Y. Hayashizaki, H. Masaki y M. Funayama, «Rapid drug extraction from huma whole blood using a modified QuEChERS extraction method,» Legal Medicine, nº 14, pp. 286-296, 2012.

[77] A. Wurita, K. Hasewaka, K. Minikata, K. Gonmori, H. Nozawa, I. Yamagishi, O. Suzuki y K. Watanabe, «Postmortem distribution of $\alpha$-pryrrolidinobutiophenone in body fluids and solid tissues of human cadaver,» Legal Medicine, $\mathrm{n}^{\circ}$ 16, pp. 241 $246,2014$.

[78] K. Usui, T. Aramaki, M. Hashiyada, Y. Hayashizaki y M. Funayama, «Quantitative analysis of 3,4-dimethylmethcathinone in blood and urine by liquid chromtographytandem mass spectromety in a fatal case,» Legal Medicine, nº 16, pp. 222-226, 2014.

[79] J. L. Poklis, C. E. Wolf, O. I. ElJordi, K. Liu, Z. Shijun y A. Poklis, «Analysis of the First and Second-Generation Raving Drangon Novelty Bath Salt Containing Methylone and Pentedrone,» Journal of Forensic Sciences, vol. 60, n S1, pp. 234$240,2015$.

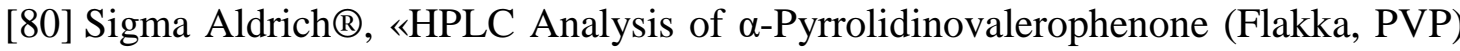
Enantiomers on Astec $®$ CHIROBIOTIC@ V2».

[81] United Niations Office on Drugs and Crime (UNODC), «Guidance for the Validation of Analytical Methodology and Calibration of Equipment using for Testing of Illicit Drugs in Seize Materials and Biological Specimen,» 2009.

[82] Moreno-González, L. Gámiz-García, A. M. García-Campaña y J. M. BusqueSendra, «Use of dispersive liquid-liquid microextraction for the determination of 
carbamates in juice samples by sweeping micellar electrokinetic chromatography,» no 400, p. 1329-1338, 20014.

[83] D. A. Bonilla Q, L. F. Peñuela-B, N. Sierra M, J. E. Díaz F y J. H. Rojas B, «Desarrollo y Validación de una Metodología Analítica por Espectrofotometría Ultravioleta para la Determinación de Cocaína en un Polímero Sintético,» Revista de la Facultad de Química Farmacéutica, vol. 15, nº 1, pp. 103-112, 2008. 